\title{
COMUNICACIONES PÓSTER
}

\section{¿CÓMO SON LOS PACIENTES QUE ATENDEMOS EN TRAUMATOLOGIAA Y LAS INTERCONSULTAS? DIFERENCIAS CON LOS ATENDIDOS POR OTROS SERVICIOS}

Rubál Bran D; Ventura Valcárcel P; López Reboiro ML; Codesal Norniella A*; Bal Alvaredo M; Sánchez Pérez-Mel MC; Fernández Rial A; Monte Secades R.

SERVICIO MEDICINA INTERNA. *SERVICIO TRAUMATOLOGÍA. HULA.

INTRODUCCIÓN: Las interconsultas (IC) suponen una importante carga de trabajo, poco reconocido, poco estudiado, organizado de forma irregular en cada servicio de medicina interna y con un progresivo crecimiento de número y complejidad. Esto es más acusado en el servicio de traumatología. Queremos saber cómo son los pacientes ingresados en traumatología, en especial los que son valorados por medicina interna (IC MI) y los que son valorados por otras especialidades (IC Otras). Objetivos Conocer las características de los pacientes ingresados en traumatología de nuestro centro y de las IC y Compararlas las características en función del servicio destinatario de la IC. Metodología Estudio observacional, descriptivo y comparativo entre grupos. Se analizaron los datos de 165 pacientes, de los 637 pacientes ingresados en el servicio de traumatología desde el 01-11-2013 al 31/03/2014. Se recogieron variables sociodemográficas, de comorbilidad, relacionadas con el ingreso, el tratamiento C. 0. T, la evolución y las interconsultas. Los datos se analizaron con SPSS 15.0. Análisis descriptivo: media (Ds) o mediana (M;m), frecuencias y porcentajes. ji-cuadrado para el análisis comparativo.

RESULTADOS: Ver tabla 1. Conclusiones Más de la mitad de los pacientes ingresados en traumatología son valorados por otro especialista debido a la edad avanzada y complejidad. Las IC de MI son sobre pacientes de mayor edad y complejidad y necesitan mayor implicación (comanagement) del servicio interconsultado que los atendidos por otras especialidades. Las IC a otros servicios son por procesos agudos, procesos crónicos agudizados (principalmente entre el grupo de 60-80) años y resueltas con una atención "puntual" a diferencia de las IC a Ml. La asistencia compartida por MI de los pacientes entre 60-80 años con procesos crónicos podría evitar las IC a otras especialidades por procesos crónicos agudizados (45\%). Son necesarios estudios diseñados para tal propósito.

\section{¿PROTEGE LA CIRROSIS DE LA TROMBOSIS?}

Vázquez $R$, Dubois $A$, Seoane $B$, Vázquez $P$, Nicolás $R$, Ramos V, Penado S, De la Iglesia F. UNIDAD DE CORTA ESTANCIA MÉDICA, SERVICIO DE MEDICINA INTERNA. COMPLEJO HOSPITALARIO UNIVERSITARIO DEA CORUÑA.

INTRODUCCIÓN: El paciente cirrótico es una población especial en la que existe un defecto en la síntesis de muchos de los factores que contribuyen a una correcta hemostasia. Es por ello que existe una creencia clásica de que poseen un estado de "autoanticoagulación" que les confiere protección frente a fenómenos como la enfermedad tromboembólica venosa (ETV). Cada vez hay más evidencia científica que rebate esta afirmación pero con todo ello existen muchas controversias en las guías clínicas en cuanto a las recomendaciones de profilaxis y tratamiento de la ETV en esta población de pacientes. OBJETIVOS Y MÉTODOS: Análisis de la profilaxis previa y manejo terapéutico tras un evento tromboembólico en los pacientes con cirrosis hepática. Para ello realizamos un estudio descriptivo, retrospectivo, que incluyó a todos los pacientes cirróticos con tomboembolismo pulmonar o trombosis venosa profunda ingresados en nuestro hospital en los últimos trece años.

RESULTADOS: En el período comprendido entre el año 2000-2013 se reclutaron un total de 36 pacientes cirróticos con ETV, de los cuales un 19, 5 \% eran mujeres. La edad media fue de 65 años (rango 37-87), con un índice de Charlson promedio de 5, 5 y 7, 8 ajustado por edad. La etiología de la cirrosis más prevalente fue la etílica $(52,7 \%)$, seguida de la vírica $25 \%$, mixta $16,6 \%$ y desconocida en un 5\%, sin ninguna diferencia significativa entre los diferentes estadíos Child. En el 66, $6 \%$ de los casos no se evidenciaron descompensaciones de la hepatopatía y en el 38, 8 \% el propio fenómeno tromboembólico fue el que motivó el ingreso. Del total de casos, el 77,7 \% no había recibido profilaxis previa al diagnóstico y se decidió anticoagulación en el 83,3 \% de los pacientes optando por heparinas de bajo peso molecular en la mayoría en los casos (70 \%). El tiempo medio de anticoagulación fueron 227 días y en el seguimiento se registraron complicaciones hemorrágicas mayores en 6 pacientes (20\%) que en ningún caso supusieron un compromiso vital para el enfermo. El 77, $7 \%$ de los pacientes fueron éxitus, teniendo como causas principales las neoplasias (32\%) y descompensación de la cirrosis hepática (25\%), con una media de 437 días desde el evento tromboembólico hasta el fallecimiento.

CONCLUSIONES: La coagulopatía existente en el paciente cirrótico no confiere protección frente a la enfermedad tromboembólica, aún así existe una reticencia al uso de profilaxis previa. En la gran mayoría de los casos se opta por el inicio de anticoagulación con heparinas de bajo peso molecular. El porcentaje de complicaciones hemorrágicas, similar al de otras series de casos, es relevante, aunque serían necesarios más estudios y con un mayor tamaño muestral.

\section{ALTERACIONES DE LA FUNCIÓN TIROIDEA ¿INFLUYEN REALMENTE EN EL IMC?}

Velo García A, Ríos Prego M, Anibarro García L, Sánchez Sobrino P. MEDICINA INTERNA Y SERVICIO DE ENDOCRINOLOGÍA. COMPLEJO HOSPITALARIO UNIVERSITARIO DE PONTEVEDRA.

Las hormonas tiroideas intervienen en múltiples procesos fisiológicos, por ello que un individuo con disfunción tiroidea puede presentar cambios en el peso y la composición corporal.

OBJETIVO: Determinar los cambios en el peso corporal en pacientes con alteraciones en las pruebas de función tiroidea tras el tratamiento y normalización de las determinaciones hormonales. MATERIAL Y MÉTODOS: Estudio descriptivo, retrospectivo, observacional de 65 pacientes seguidos en Servicio de Endocrinología del Complejo Hospitalario de Pontevedra por alteraciones de la función tiroidea entre junio de 2012 y junio de 2013. 
RESULTADOS: 65 sujetos (53 mujeres y 12 varones), 31 (47, 69\%) hipotiroideos y 34 (52, 31\%) hipertiroideos. Las características se recogen en la tabla 1, existiendo una diferencia estadísticamente significativa en la TSH basal (previa a la disfunción tiroidea) de ambos grupos ( $p=0,01)$. El IMC basal fue $27,11 \pm 3,82 \mathrm{Kg} / \mathrm{m} 2$, en el momento de la alteración de la función tiroidea $27,02 \pm 4,61$ y tras terapia y normalización de las pruebas de función tiroidea $28,66 \pm 4,62$. Se encontraron diferencias estadísticamente significativas entre el IMC basal y final $(p=0,021)$. Comparando la variación del IMC (basal-agudo-final) mediante el test de Wilcoxon en el grupo hipertiroideos entre el IMC basal y el agudo $(p=0,002)$ y entre el IMC agudo y el final $(p=0,00)$ aunque no entre el IMC basal ( $p=$ 0,068 ). El peso basal fue $71,4 \pm 10,95 \mathrm{Kg}$ y el final $73,28 \pm 10,63 \mathrm{Kg}$. La prueba de T-student obtuvo diferencias estadísticamente significativas $(p=0,007)$ con una ganancia media de $1,88 \pm$ $3,84 \mathrm{Kg}$ (IC 95\% 0, 54-3, 22). Esta variación en el conjunto de hipotiroideos no obtuvo diferencias estadísticamente significativas $(p=0,103)$ al igual que en el conjunto de hipertiroideos $(p=0,072)$. En los hipertiroideos la diferencia de medias de TSH basal $(1,46 \pm 0,94 \mu \mathrm{U} / \mathrm{mL})$ y final $(2,76 \pm 1,79 \mu \mathrm{U} /$ $\mathrm{mL})$ calculada mediante el test de Wilcoxon fue estadísticamente significativa $(p=0,006)$. CONCLUSIONES: Se ha observado un aumento estadísticamente significativo en el IMC tras tratamiento y resolución del proceso en los pacientes con alteraciones de la función tiroidea (tanto en hipertiroideos como hipotiroideos). Los cambios de peso son de pequeña magnitud, con una media inferior a $2 \mathrm{Kg}$ por lo que no justifican el desarrollo de obesidad.

\section{AMILOIDOSIS RENAL EN PACIENTE CON INMUNODEFICIENCIA COMÚN VARIABLE:}

García Alén D, Sánchez Trigo S, Sardina Ferreiro R, Gómez Buela I, Lijó Carballeda C, Bravo Blázquez I, Caínzos Romero T, Arrojo Alonso F.

MEDICINA INTERNA. COMPLEJO HOSPITALARIO DE FERROL.

INTRODUCCIÓN: La amiloidosis es una enfermedad con depósito extracelular de proteínas fibrilares en disposición beta-plegada. Existen dos tipos: la primaria, que se encuentra asociada a discrasias de células plasmáticas, y la secundaria que está en relación con enfermedades crónicas. A continuación se presenta un caso clínico de amiloidosis secundaria en un paciente con inmunodeficiencia común variable (ICV). Caso clínico: Se presenta el caso de un varón de 64 años con diagnóstico de inmunodeficiencia común variable de 10 años de evolución, que presentaba como manifestaciones clínicas: bronquiectasias bilaterales sobreinfectadas por Pseudomonas aeroginosa y desnutrición calórico-proteica. Durante el seguimiento en la consulta de medicina interna se objetivó una insuficiencia renal rápidamente progresiva. En la exporación física destacaba una auscultación pulmonar con roncus bilaterales, siendo la auscultación cardiaca normal, asi como el resto de la exploración física salvo atrofia de los cuádriceps, secundaria a su desnutrición. Como pruebas diagnósticas se realizaron una ecografía abdominal que resultó normal, una bioquímica donde destacaba una Creatinina 2' 9 $\mathrm{mg} / \mathrm{dL}$, Urea $126 \mathrm{mg} / \mathrm{dL}, \mathrm{MDRD}$ 17, siendo el resto normal; un hemograma donde se evidenciaba una anemia normocítica normocrómica; una orina de 24 horas con una proteinuria de $828 \mathrm{mg} / \mathrm{día}$, un cociente proteína/creatinina de 791, un sedimento de orina con 1-5 leucocitos/campo y 5-10 hematies/campo y citologías negativas; unas inmunoglobulinas con lgG 532 con lgA e lgM suprimidas; el estudio de autoinmunidad resultó negativo (ANAS, ANCAS, ACAS, Complemento); y las serologías de VHB, VIH, VHC, VEB, CMV también resultaron negativos. Para completar el estudio se decidió realizar una biopsia renal, siendo ésta diagnóstica para amiloidosis secundaria.

DISCUSIÓN: La ICV es una de las inmunodeficiencias primarias más conocidas y la principal causa de hipogammaglobulinemia en personas adultas. La amiloidosis secundaria es una rara complicación de la ICV, siendo más frecuente en pacientes de mediana edad, con predominio en el sexo masculino. Las manifestaciones clínicas de la amiloidosis varía según el órgano afectado, siendo el más frecuente en los pacientes con ICV el riñón. En general, los pacientes en los que la amiloidosis se ha desarrollado secundariamente a la ICV, suelen tener asociada una enfermedad infecciosa grave, bronquiectasias bilaterales, cor pulmonale 0 tuberculosis, entre otras afectaciones subyacentes. El diagnóstico tardío de la ICV o el inicio tardío del tratamiento con inmunoglobulinas estaría relacionado con el desarrollo de amiloidosis secundaria.

\section{ANÁLISIS DE LOS REINGRESOS EN EL ÁREA MÉDICA DE LUGO}

\section{Iñiguez I, Matesanz M, Rubal D, Ventura P, Romay E, Casariego E.}

MEDICINA INTERNA. LUCUS AUGUSTI.

INTRODUCCIÓN: Con el paso de los años asistimos al paulatino incremento de los reingresos en los distintos Servicios del Área Médica de adultos de nuestros hospitales. Este hecho está bien sustentado por los datos administrativos de los Centros pero seguimos sin conocer múltiples aspectos médicos de estos pacientes, las razones que los causan y sus posible soluciones.

OBJETIVO: Determinar la magnitud de este problema, describir su perfil clínico y sus consecuencias. PACIENTES Y MÉTODOS: Estudio descriptivo sobre totalidad de ingresos registrados en todos los Servicios del área Médica del Hospital Universitario Lucus Augusti de Lugo entre 2000 y 2012 . En el análisis se utilizaron técnicas habituales de estadística descriptiva. En las comparaciones entre estratos sucesivos de variables categóricas se utilizó el test ji al cuadrado de tendencia y en las comparaciones de variables cualitativas ANOVA. El nivel de significación estadístico fue $p<0.05$ RESULTADOS: En el periodo señalado se registraron 139249 ingresos en 62515 pacientes. En e primer ingreso fallecieron 3675 (5.9\%). De los 58840 dados de alta, 28648 (48, 7\%) reingresaron por segunda vez. De ellos, 26043 fueron dados de alta y $15711(60,3 \%)$ reingresaron por $3^{\mathrm{a}}$ vez. De los 14150 dados de alta reingresaron, por 4a vez, 9466 (66, 7\%). De estos, 8446 fueron dados de alta, reingresando, por $5^{\mathrm{a}} \mathrm{vez}, 6106(72,3 \%)$. De estos, 5420 se fueron de alta y reingresaron por $6^{\mathrm{a}}$ vez $4044(74,6 \%)$. A medida que se suceden los reingresos, se reduce la estancia media (11, 4 días vs.9, 9 días; $p<0.0001$ ) y se incrementan tanto las patologías crónicas ( 3,1 vs 4,$99 ; p<0.001)$ como su CIRS ( 9,4 vs.12.1; $p<0.01)$. Aunque, de la misma forma, se incrementan los reingresos para tratamiento, estos solo superan el $10 \%$ en el reingreso 6 ( $3,2 \%$ vs $10,6 \%$; $p<0.001$ ). La mortalidad (del 5, 9\% en el ingreso número 1, se redujo de manera paulatina hasta el 1, 1\% en el reingreso 5 $(\mathrm{p}<0.001)$. El Servicio de Medicina Interna asume hasta el $32,8 \%$ de los reingresos
CONCLUSIONES: A medida que se suceden los reingresos, los pacientes tienen mayor número de patologías crónicas, mayor CIRS y mayor probabilidad de reingresar al mismo tiempo que tanto su estancia en el hospital como su mortalidad se reducen paulatinamente de manera significativa. Esto sugiere que la hospitalización reiterada es una manera inadecuada de tratar a estos pacientes, reduciendo su calidad de vida y exponiéndolos a mayor morbilidad de la precisa.

\section{ANEURISMA DE AORTA TORÁCICA DEBIDO A ENFERMEDAD RELACIONADA CON IGG4. PRIMER CASO DESCRITO EN NUESTRO PAÍS}

${ }^{1}$ Velo García A, ${ }^{1}$ García García JC, ${ }^{2}$ Fachal Bermúdez C, ${ }^{1}$ Brea Aparicio $R,{ }^{3}$ Figueroa López RM, ${ }^{4}$ Durán Muñoz D, ${ }^{1}$ Dieguez Paz J, ${ }^{1}$ Fernández González A, ${ }^{5}$ Sopeña Pérez-Argüelles $B,{ }^{1}$ Anibarro García L, ' Núñez Fernández MJ

'SERVICIO MEDICINA INTERNA. ${ }^{2}$ SERVICIO DEANATOMÍA PATOLÓGICA. ${ }^{3}$ SERVICIO DE RADIODIAGNÓSTICO. ${ }^{4}$ SERVIICIO DE CIRUGÍA CARDÍACA. ${ }^{5}$ SERVICIO DE MEDICINA INTERNA.

${ }^{1}$ COMPIEJO HOSPITALARIO DE PONTEVEDRA. ${ }^{2}$ COMPIEJO HOSPITALARIO DE VIGO.${ }^{3}$ COMPIEJO HOSPITALARIO DE PONTEVEDRA. ${ }^{4}$ COMPLEJO HOSPITALARIO DE VIGO. ${ }^{5}$ COMPLEJO HOSPITALARIO DE SANTIAGO.

INTRODUCCIÓN: La enfermedad relacionada con la lgG4 (ER-lgG4) es una nueva entidad patológica con afectación multisistémica, y caracterizada por ser un proceso fibro-inflamatorio con abundantes células plasmáticas lgG4-positivas, acompañado de fibrosis estoriforme y flebitis obliterante. En 2009 se publicaron los primeros tres casos de afectación de la aorta torácica debido a ER-lgG4. Desde entonces, poco más de veinte casos han sido descritos; presentamos un nuevo caso de ERIgG4 que afecta la aorta torácica.

CASO CLínICO: Varón de 64 años estudiado por emisión de sangre en heces, anorexia adelgazamiento en los últimos dos meses. Presenta antecedentes de insuficiencia mitral, enfermedad de Peyronie, y tuberculosis pleural. En la exploración física, presenta soplo sistólico mitral. En las pruebas destacaba: VSG $60 \mathrm{~mm} / \mathrm{h}$; PCR 4'48 mgr / dl ; hemoglobina, 11'9 g / Las inmunoglobulinas eran normales. Los ANAs, el factor reumatoide, la serología de sífilis y VIH, fueron negativos. La biopsia de arteria temporal no mostró anormalidades. En la colonoscopia se objetiva un pólipo colónico hiperplásico y hemorroides. La TAC reveló: pleuritis calcificada derecha y aneurisma de aorta ascendente de 58 ' $9 \mathrm{~mm}$. Es intervenido quirúrgicamente, con reemplazo de la aorta ascendente y recambio de válvula aórtica. El análisis histológico de la aorta mostraba una pared arterial con un intenso infiltrado inflamatorio linfoplasmocítico y fibrosis estoriforme; las venas y algunos vasos arteriales muestran una proliferación endotelial que ocluye la luz. Dentro del infiltrado inflamatorio, predominan las células tipo lgG; el subtipo predominante es de lgG4, siendo el recuento en algunos campos superior a 50 células lgG4-positivas, oscilando la relación lgG4/lgG entre 0, 37 y 0,40

DISCUSIÓN. El aneurisma torácico es la manifestación más frecuente de aortitis relacionada con IgG4, afecta a hombres de entre 61 y 76 años de edad y se llega a su diagnóstico como un hallazgo incidental tras la realización de una prueba radiológica. El diagnóstico se basa en la presencia simultánea de: infiltración linfoplasmocítica, fibrosis estoriforme y flebitis obliterante. Los datos inmunohistoquímicos esenciales son: un número de células lgG4 superior a 50 y la relación de células lgG4/lgG, mayor que 0,4. Después de excluir la sífilis, el diagnóstico diferencial debe realizarse con: la arteritis de células gigantes, enfermedad de Takayasu, vasculitis ANCA positivos, espondiloartropatías HLA - B27, artritis reumatoide, lupus eritematoso sistémico, enfermedad de Adamantiades-Behçet y sarcoidosis.

CONCLUSIONES: Presentamos el primer caso diagnosticado en nuestro país de, aneurisma torácico debido a enfermedad relacionada con lgG4, una entidad clínica que se debe considerar en cualquier paciente con aortitis no infecciosa, y sin datos clínicos o analíticos sugestivos de otro proceso inmunológico.

\section{ARTRITIS SÉPTICA FACETARIA: UNA ENTIDAD INFRECUENTE}

Álvarez Otero J, Fernández Fernández F, Rodríguez Arias M, Gondar Barcala T, García Pouton N, de la Fuente Aguado J.

MEDICINA INTERNA. HOSPITAL POVISA.

INTRODUCCIÓN: La artritis séptica de la articulación facetaria es una causa infrecuente de dolor lumbar, lo que dificulta el diagnóstico en muchas ocasiones. La principal complicación local es el absceso epidural y el patógeno implicado más habitualmente es el SAMS.

OBJETIVOS: Incidir en la importancia de incluir la artritis séptica facetaria en el diagnóstico diferencial del dolor lumbar para no retrasar el inicio de tratamiento antibiótico y evitar complicaciones.

MATERIAL Y MÉTODOS: Presentamos un caso de artritis séptica facetaria con absceso epidural y paravertebral por Staphylococcus aureus.

RESULTADOS: Mujer de 48 años que acudió a nuestro centro por cuadro de 5 días de evolución de dolor lumbar acompañado de fiebre y escalofríos. Se trataba de una paciente deportista, sin antecedentes médicos de interés. En la exploración, presentaba tensión arterial 80/65 mmHg, temperatura $39^{\circ} \mathrm{C}$ y destacaba dolor selectivo a la palpación en musculatura paravertebral lumbar izquierda. Analíticamente presentaba reactantes de fase elevados sin otras alteraciones. Se realizaron hemocultivos en los que se aisló S. aureus meticilín sensible. Se solicitó RM lumbar que confirmó artritis séptica facetaria con absceso epidural y paravertebral, por lo que se realizó drenaje por radiología intervencionista aislándose S. aureus meticilín sensible. Se realizó ecocardiograma transtorácico y transesofágico sin evidencia de vegetaciones sugestivas de endocarditis. Inicialmente se instauró tratamiento con ceftriaxona y vancomicina, sustituyéndose después por cefazolina y gentamicina durante 7 días. Al alta, se mantuvo tratamiento con cefalexina y levofloxacino hasta completar 4 semanas y se revisó en consultas de Medicina Interna con buena evolución clínica y radiológica.

CONCLUSIÓN: La artritis séptica facetaria es una entidad infrecuente que hay que considerar en pacientes con dolor lumbar y síndrome febril ya que el diagnóstico precoz presenta importantes implicaciones pronósticas. 


\section{CALIDAD DE VIDA, INFECCIÓN POR VIH, VHC Y VHB Y TRASTORNOS ADICTIVOS}

${ }^{1}$ Fernández Rodríguez V; ' ${ }^{1}$ Fernández Sobrino AM; ' 2 López Castro J.

1 UNIDAD ASISTENCIAL DE DROGODEPENDENCIAS DE MONFORTE DE LEMOS; ${ }^{2}$ SERVICIO DE MEDICINA INTERNA. HOSPITAL COMARCAL DE VALDEORRAS.

INTRODUCCIÓN: La calidad de vida es un concepto que incorpora la percepción del individuo sobre el estado de salud, estilo y satisfacción con la vida, estado mental o bienestar y ayuda a identificar déficits en áreas de funcionamiento, facilitando la identificación de grupos de riesgo y la planificación de medidas preventivas.

OBJETIVO: Determinar la Calidad de Vida y el estrés percibido en pacientes a tratamiento en la Unidad Asistencial de Drogodependencias (UAD) de Monforte de Lemos (Lugo).

MATERIAL Y MÉTODOS: Se selecciona una muestra de 100 usuarios que se encuentran a tratamiento en la UAD por dependencia a distintas sustancias. Se recogen variables sociodemográficas y de estado serológico para las infecciones por VHC, VHB y VIH, y se le aplican los cuestionarios SF-36 de Calidad de Vida y PSS-14 de Estrés Percibido. Se pide consentimiento informado a todos los participantes. Se analiza la muestra con SPSS. Resultados Un 64\% de la muestra presenta serología negativa en todos los parámetros estudiados. Del 36\% restante 26 paciente están infectados por el VHC y 8 presenta coinfección por VHCNIH.1 usuario presenta serología compatible con la infección por VHB y otro individuo por VHBNHC. Los pacientes con coinfección VHCNIH obtienen puntuaciones mas bajas en el SF-36, y en aquellos que están infectados por el VHC resultan estadísticamente significativos los resultados obtenidos en Función física, Salud General, Vitalidad, Salud Mental y Salud Física General. Los resultados en las puntuaciones de estrés percibido son más altas para aquellos pacientes diagnosticados de alguna patología infecciosa sin que estos lleguen a ser estadísticamente significativos

CONCLUSIONES: Todos los pacientes infectados por el VIH lo estaban por el VHC. Las puntuaciones del SF36 en sus distintas dimensiones se ven afectadas por la presencia de infecciones como el VIH y VHC. El estrés percibido es más alto en usuarios VIHNHC + que en aquellos sin patología infecciosa.

\section{CAPILAROSCOPIA EN DERMATOMIOSITIS: DESCRIPCIÓN DE UN CASO CLÍNICO}

Caínzos Romero T, Sánchez Trigo S, Sardina Ferreiro R, Gómez Buela I, Lijó Carballeda C, García Alén D, Bravo Blázquez I, Vilariño Maneiro L, Sesma Sánchez P, Suárez Amor OM. MEDICINA INTERNA. DERMATOLOGÍA. COMPLEXO HOSPITALARIO UNIVERSITARIO FERROL.

INTRODUCCIÓN: La capilaroscopia periungueal es un método de interés en el diagnóstico y pronóstico de algunas enfermedades sistémicas autoinmunitarias, fundamentalmente aquellas que cursan con fenómeno de Raynaud. Es un método sencillo y no invasivo que permite una ventana a la microcirculación. Su uso está más extendido en la esclerosis sistémica, presentando unos patrones característicos bien definidos. A continuación se presenta un caso de dermatomiositis (DM), en la cual la capilaroscopia puede tener un papel importante.

CASO CLíNICO: Se presenta el caso de una mujer de 65 años, diagnosticada de DM, con clínica subaguda de meses de evolución, de debilidad en cintura escapular y pelviana, presentando erupción pruriginosa en áreas fotoexpuestas. En la exploración física se objetivaban esiones de aspecto liquenoide en eminencias óseas de manos y dedos (pápulas gottron) sin objetivar pérdida de fuerza por grupos musculares. Se realizaron diversas pruebas complementarias, entre ellas bioquímica completa, hemograma, autoinmunidad, destancando ANAS positivos a título 1: 320 (patrón moteado), siendo los anticuerpos específicos y asociados a DM negativos, así como los enzimas musculares (CK, aldolasa) normales. Se realizó screening de neoplasia negativo. Se solicitó un EMG con leves cambios miopáticos en cintura escapular derecha (deltoides) con datos inflamatorios leves. Se realizóbiopsia muscular con resultado compatible con DM y biopsia cutánea de las pápulas de gottron con patrón liquenoide también compatible. Se trató con prednisona a dosis de $1 \mathrm{mg} / \mathrm{kg}$ día, presentando remisión parcial, por lo que se asoció durante el seguimiento metotrexate alcanzando remisión completa. Durante el seguimiento, a los 4 años de remisión se decidió suspender metotrexate, presentando de nuevo brote con las mismas características que al diagnóstico. En este momento se realizó capilaroscopia, visualizándose megacapilares, discretas áreas avasculares y escasas hemorragias, con áreas de neoangiogenesis mostrando ramnificaciones arboriformes de los capilares.

DISCUSIÓN: En los pacientes con DM existe un patrón de capilaroscopia bien definido que asocia similitudes con el patrón de esclerodermia. Hay autores que han demostrado una correlación entre actividad clínica y alteración capilaroscópica, mostrando remisión de las alteraciones capilares tras alcanzar remisión completa mantenida en el tiempo. Se ha descrito igualmente un patrón característico de DM paraneoplásica con importante desestructuración del lecho capilar, que obligaría a realizar screening de neoplasia con mayor frecuencia.

\section{CAPILAROSCOPIA EN ESCLEROSIS SISTÉMICA: ESCLEROSIS SISTÉMICA SINE SCLERODERMA}

Caínzos Romero T, Sánchez Trigo S, Sardina Ferreiro R, Gómez Buela I, Lijó Carballeda C, García Alén D, Bravo Blázquez I, Vilariño Maneiro L, Sesma Sánchez P. MEDICINA INTERNA. COMPLEXO HOSPITALARIO UNIVERSITARIO FERROL.

INTRODUCCIÓN: La capilaroscopia periungueal es una técnica de gran valor para estudiar la microcirculación. Tiene un papel muy importante en el diagnóstico de la esclerosis sistémica (ES), en la que se observan anormalidades en un $90 \%$ de los pacientes, importantes como apoyo al diagnóstico e información pronóstica. Se presenta un caso clínico de esclerosis sistémica sin esclerodermia, en el que la capilaroscopia facilitó información importante como apoyo al diagnóstico. Caso clínico: Se presenta un caso de un hombre de 71 años, con el diagnóstico de esclerosis sistémica sine scleroderma. Clínicamente presentaba fenómeno de Raynaud, enfermedad pulmonar intersticial pulmonar (EPID), hipertensión pulmonar grave (HTAP), watermelon stomach y ANAS positivos a título 1: 1280 (patrón anti-NuMA), con ENAS negativos, scon índice Rodnan cero en la exploración física. Se realizó capilaroscopia con presencia frecuente de megacapilares, hemorragias capilares y pérdida capilar leve-moderada correspondiéndose con patrón esclerodermiforme activo de Cutolo, apoyando el diagnóstico de esclerosis sistémica. Se inició anticoagulación oral, corticoides orales y calcio antagonistas, con escasa mejoría clínica. Estando el paciente en clase funcional II de la OMS se decidió inicio de bosentán con gran mejoría clinica de la capacidad funcional. DISCUSIÓN: El patrón capilaroscópico en la ES tiene una sensibilidad del 85 \% y una especificidad del $95 \%$, sin embargo la presencia de alteraciones capilaróscópicas no son patognomónicas aunque pueden ser muy útiles como ayuda del diagnóstico y pronóstico. En el año 2000 Cutolo y colaboradores redefinieron los patrones capilaroscópicos de esta entidad: precoz, activo y tardío. El patrón precoz se caracteriza por la presencia de dilataciones y megacapilares aislados, escasas hemorragias, sin evidencia de pérdida capilar; en el patrón activo son frecuentes los megacapilares y microhemorragias acompañados de una pérdida moderada de capilares; el patrón tardío se caracteriza por pérdida de capilares importante, y neoangiogénesis con capilares ramificados, con escasos o ningún megacapilar y con pocas o ninguna hemorragia. En el caso de nuestro paciente la capilaroscopia asociada a ANAS positivos, fenómeno de Raynaud, EPID y HTAP apoya el diagnóstico de esclerosis sistémica sine scleroderma.

\section{CARACTERISTICAS DE LA MENINGITIS POR VIRUS VARICELA ZOSTER EN EL ÁREA SANITARIA DE LUGO}

Piñeiro Fernández JC, Rubal Bran D, Iñiguez Vázquez I, Ventura Valcarcel P, López Reboiro ML, Romay Lema E, Rabuñal Rey $R$.

MEDICINA INTERNA. HOSPITAL UNIVERSITARIO LUCUS AUGUSTI.

OBJETIVO: Describir las características clínicas, diagnóstico y tratamiento de la meningitis por WZ en nuestro medio.

MATERIAL Y MÉTODO: Estudio descriptivo de los ingresos por meningitis por WZ en el HULA a lo largo de 5 años. Se estudiaron las siguientes variables: edad, sexo, comorbilidad, características clínicas, pruebas complementarias, tratamiento y evolución. Análisis estadístico con el programa SPSS 17.

RESULTADOS: Se estudiaron 19 pacientes, un 63.2\% varones. La edad media fue de 58 años (DS 22.4). No se objetivó un predominio estacional, pero sí un mayor número de casos en Otoño e Invierno. Sólo un paciente (5.3\%) tenía comorbilidad y ninguno era inmunodeprimido. Los hallazgos clínicos más habituales fueron la fiebre (68.4\%), la cefalea (63.2\%) y el meningismo (36.8\%). Un 94. 7\% presentaba lesiones cutáneas compatibles con Herpes Zoster, 52.6\% de aparición previa a la clínica neurológica y $36.8 \%$ posterior, siendo de predominio torácico $(47.4 \%$ ) y facial $(31.6 \%)$, con más del $50 \%$ localizadas en el hemicuerpo derecho. Todos presentaban pleiocitosis linfocitaria con hiperproteinorraquia en el LCR. Tres pacientes presentaron hipoglucorraquia (18.8\%). La PCR en el LCR fue positiva en 8 de 14 casos (42.1\% del total). Fue realizado un TC a 16 pacientes (84.5\%) y una RMN a 6 (31.6\%), todos sin alteraciones. Se diagnosticó al ingreso un 89.5\% de los pacientes. El tiempo entre el inicio de la clínica y el tratamiento fue de 6.22 días (DS 1.5). Todos fueron tratados con Aciclovir con una media de 9.21 días (DS 1. 7). La complicación y secuela más habitual fue la neuralgia posherpética (21.1\%). Ningún paciente requirió ingreso en UCI ni hubo fallecidos.

CONCLUSIONES: la meningitis por WZ es una entidad infrecuente, por lo general de evolución benigna con tratamiento. La presencia de glucosa baja en el LCR no excluye el diagnóstico de meningitis por WZ

\section{CARCINOMA BASOESCAMOSO METASTASICO}

Fernández Bouza E, Mella Pérez C, Gómez Buela I, Sardina Ferreiro R, Lijó Carballeda C, García Alén D, Bravo Blázquez I, Sesma Sánchez P. MEDICINA INTERNA. COMPLEXO HOSPITALARIO UNIIVESSTTARIO DE FERROL.

INTRODUCCIÓN: Los tumores cutáneos malignos no melanomas más frecuentes son los basaliomas. Tienen un comportamiento benigno y excepcionalmente metastatizan. OBJETIVO: Se presenta un caso infrecuente de cáncer cutáneo no melanoma metastásico.

MATERIAL Y MÉTODO: Mujer de 67 años con lumbalgia inflamatoria de semanas de evolución sin otros síntomas por aparatos. En la exploración destaca únicamente una lesión en cuero cabelludo exofítica de $3 \mathrm{~cm}$ de diámetro, ulcerada. La radiografía lumbar muestra lesiones óseas líticas en L2 y L5. El hemograma, la función hepática, renal, iones, proteinograma e inmunoglobulinas, proteinuria de Bence Jones, marcadores tumorales y mamografía son normales. La TAC tóraco-abdóminopélvica no muestra lesiones viscerales ni adenomegalias. En RNM hay lesiones destructivas en cuerpos vertebrales L2, L5 y sacro. La gammagrafía ósea muestra acúmulos de trazador en L1-L2 y L5. Se practicó biopsia ósea vertebral percutánea, sin displasia, neoplasia ni metastásis, ni bacilos ácido -alcohol resistente o granulomas, compatible con fractura ósea. Se realizó biopsia cutánea con diagnóstico de carcinoma baoescamoso. Se realiza PET -TAC, con focos de captación en esternón clavícula derecha, costillas, escápula derecha, columna dorso lumbar, sacro, sacroilíacas e ilíacos compatibles con metástasis, con captación en lesión de cuero cabelludo, sin otros focos tumorales. En TAC de cabeza y cuello no se identifica invasión ósea de la lesión cutánea ni adenopatias patológicas. Se reseca la lesión en cuero cabelludo, con diagnóstico de carcinoma basoescamoso infiltrante con bordes libres. Se concluye que la enferma sufre metástasis óseas secundarias a carcinoma basoescamoso

DISCUSIÓN: El carcinoma basocelular constituye el $80 \%$ de los tumores cutáneos no melanomas; excepcionalmente metastatiza (0.1\%). Dentro de ellos está el carcinoma basoescamoso, mucho menos frecuente (1, 5 a 2, 7\% de los cánceres de piel), que reúne características de carcinoma basocelular y espinocelular, con un comportamiento mucho más agresivo. Predomina en los varones y la localización más frecuente es en cabeza y cuello (80\%). Tiene mayor incidencia de metástasis (entre un $5 \%-7 \%$ ). El tamaño mayor de $10 \mathrm{~cm} 2$ de superficie es un factor de riesgo para desarrollarlas. Suelen afectar a ganglios, pulmón, hueso, piel e hígado. El pronóstico de la enfermedad mestastásica es malo con una media de supervivencia de 10 meses. 


\section{CARGA ASISTENCIAL}

\section{EN PLANTA (RELATIVA/ABSOLUTA)}

López Mouriño VM; Alvarez Asensio E; Monteagudo Sánchez B; Martínez Velado E; Boado Martínez M; Otero Alvarín E; Fariña Sarasqueta S; Edesio Firvida J.

MEDICINA INTERNA. HOSPTAL COMARCAL DE MONFORTE DE LEMOS.

INTRODUCCIÓN: Intentamos demostrar los cambios que se producen desde el año 2006 en la carga asistencial referida al $n^{0}$ de ingresos procedentes de Urgencias.

OBJETIVOS: Pretendemos demostrar como en la Sección de Medicina Interna se ha producido un aumento progresivo del número de ingresos, que no se observa en otras especialidades. MATERIAL Y MÉTODOS: Se contabilizan el no de ingresos desde el año 2006 y hasta el 2013 ambos inclusive, procedentes de Urgencias (se excluyen ingresos programados o de consulta), tanto de la sección de Medicina Interna, como en el resto de Especialidades. También se determinan el nº de facultativos en cada Sección.

RESULTADOS: ver tabla

CONCLUSIONES: - ha habido un aumento progresivo del no de ingresos hasta casi duplicarse 565 año 2006, 1134 año 2012 - por el contrario el número de facultativos ha disminuido - cabría preguntarse si son suficientes los facultativos actuales para atender adecuadamente el incremento de la carga asistencia

\section{COMORBILIDAD EN PACIENTES CON AISLAMIENTO DE ASPERGILLUS EN MUESTRA RESPIRATORIA}

Rodríguez-Fernández $S^{\prime}$, Molinos-Castro $S^{\prime}$, Pesqueira-Fontán PM', Balo-Araujo $S^{\prime}$, Gayol-Fernández MC', Rodríguez-Framil M', Padín Paz EM', García-Suárez F3, Naveiro-Soneira J', Varela García PM', Díaz-Peromingo JA3, Pérez del Molino ML', Rial Rama MP, Iglesias Gallego M'.

'SERVICIO DE MEDICINA INTERNA, HOSPITAL BARBANZA (A CORUÑA). ${ }^{2}$ SERVICIO DE RADIOLOGÍA, HOSPITAL BARBANZA (A CORUÑA). ${ }^{3}$ SERVIIIO DE MEDIIINA INTERNA, C. H. U. DE SANTIAGO DE COMPOSTELA (A CORUÑA). ${ }^{4}$ SERVICIO DE MICROBIOLOGÍA, C. H. U. DE SANTIAGO DE COMPOSTELA (A CORUÑA). HOSPITAL BARBANZA, CHUS.

INTRODUCCIÓN: En los últimos años, se ha observado un aumento de infecciones por Aspergillus en pacientes sin inmunodepresión severa: neumopatías crónicas con corticoides, neoplasias, hospitalizaciones prolongadas ó estancias en UCI.

OBJETIVOS: Conocer comorbilidades de pacientes con aislamiento de Aspergillus sp. y cuáles se asocian a presencia de enfermedad frente a colonización.

MATERIAL Y MÉTODOS: Estudio de cohortes retrospectivo en pacientes con Aspergillus sp en muestra respiratoria en nuestro centro (1 de Enero de 2007 y 31 de Diciembre de 2012). Se clasificaron en dos categorías (enfermedad/colonización) según criterios clínicos, microbiológicos y radiológicos. Se recogieron variables relacionadas con comorbilidad y se realizó un análisis univariante aplicando test estadísticos paramétricos y no paramétrico, y análisis de regresión logística binaria (SPSS v.18). RESULTADOS: Un total de 122 pacientes (56 colonizados y 66 con aspergilosis pulmonar). Edad avanzada (media 75+9 años), Charlson $2.6+2$ y Charlson ajustado a edad 6.1+2.3. La mayoría presentaban neumopatía (n 112, 91, 8\%) ó alteración estructural pulmonar previa (n 94, 77\%), siendo las más frecuentes las bronquiectasias. EPOC 53\% (n 65), la mayoría estadío III-IV (n 37, 56.9\%) y fenotipo D (n 23, 35\%). Un tercio (33\%) tenían insuficiencia respiratoria crónica con 02 domiciliario. Mayor riesgo de enfermedad pulmonar por Aspergillus: presencia de neumopatía (OR 5.33, p 0.043), alt. estructural previa (OR 4.02, p 0.002), estadío II-IV EPOC (OR 5. 70, p 0.001) y 02 domiciliario (OR $10.18, p<0.001)$. En el análisis multivariante mantienen significación estadística: alt. estructural previa (OR 5.22, p 0.015) y necesidad de 02 domiciliario (OR 10.96, p 0.001

CONCLUSIONES: La población en la que se aisla Aspergillus sp. presenta neumopatia crónica. La alteración pulmonar estructural previa y la utilización de oxigenoterapia domiciliaria son factores relacionados con enfermedad pulmonar por Aspergillus.

\section{CONSULTA DE CRÓNICOS:}

\section{RESULTADOS DE UN PROGRAMA PILOTO DE MEJORA}

Sánchez Trigo S, Caínzos Romero T, Vilariño Maneiro L, Sardina Ferreiro R, Gómez Buela I, Lijó Carballeda C, García Alén D, Bravo Blázquez I, Gómez Gigirey A.

UNIDADE DE CRÓNICOS. SERVIZO DE MEDIIINA INTERNA. COMPLEXO HOSPITALARIO UNIVERSITARIO DE FERROL.

OBJETIVO: Valorar el impacto de un programa de mejora en la calidad asistencial y el consumo de recursos.

INTRODUCCIÓN: Los pacientes crónicos pluripatológicos consumen cuantiosos recursos sanitarios. Para mejorar la eficiencia de su atención en un hospital de Área se introdujo un programa de mejora basado en un dispositivo asistencial, que incluía una consulta especifica, una sala de tratamiento de día y un sistema normalizado de consulta telefónica.

MATERIAL Y MÉTODO: Se han revisado las historias clínicas electrónicas de todos los pacientes que han pasado al menos una vez por la consulta externa de Crónicos, entre el 1 de mayo de 2013 y el 31 de octubre. Se valoró en cada caso tanto las categorias diagnósticas (utilizando la clasificación de Ollero), como el número de consultas y hospitalizaciones en un periodo de 6 meses antes y despues de la fecha de inclusión en el programa.

RESULTADOS: Se incluyeron 211 pacientes, 113 (53.55\%) fueron mujeres. La edad media fue de 80.61 años. La clasificación de pacientes pluripatológicos por categorías, identificó una media de 2 , 15 categorías por paciente paciente, siendo la más frecuente fue la A (ICC en Clase funcional II o más: Cardiopatía isquémica): 147 (69.66\%), seguida de la B (ERC, Vasculitis o enfermedades sistémicas) 77 (36.49\%), la C (enfermedad respiratoria crónica): 65 (30.8\%), la E (enfermedad neurológica/ deterioro cognitivo): 52 (24.64\%), la G (anemia crónica): 38 (18\%), la F (arteriopatía periférica y DM con retinopatía o neuropatía) 35 (16.58\%), la H (enfermedad osteoarticular crónica): 30 (14.21\%) y la D (enfermedad inflamatoria intestinal y hepatopatía crónica): 9 (4.26\%). El número de consultas en área médica previas a la consulta indice (Crónicos - MI) fue de 270 y tras 6 meses el número de consultas activas era de 181, lo que supone un descenso absoluto de 89 consultas (52 de Cardiología
18 de Neumología, 5 de Endocrinología, 5 de Nefrología, 4 de Reumatología, 3 de Digestivo, 1 de Hematología y 1 de Neurología). El número de ingresos en los 6 meses previos a la primera visita fue de 149, frente a los 53 posteriores, lo que supuso un descenso absoluto de 96 ingresos. Con respecto a las asistencias en urgencias, la reducción fue de 119 asistencias en urgencias (185 en los 6 meses previos frente a 66 posteriores).

CONCLUSIÓN: Los resultados obtenidos, aunque preliminares, sugieren que la implantación de la unidad incide favorablemente en el reducción del consumo de recursos en estos pacientes.

\section{CONTROL DE FACTORES DE RIESGO CARDIOVASCULAR EN PACIENTES CON INFECCIÓN POR VIH Y CARDIOPATÍA ISQUÉMICA}

Mateo-Mosquera LM, Martínez-Braña L, Bermúdez-Ramos M, Losada E, Antela A. UNIDAD DE ENFERMEDADES INFECCIOSAS. MEDICINA INTERNA. COMPLEJO HOSPITALARIO UNIVERSITARIO DE SANTIAGO DE COMPOSTELA (CHUS).

INTRODUCCIÓN: Desde que en 1996 se introdujo el tratamiento antirretrovírico de gran actividad la mortalidad y la morbilidad de la población infectada por VIH descendió de forma dramática por lo que en los últimos años ha ganado importancia la morbimortalidad cardiovascular. Se ha demostrado que globalmente los pacientes con infección por VIH tienen mayor riesgo de tener enfermedad cardiovascular y el propio VIH se contempla como un factor de riesgo cardiovascular independiente. OBJETIVOS: Conocer la prevalencia de los factores de riesgo cardiovascular (FRCV) en pacientes con infección por VIH y cardiopatía isquémica antes y tras el evento isquémico.

MÉTODOS: Del total de pacientes con infección por VIH seguidos en la Unidad de infecciosas del CHUS, se evaluaron los pacientes que habían sufrido un evento isquémico cardiovacular y se compararon sus características clínicas en el momento del evento y en la actualidad (> 3 meses).

RESULTADOS: De los 735 pacientes seguidos en la Unidad de Enfermedades Infecciosas con infección por VIH 13 pacientes fueron diagnosticados de IAM (2\%). La mediana de edad fue de 53 años (DT 7) y todos ellos eran varones. En la tabla adjunta se resumen la comparación de los FRCV. CONCLUSIÓN: Tras un evento isquémico coronario mejora el control de FRCV en los pacientes con infección por VIH y cardiopatía isquémica seguidos en nuestra Unidad, pero aún así sólo el 38.5 \% cumplen objetivos lipídicos (C-LDL) y un 70\% objetivos de TA.

\section{CUANDO LOS HEMOCULTIVOS SON NEGATIVOS}

\section{Porto Pérez AB, Piñeiro Parga P, Sousa Regueiro D, Mosquera Martínez I.} MEDICINA INTERNA Y CIRUGIA VASCULAR. COMPLEJO HOSPITALARIO DEA CORUÑA.

INTRODUCCIÓN: Presentamos un caso de un paciente varón sextagenario con un aneurisma de aorta abdominal infectado por Coxiella burnetii OBJETIVO. Resaltar que la identificación rápida y precisa del agente etiológico es fundamental para poder iniciar un tratamiento antibiótico dirigido y disminuir las tasas de mortalidad, pero que el flujo de trabajo convencional puede tomar hasta varios días. Además, microorganismos exigentes y de crecimiento lento, así como muestras obtenidas tras inicio de antibioterapia pueden conducirnos a falsos negativos,

MÉTODO: Varón 62 años, hipertenso, dislipémico y exfumador en seguimiento por Cirugía por una historia de larga evolución de claudicación intermitente y aneurisma de aorta abdominal infrarrenal; que ingresa de forma programada emergente desde las consultas de Cirugía Vascular tras la realización de tomografía axial computerizada (TAC) abdominal de control, que puso de manifiesto colecciones periaórticas sugestivas de proceso inflamatorio ó infeccioso. Previo al ingreso, el paciente había presentado dolores abdominales inespecíficos con aumento de parámetros inflamatorios en analítica pero sin presentación de fiebre ni ninguna otra clínica relevante. Se interviene de forma programada realizándose laparotomía exploradora, donde se objetiva la presencia de varias colecciones periaórticas. Por lo que se procede a limpieza quirúrgica, obteniéndose drenaje de las colecciones para la toma de cutivos intraoperatorios; siendo los resultados microbiológicos obtenidos en el acto quirúrgico y los cultivos posteriormente procesados negativos obteniéndose lgG en fase I positivos para Coxiella Burnetii y reacción en cadena de polimerasa (PCR) positiva para el mismo agente en las muestras intraoperatorias. Se inicicia tratamiento con doxiciclina y levofloxacino mejorando clínica y analíticamente, siendo dado de alta y acualmente a seguimiento en consultas.

CONCLUSIÓN: Considerar la amplia gama de agentes atípicos cuando los cultivos obtenidos son negativos - Necesidad de desarrollo de técnicas moleculares para diagnósticos microbiológicos más rápidos y certeros

\section{DABIGATRÁN: EVENTOS ISQUÉMICOS EN LA PRÁCTICA CLÍNICA HABITUAL}

Álvarez Otero J, Araújo Fernández S, González González L, Puerta Louro R, Lamas Ferreiro JL, de la Fuente Aguado J.

MEDICINA INTERNA. HOSPITAL POVISA.

INTRODUCCIÓN: Dabigatrán es un fármaco anticoagulante inhibidor directo de la trombina. OBJETIVOS: Determinar la frecuencia y gravedad de eventos adversos isquémicos en pacientes con fibrilación auricular permanente anticoagulados de forma crónica con dabigatrán.

MATERIAL Y MÉTODOS: Estudio descriptivo y retrospectivo en el que se seleccionaron pacientes que iniciaron tratamiento anticoagulante con dabigatrán entre los meses de noviembre de 2011 y septiembre de 2012. El tiempo de seguimiento fue hasta febrero de 2014. Se recogieron las siguientes variables: edad; sexo; comorbilidades: hipertensión arterial, insuficiencia cardiaca, diabetes mellitus, insuficiencia renal e ictus previo. Se analizaron los eventos isquémicos de origen cerebral, cardíaco y periférico.

RESULTADOS: Se incluyeron 316 pacientes (53,5\% hombres) con media de edad de 76, 46 años. Entre los antecedentes personales se observó que el más frecuente fue HTA en el $80,8 \%$, seguido de Diabetes Mellitus (19, 2\%), ictus isquémico (13,3\%), ICC (10, 8\%) e insuficiencia renal (1, 9\%). Dos pacientes presentaron ictus isquémico: 1 amaurosis fugax y otro un ictus de ACM izquierda. Ocho (2, 53\%) pacientes (1, 26/100-pacientes-año) tuvieron un evento adverso isquémico, de origen cardíaco 
en 5 (1, 58\%, 0, 79/100-pacientes-año) pacientes y periférico en 3 (0, 94\%, 0, 47/100-pacientes año). Todos los pacientes que presentaron isquemia cardíaca fue en forma de SCASEST, ninguno de ellos estaba con tratamiento antiagregante previo. En 2 pacientes el tratamiento fue con stent, 1 revascularización quirúrgica y en los otros 2 se administró sólo tratamiento médico. Cuatro de los pacientes mantuvieron anticoagulación y antiagregación de forma permanente y en uno se suspendió la antiagregación.

CONCLUSIONES: Dabigatrán en la práctica clínica habitual es eficaz en la prevención de ictus y presenta un perfil de seguridad respecto a la aparición de eventos isquémicos no cerebrales similar al reportado en los ensayos clínicos.

\section{DAÑO HEPÁTICO INDUCIDO POR FÁRMACOS EN PACIENTES HOSPITALIZADOS}

Gondar Barcala T, Álvarez Otero J, García Poutón N, Fernández Fernández FJ, Puerta Louro R, De la Fuente Aguado J.

MEDICINA INTERNA. POVISA S. A.

INTRODUCCIÓN: El daño hepático inducido por drogas (DHID) representa un problema sanitario creciente debido a laintroducción de nuevos agentes en el mercado, el aumento de la esperanza de vida, la polifarmacia y el incremento de uso de productos de herboristería.

OBJETIVOS: Identificar a los pacientes con DHID sintomático y los fármacos implicados. Analizar el tipo de hepatitis, gravedad de la misma e incidencia de cronificación del daño hepático.

MÉTODOS: Realizamos un análisis retrospectivo de los pacientes ingresados en nuestro centro desde el 01/01/2009 hasta el 31/12/2013 entre cuyos diagnósticos se incluía probable hepatitis tóxica por efecto adverso a medicamentos. Recogimos variables demográficas, de laboratorio y clínicas.

RESULTADOS: Presentaron DHID sintomático 41 pacientes, con una incidencia anual de 0,15\%. La edad media fue 63 años. El 34\% estaban polimedicados y el 39\% consumía alcohol. El 15\% presentaba elevación persistente de las enzimas hepáticas previamente y el 17\% tenía esteatosis hepática. El 71\% tenía una comorbilidad asociada: 19\% neoplasia activa, 19\% obesidad, 12\% tratamiento quimioterápico o inmunosupresor, 12\% DM y 7\% tuberculosis pulmonar. Un paciente presentaba hepatitis crónica por VHC, 2 pacientes eran portadores asintomáticos del VHB y 3 pacientes tenían infección por VIH con carga viral negativa. Los síntomas más frecuentes fueron: astenia 39\%, ictericia $34 \%$, anorexia $32 \%$, dispepsia $32 \%$, coluria $29 \%$, dolor abdominal $27 \%$, náuseas $24 \%$ y vómitos 17\% Los fármacos implicados fueron antimicrobianos en un 50\% (amoxicilina-clavulánico: $22 \%$, isoniazida $10 \%$, ceftazidima: $7 \%$, ciprofloxacino $5 \%$ ), antineoplásicos en un $10 \%$, neurolépticos en el 7\%, e inmunosupresores, AINES y paracetamol en el 5\%. Existió concomitancia farmacológica en el $78 \%$ al haber introducido 20 más principios activos simultáneamente, y en el $24 \%$ con tóxicos (15\% alcohol, $7 \%$ productos de herboristería). La latencia media desde el inicio del tratamiento hasta la aparición de síntomas fue de 10 días. El patrón de daño hepático fue citotóxico en el 51\%, colestásico en el $17 \%$, mixto en el $22 \%$ y en el $10 \%$ no se pudo precisar. En 8 pacientes las enzimas hepáticas permanecieron elevadas a los 6 meses tras el alta; de ellos el 50\% tenía la función hepática alterada previamente y en el $29 \%$ no se pudo precisar por tiempo de seguimiento insuficiente. La fue grave en 4 pacientes; la isoniazida representó el fármaco implicado en 3 de ellos y el ibuprofeno en 1. Registramos un único caso de hepatitis fulminante, también causada por isoniazida. Ningún paciente precisó trasplante hepático.

CONCLUSIONES: EI DHID sintomático es causa infrecuente de ingreso en nuestro hospital. Probablemente el DHID está infradiagnosticado, ya que en muchos casos no produce síntomas. Debe tenerse en cuenta fundamentalmente en pacientes con comorbilidad y polifarmacia. Los agentes causales principales son los antimicrobianos: amoxicilina-clavulánico e isoniazida como los más frecuentes.

\section{DERRAME PLAURAL SEROHEMÁTICO POR SCHWANNOMA PLEURAL BENIGNO GIGANTE}

Bravo Blázquez I, Sardina Ferreiro R, Gómez Buela I, Lijó Carballeda C, García Alén D, Sánchez Trigo Sabela, Caínzos Romero T, Vilariño Maneiro L, Álvarez Díaz H, Pérez Valcárcel J.

MEDICINA INTERNA. COMPLEXO HOSPITALARIO UNIVERSITARIO DE FERROL

INTRODUCCIÓN: Descripción de un caso de schwannoma pleural benigno gigante que se presentó como derrame pleural masivo y serohemático.

CASO CLÍNICO: Varón de 47 años, arquitecto, sin antecedentes de interés, que acudió a urgencias por cuadro de 2 meses de evolución consistente en disnea progresiva, sensación opresiva en hemitórax derecho y febrícula vespertina; no refería pérdida ponderal, anorexia, tos, expectoración o la existencia de convivientes con clínica similar. En la exploración física destacaba una marcada hipoventilación con disminución de la transmisión de vibraciones vocales a nivel de los dos tercios inferiores del hemitórax derecho. Se solicitaron hemograma, bioquímica y coagulación urgentes, que resultaron normales, así como una radiografía de tórax, en la que se objetivó derrame pleural en las tres cuartas partes basales del hemitórax derecho. Ante dicho hallazgo, se realizó toracocentesis diagnóstico-evacuadora, de la que se obtuvieron $660 \mathrm{cc}$ de líquido serohemático con perfil compatible con exudado, celularidad baja con predominio MMN, sin consumo de glucosa, pH y ADA normales y citología sin datos de malignidad. Fue ingresado en la Unidad de Enfermedades Infecciosas con el diagnóstico de sospecha de pleuritis tuberculosa. Se solicitaron Mantoux (induración Omm a las 72h) y TC torácica. En esta última se evidenció masa tumoral de $12 \times 14 \times 16 \mathrm{~cm}$, de base pleural, situada en la región posterior del hemitórax derecho, redondeada, bien delimitada, isoatenuada en su mayor parte, que captaba contraste de manera heterogénea y que no infiltraba estructuras adyacentes; además se obtetivó un derrame pleural cuantioso y una atelectasia basal del pulmón derecho. Se realizó biopsia percutánea guiada por TC de la masa, siendo el resultado de la Anatomía Patológica compatible con proliferación mesenquimal benigna. El paciente fue remitido al servicio de Cirugía Torácica para la realización de toracotomía derecha. El diagnóstico patológico definitivo de la pieza quirúrgica fue de schwannoma benigno pleural.

DISCUSIÓN: Los schwannomas constituyen un subgrupo excepcional dentro de las tumoraciones pleurales. Son tumores originados de fibras nerviosas autonómicas existentes en la superficie pleura del pulmón. Usualmente aparecen en varones de entre 30 y 50 años, presentan un crecimiento lento y son asintomáticos. Característicamente, en la TC torácica, se comportan como tumores bien definidos, ovoides o redondeados, iso o hipoatenuados, que captan contraste de manera heterogénea. A pesar de que aproximadamente la mitad de los tumores pleurales primarios presentan características de malignidad en la Anatomía Patológica, el riesgo de malignización de los schwannomas pleurales, es mínimo (1-5\%); por ello ante un tumor pleural con las citadas características. es importante incluir a la nombrada entidad dentro del diagnóstico diferencial del mismo, ya que su único tratamiento consiste en la exéresis quirúrgica del tumor.

\section{DIABETES Y DISLIPEMIA EN NUESTRA CONSULTA}

López Mouriño VM, Otero Alvarín E, Monteagudo Sánchez B, Martínez Velado E, Boado Martínez M, Alvarez Asensio E, Fariña Sarasqueta S, Edesio Fírvida J.

MEDICINA INTERNA. HOSPITAL COMARCAL MONFORTE DE LEMOS.

INTRODUCCIÓN: se trata de un estudio transversal sobre la hipercolesterolemia en nuestras consultas. OBJETIVOS: Analizar la situación real sobre la situación del manejo de la hipercolesterolemia en consultas externas

MATERIAL Y MÉTODOS: -se coge una muestra de los 100 primeros paciente diabéticos de nuestras consultas externas, citados a partir del uno de enero de 2013, recogiendo los siguientes items - 1) se asigna a cada uno un $n^{\circ}$ (del 1 al 100), -2) cifra colesterol total -3) cifra colesterol HDL -4) cifra colesterol LDL -5) estatinas (si/no) al entrar en consulta - 6) tipo de estatina -7) ezetimibe si/no -8) se cumple objetivo ( $(\mathrm{DL}<100$ según guías ADA 2013) -9) se realiza cambio de tratamiento en consulta $($ si $/$ no) -10 ) cambios de tratamiento $+a)$ inicio de estatina + b) cambio de estatina $+c$ ) aumento de dosis de estatina $+d$ ) asociar ezetimibe.

RESULTADOS: - de 100 pacientes diabéticos $64 \%$ cumplían niveles LDL objetivos - de esos $64 p$, 46 recibían tto, y 18 no - 36 \% pacientes no cumplían objetivo - de esos 36 p 12 recibían tratamiento y se cambio en 8, 4 permanecieron con el mismo - de los 36 pacientes 24 no recibían tto, en 6 se inició, 24 continuaron sin él - 57 pacientes recibían Estatinas - 20 Atorvastatina -8 pravastatina - 9 rosuvastatina -2 pitavastatina -2 fluvastatina - 16 simvastatina - 13 p recibían Ezetrol (11 con estatina y 2 en monoterapia) - 14 p salieron con un tto distinto de consulta: 8 (inicio de est. ), 2 cambio de est, 2 aumento de dosis de est, 2 asociación de ezetrol.

CONCLUSIONES: - más de 1/3 (36 \%)de los pacientes diabéticos de nuestras consultas no cumplen objetivos LDL-c - de los p. que cumplen objetivos $3 / 4$ (46/64) partes reciben to - de los p que no cumplen objetivos solo 1/3 reciben tto (12/36) - las estatinas más utilizadas son Atorvastatina 20 $\%$ y simvastatina $16 \%$ - $13 \%$ de los pacientes tomaban ezetimibe (de ellos $2 \%$ en monoterapia) elcambio más frecuente fue el inicio de estatina $8 \%$.

\section{DIAGNÓSTICO ETIOLÓGICO EN UN CASO DE ESPONDILODISCITIS}

Lorenzo Castro R: Villaverde Álverez, Iria; Val N: Baroja AL: Sousa Domínguez A; Gómez Sousa JM: Soto Peleteiro A; Pérez Rodríguez MT; Argibay Filgueira AB; Nódar Germiñas A; Rivera Gallego A. MEDICINA INTERNA. HOSPITAL XERAL DE VIGO.

INTRODUCCIÓN: La espondilodiscitis es una entidad con una incidencia en aumento debido a una mayor predisposición de la población y también a un mayor diagnóstico por la mejoría de las técnicas de imagen. La obtención de muestra para el aislamiento microbiológico es fundamental para la elección del antibiótico adecuado. En los casos en que no se conoce el microorganismo (hasta un 14\%) no existe actualmente en la literatura un algoritmo claro a seguir. OBJETIVOS: Presentación de un caso de espondilodiscitis y abordaje para obtención de aislamiento microbiológico.

MÉTODOS: Presentación de un caso.

RESULTADOS: Varón de 43 años que acudió por lumbalgia progresiva desde hacía 8 meses, de características mecánicas. Entre los antecedentes destacar el ser fumador y consumidor activo de cocaína inhalada, VIH positivo no progresor (carga viral indetectable y CD4 de 518/mmc). Se le había realizado una nefrectomía izquierda, hepatectomía parcial y resección parcial de colon tras accidente de tráfico. En la anamnesis negaba fiebre y síndrome constitucional. No refería traumatismo. № presentaba alteraciones en la exploración neurológica. En la analítica presentaba PCR $25 \mathrm{mg} / \mathrm{y}$ VSG $71 \mathrm{~mm} / \mathrm{h}$, sin leucocitosis, ni anemia. Hemocultivos y las serologías para Brucella, Coxiella y Bartonella fueron negativos. La RM lumbar mostró datos altamente sugestivos de espondilodiscitis L3-L4 con destrucción ósea. Ante estabilidad del paciente no se inició tratamiento antibiótico. Se realizaron dos punciones percutáneas con biopsia ósea sin obtenerse aislamiento microbiológico (cultivo ordinario, hongos, mycobacterias y PCR para M. tuberculosis). Ante la progresión de la lesión radiológica se realizó biopsia abierta obteniéndose crecimiento de Staphylococcus lugdunensis.

CONCLUSIÓN: Para un correcto manejo de las espondilodiscitis se ha de intentar siempre realizar un diagnóstico etiológico. Si tras dos punciones percutáneas no se obtiene resultado, la biopsia abierta puede ser útil.

\section{DIARREA POR CLOSTRIDIUM DIFFICILE Y AEROMONAS HYDROPHILA EN UNA PACIENTE INMUNODEPRIMIDA}

Soto Peleteiro A, Pérez-Rodríguez MT, Martínez-Lamas L1', Gómez JM, Val N, Baroja A, Lorenzo R, Alonso M, Argibay A, Nodar A, Rivera A.

UNIDAD DE PATOLOGÍA INFECCIOSA. SERVICIO DE MEDICINA INTERNA. 'SERVICIO DE MICROBIOLOGÍA. HOSPITAL XERAL-CIES. COMPIEJO HOSPITALARIO UNIVERSTTARIO DEVIGO. HOSPITAL XERAL-CIES. COMPIEJO HOSPITALARIO UNIVERSITARIO DE VIGO.

INTRODUCCIÓN Y OBJETIVOS: Aeromonas es un bacilo gramnegativo, cuyo hábitat habitual es el medio ambiente. Las especies que ocasionan más del $85 \%$ de las infecciones son A. hydrophila, A. caviae y A. veronii biotipo sobria. El cuadro clínico más frecuente es la gastroenteritis aguda. El objetivo es presentar un caso clínico de diarrea por Aeromonas y C. difficile.

MATERIAL Y MÉTODO: Presentación de un caso clínico y revisión de la literatura. 
RESULTADOS: Mujer de 80 años, con valvulopatía mitral y leucemia linfática crónica B no tratada. Los meses previos había recibido múltiples antibióticos por infecciones urinarias y respiratorias. Acudió por febrícula y diarrea acuosa de 6 semanas de evolución asociada a pérdida de peso. En la exploración física destacaba deshidratación mucocutánea, soplo sistólico mitral, crepitantes secos bibasales, edemas con fóvea hasta rodillas y abdomen anodino. La analítica presentaba: leucocitos 94.180/ul, neutrófilos 8. 730/ul, linfocitos 82.830/ul, anemia normocítica hipocrómica, PCR 300 mg/L y VSG 51 $\mathrm{mm} / \mathrm{h}$. Urocultivo y hemocultivos fueron negativos. Toxina C. difficile en heces fue positiva iniciándose tratamiento con vancomicina vía oral, con persistencia de febrícula y diarrea. TC abdominal visualizó engrosamiento de todo el marco cólico. Posteriormente se aisló A. hydrophila en el coprocultivo, por lo que se trató con ceftriaxona, con evolución clínica favorable. La paciente fue dada de alta con normalización del ritmo intestinal y de los reactantes de fase. En la revisión de la literatura hay pocos casos descritos de coinfección de C. difficile y otros patógenos (CMV, norovirus y Giardia lamblia) y no se ha encontrado ningún caso de coinfección con Aeromonas.

CONCLUSIÓN: En pacientes con diarrea por C. difficile y mala respuesta al tratamiento se debería descartar coinfección por otro microorganismo, especialmente si presentan alguna inmunodepresión.

\section{DIPLEJIA FACIAL DE INSTAURACIÓN AGUDA}

Lamas Ferreiro $\mathrm{JL}^{1}$, González González $\mathrm{L}^{1}$, Criilo I², Álvarez J'S Sanjurjo $A^{1}$, Pato $A^{3}$, de la Fuente Aguado $\mathrm{J}$.

'MEDICINA INTERNA, ${ }^{2}$ MEDICINA FAMILIARY COMUNITARIA, ${ }^{3}$ NEUROLOGIA. POVISA, VIGO (PONTEVEDRA).

INTRODUCCIÓN: La parálisis facial periférica bilateral simultánea presenta una incidencia anual estimada de 1/5000000. La causa más frecuente es la parálisis de Bell. Otra etiología a destacar es el Síndrome de Guillain Barré, existiendo una variante de este cuadro que cursa prominentemente con diplejia facial asociada a parestesias e hiporreflexia sin pérdida de fuerza en extremidades. Se han descrito otras múltiples causas, como la enfermedad de Lyme, la sarcoidosis, etc.

OBJETIVOS: mejorar el conocimiento de la parálisis facial periférica de presentación simultánea aportando un nuevo caso clínico a los ya descritos en la literatura médica.

MATERIAL Y MÉTODOS: Presentamos un caso de parálisis facial periférica bilateral de instauración aguda en el que no se pudo establecer una etiología específica, por lo que se realizó el diagnóstico de parálisis facial idiopática bilateral.

RESULTADOS: paciente de 69 años con disartria y dificultad para la ingesta de alimentos con babeo de 24 horas de evolución, sin disfagia. Como antecedentes presentaba hipertensión arterial, dislipemia y temblor esencial. En la exploración destacaba una tensión arterial sistólica de $185 \mathrm{mmHg}$ y la presencia de una diplejia facial completa. El resto de la exploración era normal. Se realizó hemograma, bioquímica completa, coagulación, ANA, ANCA, ECA, proteinograma, ECG y radiografía de tórax que fueron normales. Las serologías para borrelia, brucella, herpes virus, VIH, VHB, VHC y sífilis fueron negativas (solo lgG positiva para virrus de Epstein-Barr). El análisis de LCR mostró unas proteínas de $49,9 \mathrm{mg} / \mathrm{dL}$, sin otras alteraciones, siendo el cultivo y la PCR para herpes virus negativos. Se realizó una RNM cerebral y de oído interno, con signos sugestivos de neuritis del VII par bilateral sin otras lesiones agudas. Con el diagnóstico de parálisis de Bell bilateral, se inició tratamiento con prednisona y valaciclovir, con resolución prácticamente completa en 4 semanas.

CONCLUSIONES: la parálisis facial periférica bilateral simultánea es una entidad muy infrecuente, siendo la forma idiopática la causa más común, presentando en estos casos un pronóstico muy favorable. Es importante tener en cuenta la posible asociación de enfermedades sistémicas graves en estos pacientes, principalmente el síndrome de Guillain Barré.

\section{DOSCIENTOS PACIENTES CON ENFERMEDAD TROMBOEMBOLICA VENOSA}

Fernández Bouza E, Barbagelata López C, Mella Pérez C, Vázquez Vázquez B, Sardina Ferreiro R, Gómez Buela I, Lijó Carballeda C, García Alén D, Bravo Blázquez I, Sesma sánchez P. MEDICINA INTERNA. COMPLEJO HOSPITALARIO UNIVERSITARIO DE FERROL.

INTRODUCCIÓN: la enfermedad tromboembólica venosa (ETV) es frecuente en nuestras consultas; conocer las características de los pacientes puede contribuir a un mejor manejo.

OBJETIVOS: analizar los datos epidemiológicos y clínicos de los pacientes atendidos en una consulta monográfica de ETV.

MATERIAL Y MÉTODOS: se registraron las condiciones de los 200 primeros pacientes seguidos tras haber sufrido un episodio de ETV.

RESULTADOS: entre Julio-2012 y Febrero-2014 hubo 200 casos. El 56\% (113) fueron mujeres. E $69 \%(138)$ precisaron ingreso hospitalario. El 55\%(111) tuvieron trombosis venosa profunda (TVP), e $39 \%$ (77) embolismo pulmonar (EP) y el 6\%(12) ambos. El EP fue central en $41 \%$ (36) y periférico en $59 \%$ (51). Se consideró masivo en 5.8\%(5), submasivo en 22\% (19) y leve en 71\% (61). Ingresaron el 89\%(78) de los EP y 11\%(9) se trataron ambulatoriamente (todos EP diagnosticados incidentalmente en pacientes con cáncer). Ingresaron el $57 \%$ de las TVP (70) y 43\%(52) se trataron ambulatoriamente. La TVP fue femoral 46\%(56), poplítea 28\%(34), ilíaca 7.4\%(9), tibioperonea 4.1\%(5) y 14\%(17) en otras localizaciones (miembros superiores, subclavia, cava. ). El 100\% de las TVP fueron sintomáticas. Tres (3.3\%) EP se diagnosticaron con gammagrafía de ventilación- perfusión y el resto con TAC de arterias pulmonares. En 26\% de casos (53) se hizo estudio de trombofilia;fue positivo en el 13\%: 1 paciente déficit de antitrombina, 3 heterocigotos para factor $V$ Leiden, 1 paciente homocigoto y 2 heterocigotos para mutación en gen de protrombina. Oros factores de riesgo para ETV fueron: inmovilismo 48\%(96), cáncer 22.5\%(45), ETV previa 9.5\%(29), cirugía 8.5\% (17), fractura 5.5\%(11), uso de anovulatorios $4.5 \%$ (9) y gestación 1\%(2). № hubo trombofilia entre las usuarias de anovulatorio; Una de las gestantes tenía homocigosis para mutación en gen de protrombina. El cáncer fue de mama 24\%(11), colorrectal 22\%(10), pulmón 8.8\%(4), ginecológico 4.4\%(2), hematológico 4.4\%(2), cerebral 2.2\%(1) y otros $33 \%(15)$; el adenocarcinoma fue el más común $(66 \% ; 30$ y el estadio IV el más frecuente (37\%; 17). Iniciaron tratamiento con heparina de bajo peso molecular (193;95.5\%), con heparina no fraccionada el $1.5 \%(3)$ y con otros $2 \%(4)$. El $80 \%$ continuaron tratamiento con anticoagulantes orales. Hubo una hemorragia que obligó a suspenderlo. No se estudió la mortalidad porque las condiciones del registro la hacen no representativa de la muerte asociada a ETV.
CONCLUSIONES: en nuestros pacientes con EP, la TVP probablemente está infradiagnosticada. Como en la literatura, encontramos la TVP más frecuente que el EP. Los EP hallados incidentalmente en pacientes oncológicos se tratan ambulatoriamente con más frecuencia que los sintomáticos. El inmovilismo es el factor de riesgo predominante. A diferencia de otras series, tenemos un alto porcentaje de ETV asociada a cáncer, fundamentalmente en estadios avanzados, achacable a las características asistenciales del centro.

\section{EL TRATAMIENTO DEL TABAQUISMO EN LA UNIDAD ASISTENCIAL DE DROGODEPENDENCIAS. ¿RECURSO INFRAUTILIZADO POR EL SISTEMA SANITARIO PÚBLICO?}

'Fernández Rodríguez V;' González Rodríguez M; ' ${ }^{1}$ Fernández Sobrino AM; ' 2López Castro J.

'UNIDAD ASISTENCIAL DE DROGODEPENDENCIAS DE MONFORTE DE LEMOS; ${ }^{2}$ SERVICIO DE MEDICINA INTERNA. HOSPITAL COMARCAL DEVALDEORRAS.

INTRODUCCIÓN: El tabaquismo genera cada año importantes gastos sanitarios y es la principal causa de muerte evitable conocida en las sociedades desarrolladas. El abordaje de la dependencia de la nicotina se realiza desde un punto de vista integral y multidisciplinar, de forma individual o grupal, con la ayuda del arsenal farmacoterapéutico disponible en la actualidad. La Unidad Asistencial de Drogodependencias (UAD) de Monforte de Lemos es centro de referencia para el tratamiento de tabaquismo en las Áreas sanitarias de Monforte de Lemos y 0 Barco de Valdeorras. El objetivo del presente trabajo es describir las características de los usuarios a tratamiento por su dependencia a la nicotina y su vía de acceso.

MATERIAL Y MÉTODOS: Se selecciona una muestra de 106 usuarios que durante los años 2012 y 2013 habían iniciado o continuado con un proceso de deshabituación tabáquica en la UAD. Se recogieron variables sociodemográficas y relativas al consumo. Para su análisis se utilizó el paquete estadístico SPSS. Resultados En el año 2012 se atendieron 55 personas para tratar su adicción a la nicotina y en el año 2013 el número de usuarios que solicitaron tratamiento fue de 51 . En cuanto al sexo la muestra está constituida por un $55,7 \%$ de mujeres frente al $44,3 \%$ de hombres. Con una edad media de 44, 86 años (DT=11, 19). La vía principal de acceso a nuestro servicio es la iniciativa propia que supone un 39, 6\% del total de admitidos a tratamiento seguida del Médico de Atención Primaria que representa $14,2 \%$, otra fuente de referencia importante son los amigos con un $13,2 \%$. CONCLUSIONES: La nicotina es la única sustancia en la que el número de mujeres a tratamiento supera al de hombres. Estar integrado en una Red sanitaria pública paralela al Servicio Galego de Saúde supone una infrautlización del servicio.

\section{ENCEFALITIS HERPÉTICA, CARACTERÍSTICAS Y EVOLUCIÓN}

Piñeiro Fernández JC, Ventura Valcárcel P, López Reboiro ML, Romay Lema E, Suárez Gil $R$ Rabuñal Rey $R$.

MEDICINA INTERNA. HOSPITAL UNIVERSITARIO LUCUS AUGUSTI.

OBJETIVO: Estudiar la clínica, diagnóstico, tratamiento y pronóstico de la encefalitis herpética en nuestra área sanitaria.

MATERIAL Y MÉTODO: Estudio retrospectivo de los pacientes ingresados con encefalitis herpética en 11 años. El diagnóstico se estableció por una clínica o LCR compatible, junto con una PCR positiva para VHS y/o una RMN sugestiva. Se analizaron las siguientes variables: edad, sexo, comorbilidad, clínica, pruebas complementarias, tratamiento y evolución. El análisis estadístico se realizó con el SPSS 17. RESULTADOS: Se incluyeron 15 pacientes, un 60\% varones. La edad media fue de 66 años (DS 19.2), 66.5\% mayores de 65 años. La estancia media fue de 21 días (DS 1.5). Un 33.3\% tenía comorbilidad y 2 (13.3\%) eran inmunodeprimidos. Los hallazgos clínicos más habituales fueron la fiebre (100\%), alteraciones del comportamiento (86. 7\%), alteración del nivel de conciencia (66. $7 \%$ ), cefalea (53.3\%) y focalidad (53.3\%). Un paciente mostró un LCR normal, siendo la pleiocitosis linfocitaria con hiperproteinorraquia leve y euglucorragia el hallazgo habitual. La PCR resultó positiva en $6 / 12$ casos ( $40 \%$ del total). La rentabilidad diagnóstica fue del $86.7 \%$ para la RMN, $40 \%$ para el EEG y 26. 7\% para el TC. La demora en el inicio del tratamiento fue de 3.3 días (DS 3). Todos fueron tratados con Aciclovir una media de 17.6 días (DS 6.8). Recibieron corticoides el $46.7 \%$ y antiepilépticos el 53.3\%. Presentaron complicaciones 13 pacientes (86. 7\%) 46. 7\% infecciosa, 40\% neurológica, 26. 7\% metabólica (todos SIADH), 13.3\% ETEV y un caso de reactivación. Ingresaron en UCI 5 enfermos, requiriendo 3 ventilación mecánica. Fallecieron 2 pacientes (13.3). Los que presentaron complicaciones neurológicas mantuvieron secuelas a largo plazo (un 26.7\% dependientes para las ABVD).

CONCLUSIONES: El diagnóstico de la encefalitis herpética debe ser clínico, con el apoyo del LCR y la RMN cerebral. Las secuelas neurológicas y funcionales son habituales en la evolución de la enfermedad.

\section{ENFERMEDAD DE FABRY}

Vares M, Arévalo A, Rivera S, Barbagelata C, Llinares D, Rodríguez A, Freire S. MEDICINA INTERNA. HOSPITAL A CORUNNA.

INTRODUCCIÓN: La enfermedad de Fabry es una enfermedad multisistémica de depósito lisosomal, debida a mutaciones en el gen GLA que codifica la enzima alfa-galactosidasa A. Forma parte de las denominadas enfermedades raras, entidades poco conocidas que pueden pasar desapercibidas. En la actualidad existe un tratamiento específico que administrado de forma precoz puede enlentecer la enfermedad.

OBJETIVOS: Mostrar las características de los pacientes de nuestro hospital con enfermedad de Fabry. MATERIAL Y MÉTODOS: Se recogieron los datos de los pacientes diagnosticados de enfermedad de Fabry en nuestro hospital hasta abril de 2014. Mediante el paquete estadístico SPSS $19.0 \mathrm{se}$ analizaron las características clínicas, métodos diagnósticos y criterios de tratamiento.

RESULTADOS: Se recogieron 6 pacientes. Todos presentaban mutaciones en el gen GLA y actividad enzimática baja. La edad media de presentación fue de 17 años y la de diagnóstico de 
38 años, con un retraso medio de diagnóstico de 22 años.1/3 presentaban el fenotipo clásico de la enfermedad (acroparestesias, angioqueratomas, intolerancia al calor, córnea verticilata, hipertrofia ventricular izquierda e insuficiencia renal). Otro tercio presentaron una variante cardio-renal precisando transplante renal por insuficiencia renal terminal a la edad media de 33 años, además de miocardiopatía hipertrófica severa. Los otros 2 eran portadores asintomáticos en el momento de diagnóstico, desarrollando posteriormente afectación renal. Todos los pacientes sintomáticos cumplían criterios de tratamiento.

CONCLUSIONES: - La enfermedad de Fabry es una entidad poco frecuente y su diagnóstico habitualmente tardío. - Las manifestaciones clínicas son diversas, pudiendo presentarse como insuficiencia renal y/o miocardiopatía hipertrófica. - La mayoría de los pacientes cumplen criterios de tratamiento al diagnóstico. - El conocimiento de esta enfermedad es por tanto básico para los internistas.

\section{ENFERMEDAD DE LYME EN EL ÁREA SANITARIA DE LUGO DEL 2008-2012}

López-Reboiro ML; Ventura-Valcárcel P; Piñeiro-Fernández JC; Romay-Lema EM; Moreno-Lugris C; Coira A.

MEDICINA INTERNA. HOSPITAL UNIVERSITARIO LUCUS AUGUSTI.

INTRODUCCIÓN: La enfermedad de Lyme es relativamente joven en cuanto a su descubrimiento, su incidencia está aumentando y, dentro de Galicia, en Lugo es frecuente.

OBJETIVOS: Caracterizar la población a estudiar. Ver la expresión clínica y el contagio, así como las pruebas diagnósticas empleadas. Respuesta al tratamiento. Consumo de recursos.

MATERIAL Y MÉTODOS: Realizamos un estudio descriptivo observacional, en la áera sanitaria de Lugo entre el 2008 y 2012, sobre los pacientes con serología positiva para Borrelia y clínica compatible con la Enfermedad de Lyme. Recogemos las variables y las analizamos con Excell 2010.

RESULTADOS: Seleccionamos 85 pacientes, con 54 años de edad media. La mayor incidencia está localizada en la Ribeira de Pinquín, seguido de la Fonsagrada. La mayoría de los pacientes recordaban la picadura (62\%) que se produjo en los meses de Junio, Julio y Agosto; presentado la clínica precozmente (25\% en el mismo mes de la picadura). La clínica más prevalerte fue el eritema migratorio (46\%) y la radiculopatía (26\%). La serología para borrelia positiva para lgG y lgM en suero (65\%) y en LCR (87\%). La neuroborreliosis presenta una meningitis linfocitaria (82\%) con proteinorraquia ( $82 \%$ ) sin consumo de glucosa (100\%). El 40\% de los pacientes recibieron ceftriaxona con curación en el $67 \%$, la secuela más frecuente son algias (7\%). Generaron 107 visitas a urgencias, 44 ingersos y 61 consultas para llegar al diagnóstico.

CONCLUSIONES: Estamos ante una población joven, de ayuntamientos forestales como Ribeira de Pinquin y Fosagrada. La incidencia aumenta en comparación con estudios previos. La picadura es recordada en la mayoría de los casos, teniendo lugar en meses estivales. La clínica es precoz, con manifestaciones dermatológicas y neurológicas sobre todo. El tratamiento de elección es la ceftriaxona, con la curación completa en la mayoría de los pacientes. Generan un consumo de recursos a expensas de consultas al servicio de urgencias.

\section{ENFERMEDAD DE POMPE EN EL ADULTO CON HIPER- CPK-EMIA: MANTENER SOSPECHA CLÍNICA PARA UN DIAGNÓSTICO PRECOZ}

Baroja Basanta A; Villaverde Álvarez I'; Vázquez Triñanes C1; Rodríguez Gómez A; Val Dominguez N; Pérez-Rodriguez MT; Argibay Filgueira A; Freire Dapena M; Rivera Gallego A.

MEDICINA INTERNA. 'INIDAD DE ENFERMEDADES MINORTIARIAS. XERAL-CIES (IIGO),

INTRODUCCIÓN: La enfermedad de Pompe o Glucogenosis tipo II es una enfermedad rara lisosomal caracterizada por el acúmulo de glucógeno, principalmente en el tejido muscular. Esto dará lugar a una debilidad progresiva que afecta a todos los músculos. La afectación de la musculatura torácica, puede condicionar insuficiencia respiratoria. El tratamiento con sustitución enzimática puede revertir la pérdida de función en la musculatura esquelética pero la insuficiencia respiratoria es irreversible y no responde al tratamiento. Es importante por lo tanto un diagnóstico precoz, debido a que se dispone de un tratamiento específico.

OBJETIVOS: Remarcar la importancia de mantener un alto índice de sospecha clínica para un diagnóstico precoz que modifique el curso natural de la enfermedad, aun en adultos paucisintomáticos, con elevación de CPK sérica.

MÉTODOS: Exposición del caso clínico, pruebas complementarias realizadas y resultados obtenidos. RESULTADOS: Presentamos el caso de un varón de 57 años, bebedor de 2 vasos de vino al día, hipertenso, con antecedentes de hipertransaminasemia y esteatosis hepática. Empezó a presentar calambres musculares hace 7 años en reposo y con el ejercicio, acompañados de dolor y dificultad para la movilidad de las piernas, que no le impedían la realización de sus actividades habituales ni la práctica de deporte que realizaba de forma habitual desde la juventud. En una revisión rutinaria con su Médico de Atención Primaria le comentó estos episodios, y éste detectó en la analítica general una elevación de enzimas musculares (CPK 359 U///, LDH 510U//, aldolasa 8.2 U/// a 37\%), por lo que Io remitió a Consulta Externa de Medicina Interna. La exploración física no reveló ninguna anomalía de interés. La fuerza estaba conservada, $5 / 5$ en todos los grupos musculares y los reflejos osteotendinosos eran normales. No tenía afectación de musculatura respiratoria. La electromiografía mostró una actividad espontánea patológica en varias unidades musculares (trapecio izquierdo, vasto y tibial anterior derecho) y potenciales de acción motora de características neurógenas. Se realizó en ese momento test de screening de enfermedad de Pompe en gota gruesa con resultado dudoso. Se confirmó la actividad enzimática en leucocitos en sangre venosa con resultado positivo en leucocitos. En la biopsia de vasto interno de miembro inferior derecho presentó inclusiones tipo cuerpos citoplasmáticos con ausencia de infiltrados inflamatorios. El estudio genético, solicitado al laboratorio de referencia, sigue pendiente en el momento actual.

CONCLUSIONES: La enfermedad de Pompe, aunque es una enfermedad rara, y que habitualmente debuta en la infancia, puede presentarse en el adulto de forma paucisontomática. La elevación de CPK sérica de causa no aclarada en la primera aproximación al diagnóstico debería ser un motivo de screening de enfermedad de Pompe, debido a que se cuenta con un tratamiento específico que puede modificar el curso de la enfermedad.

\section{ENFERMEDAD POR ARAÑAZO DE GATO: REVISIÓN DE CASOS EN EL COMPLEXO HOSPITALARIO UNIVERSITARIO DE OURENSE}

González Noya A, López Mato P, Fernández Regal I, Pérez Carral V, Rodríguez Álvarez P. MEDICINA INTERNA. CHUO

INTRODUCCIÓN: La enfermedad por arañazo de gato es una enfermedad infecciosa aguda usualmente benigna causada por Bartonella henselae, cuya transmisión al ser humano se produce por el arañazo o mordedura de gato o por la picadura directa de la pulga. Se caracteriza típicamente por linfadenopatías asociadas a una lesión de inoculación, a menudo acompañada de fiebre.

OBJETIVO: Conocer la incidencia y características clínicas de la enfermedad por arañazo de gato en el área sanitaria del CHUO en los últimos 5 años.

MATERIAL Y MÉTODOS: estudio descriptivo retrospectivo donde se han seleccionado y estudiado pacientes mayores de 15 años diagnosticados de enfermedad por arañazo de gato. RESULTADOS: Se han registrado ocho casos, con una mayor afectación en hombres. La presentación clínica más frecuente fue fiebre acompañada de adenopatías, sobre todo a nivel axilar, presentando un curso autolimitado y con buena respuesta a antibioterapia.

CONCLUSIÓN: La enfermedad por arañazo de gato ha de considerarse como posibilidad diagnóstica ante un paciente de que presenta adenopatías, y en el diagnóstico diferencial de un síndrome febril, especialmente en pacientes jóvenes, siendo muy importante el antecedente epidemiológico de contacto con gatos.

\section{ESCLERODERMIA EN VARONES DEL ÁREA SANITARIA DE VIGO: CARACTERÍSTICAS CLÍNICAS DIFERENCIALES}

Val Domínguez N, Gómez Sousa JM, Soto Peleteiro A, Martínez Vidal A, Alonso Parada M, Sousa Domínguez A, Freire Dapena M, Rivera Gallego A.

UNIDAD DE TROMBOSIS Y VASCULITIS, SERVICIO DE MEDICINA INTERNA. HOSPITAL XERAL-CIES DE VIGO. COMPLEJO HOSPITALARIO UNIVERSITARIO DE VIGO (CHUVI).

INTRODUCCIÓN Y OBJETIVOS: El 85-90\% de los pacientes con esclerosis sistémica (SSc) son mujeres y pocas series evaluaron los aspectos clínicos distintivos en varones. Describimos el subgrupo masculino de una cohorte de pacientes de nuestro centro con SSc comparándola con el subgrupo femenino. MATERIAL Y MÉTODOS: Se recogieron los datos de los pacientes codificados con diagnóstico de SSc entre 1985 y 2013 y se clasificaron según los criterios de LeRoy y Medsger: esclerosis sistémica difusa (dcSSc), esclerosis sistémica limitada (IcSSc), esclerosis sistémica sine esclerodermia (SSSSc) y pre-esclerodermia (pre-SSc).

RESULTADOS: De los 114 pacientes, 17 (15\%) eran varones: 10 (59\%) dcSSc y 7 (41\%) IcSSc. La edad media al diagnóstico fue 49 años.9 (53\%) tenían relación con tóxicos (8 sílice, 1 cloruro de vinilo). Todos tenían ANA+, 3 ACA, 8 Scl70, 3 dsDNA, 2 antiRo, 1 antiLa, 1 antiRNP y 1 antiSm. Se realizó capilaroscopia en $3(18 \%)$, todos con megacapilares y pérdidas, y ramificaciones en 2 . En el seguimiento (media 11 años), 15 (88\%) presentaron Raynaud, 10 (59\%) disnea, 9 (53\%) úlceras, 7 (41\%) teleangiectasias y $4(23 \%)$ trastornos digestivos. Se observó EPI asociada en $10(55 \%)$ e HAP en $3(16 \%) .12$ (71\%) fallecieron (promedio de 10 años); la causa fue respiratoria en $4(33 \%)$, cardíaca en 2 (17\%), cáncer en $3(25 \%)$, cirrosis en 1 (8\%) y desconocida en 2 (17\%). El análisis multivariante mostró menor edad en varones al diagnóstico ( $p 0.017)$ y muerte ( $p$ 0.001), y predominio en estos de exposición a tóxicos ( $p$ 0.05), dcSSc (p 0.003), ScI70+ ( $p$ 0.004), EPI ( $p$ 0.002), megacapilares ( $p$ 0.05), pérdida capilar ( $p$ 0.02) y ramificaciones ( $p$ 0.003). No hubo diferencias significativas en mortalidad y supervivencia desde el diagnóstico.

CONCLUSIONES: en más de la mitad de los varones existía relación con tóxicos. El subgrupo masculino se diferenció en la aparición más temprana, predominio de dcSSC, ScI70+, EPI asociada y capilaroscopia compatible con daño endotelial avanzado.

\section{ESTUDIO DE 11 AÑOS DE TUBERCULOSIS GANGLIONAR PERIFÉRICA EN EL ÁREA DE PONTEVEDRA}

Brea-Aparicio $R^{1}$, Velo-García $A^{1}$, Calviño $L^{1}$, Pallarés $A^{2}$, Núñez $M J^{\prime}$ Anibarro $L^{1,3}$ 'UNIDAD DE TUBERCULOSIS, SERVICIO DE MEDICINA INTERNA. COMPLEXO HOSPITALARIO DE PONTEVEDRA; ${ }^{2}$ SERVICIO DE NEUMOLOGÍA. COMPLEXO HOSPITALARIO DE PONTEVEDRA; INSTTTUTO DE INVESTIGACIÓN BIOMÉDICA (IVIB). UNIVERSIDAD DE VIGO. COMPLEJO HOSPITALARIO DE PONTEVEDRA.

INTRODUCCIÓN: La tuberculosis (TB) de ganglios periféricos (TBG) es una de las localizaciones más frecuentes de la TB extrapulmonar (25-60\%).

OBJETIVO: Evaluar los métodos diagnósticos y características clínicas, epidemiológicas, microbiológicas y evolutivas de los casos de TBG en el área de Pontevedra entre los años 2003 y 2013. MATERIAL Y MÉTODOS: Análisis retrospectivo con datos obtenidos del registro gallego de TB. RESULTADOS: Se registraron 116 casos (10\% del total de casos de TB), se excluyeron para el estudio 12 casos por no disponer de información suficiente. $47 \%$ eran varones, la edad media fue de 48 años y 11 presentaban coinfección por el virus de inmunodeficiencia humana (VH) La localización cervical (74\%) fue la más frecuente, seguida de supraclavicular (30\%), axilar (18\%), submandibular (11.5\%) e inguinal (8\%).36\% presentaban $\geq 2$ localizaciones. En 19 pacientes (18\%) había localización extraganglionar, confirmada microbiológicamente en 12 casos.42 pacientes (44\%) presentaban síntomas generales, relacionándose inversamente con el tiempo de evolución de las adenopatías y con la coinfección por VIH La ecografía demostró granulomas con hipodensidad central en $47 \%$ de Ios pacientes en los que se realizó, frente al 63\% de los que se realizaron TAC Se realizó punciónaspiración en 51 casos y biopsia en 84 con los siguientes.

RESULTADOS: 20 pacientes presentaron fistulización sin relacionarse con la realización de PAAF. La respuesta paradójica se presentó en 19 pacientes en forma de fistulización (9), aumento de 
tamaño (11), nuevos ganglios (5), eritema doloroso (5) y sintomatología (9). La respuesta paradójica se relacionó únicamente con el sexo femenino.5-Conclusión: La rentabilidad microbiológica de la biopsia y la aspiración es similar, siendo la biopsia el método diagnóstico de elección en caso de dudas diagnósticas. La aparición de respuesta paradójica no es infrecuente, sin encontrase variables sobre las que actuar para prevenir su aparición.

\section{EVOLUCIÓN DE LA PRESENTACIÓN CLÍNICA EN EL DIAGNÓSTICO DE LA INFECCIÓN POR VIH EN LA ÚLTIMA DÉCADA}

Mateo-Mosquera LM, Martínez-Braña L, Losada E, Antela A.

UNIDAD DE ENFERMEDADES INFECCIOSAS. SERVICIO DE MEDICINA INTERNA. HOSPITAL CLIINICO UNIVERSITARIO DE SANTIAGO DE COMPOSTELA.

INTRODUCCIÓN: En el año 2012 en España se diagnosticaron 3.210 nuevos casos de VIH, lo que supone una tasa de 8,5/100.000 habitantes. El 48\% fueron diagnósticos tardíos, es decir, presentaban una cifra de $\mathrm{CD} 4<350$ células/ul. El retraso diagnóstico tiene consecuencias negativas tanto para el paciente como para la comunidad. En España la recomendación para el diagnóstico de la infección por VIH es el cribado en individuos potencialmente expuestos.

OBJETIVO: El objetivo del presente estudio fue comparar las características clínico-epidemiológicas de los pacientes diagnosticados de infección por VIH a lo largo de una década.

MÉTODOS: Se comparan tres series de pacientes diagnosticados de infección por VIH durante tres años diferentes 2003 ( $n=25), 2008$ ( $n=28)$ y 2013 ( $n=26)$ en la Unidad de Enfermedades Infecciosas del Hospital Clínico de Santiago de Compostela.

RESULTADOS: En la tabla adjunta se resume la comparación entre las tres series.

CONCLUSIÓN: En los últimos años ha cambiado la vía de adquisición del VIH siendo en la actualidad la más frecuente la vía sexual mientras que en el 2003 predominaba la vía parenteral. En relación con esto ha disminuido de forma significativa la prevalencia de la infección por VHC. No se han encontrado diferencias estadísticamente significativas en cuanto a la prevalencia del diagnóstico tardío o la presencia de infecciones oportunistas al diagnóstico por lo que es necesario mejorar las medidas para el diagnóstico precoz.

\section{FACTORES DE RIESGO RELACIONADOS CON HEMORRAGIA POST-PARACENTESIS: A PROPÓSITO DE UN CASO Y REVISIÓN DE LA LITERATURA}

Val Domínguez N, Freire Dapena $M$ MEDICINA INTERNA. HOSPITAL XERAL DEVIGO (CHUVI).

INTRODUCCIÓN: Las complicaciones derivadas de la paracentesis, como el sangrado o la perforación intestinal, son extremadamente raras (entre un 1-2\%) pero potencialmente fatales, sobre todo en los casos de sangrado (0.19\%, con una mortalidad aproximada del $0.016 \%$ ). La identificación de grupos de riesgo podría ayudarnos a extremar precauciones y disminuir aun más la morbimortalidad asociada. OBJETIVOS: descripción de un caso clínico de hemorragia por paracentesis y revisión de la literatura de los factores de riesgo identificados.

MÉTODO: revisión de la historia clínica del enfermo y búsqueda en MEDLINE sin límite de fecha con las palabras clave "paracentesis" or "paracenteses" and "adverse effects", "mortality" or "hemorrhage". RESULTADOS: Mujer de 35 años con infección por VHC genotipo1a en fase cirrótica, con trombopenia (en el momento del ingreso 105.000 plaquetas, con coagulación normal) y crioglobulinemia mixta con insuficiencia crónica renal secundaria (Clcr $53.2 \mathrm{ml} / \mathrm{min}$ ) que ingresa por ascitis a tensión precisando paracentesis terapeútica. A las pocas horas, la paciente presenta un shock hemodinámico secundario a la punción accidental de la arteria epigástrica inferior con hemoperitoneo secundario. Tras embolización selectiva mediante abordaje femoral, se consigue controlar la hemorragia. En los casos revisados en la literatura, los problemas relacionados con la técnica como la necesidad de recolocar el catéter o de realizar dos punciones durante el mismo procedimiento, el tipo de catéter empleado y la experiencia del operador, no implicaron mayor riesgo de presentar complicaciones. La coagulopatía o trombopenia en ningún caso aumentó la incidencia de sangrado. Existe mayor riesgo en las paracentesis diagnósticas frente a las terapéuticas. En pacientes con enfermedad renal de base el riesgo de sangrado está aumentado de manera significativa y en algunos estudios se sugiere la posibilidad de administrar plasma fresco congelado antes de la punción. Los pacientes con clase C de Child-Pug o con hepatopatía alcohólica de base tienen mayor tendencia a presentar complicaciones hemorrágicas asociadas a la paracentesis. La ecografía podría disminuir el riesgo de complicaciones asociadas a la punción accidental de algún vaso arterial.

CONCLUSIONES: la paracentesis terapéutica, la enfermedad renal de base y probablemente los pacientes con clase funcional Child-Pug $C$ y hepatopatía alcohólica tienen un mayor riesgo de hemorragia asociado a la paracentesis. En nuestra paciente identificamos al menos tres de estos factores, La administración previa de plasma fresco o la punción guiada por ecografía en pacientes seleccionados podrían minimizar el riesgo de este tipo de complicación.

\section{FACTORES QUE PRECIDEN LA PRESENCIA DE NEOPLASIA EN LOS PACIENTES CON PÉRDIDA NO INTENCIONADA DE PESO ATENDIDOS EN UNA CONSULTA DE MEDICINA INTERNA}

Carballo Fernández I, Beceiro Abad MC, Valcárcel García MA, Rodríguez Cordero M, Martínez Braña L, Mateo Mosquera L, Díaz Peromingo JA, González Quintela A.

SERVICIO DE MEDICINA INTERNA. COMPLEJO HOSPTTALARIO UNIVERSITARIO DE SANTIAGO DE COMPOSTELA.

INTRODUCCIÓN: La pérdida no intencionada de peso (combinada o no con astenia y anorexia configurando el llamado "síndrome general") es un motivo frecuente de consulta en Medicina Interna. Una pregunta inmediata en estos casos es si subyace una neoplasia maligna o no.
OBJETIVOS: Conocer los factores que predicen la presencia de neoplasia en los pacientes con pérdida no intencionada de peso atendidos en una consulta de Medicina Interna.

MATERIAL Y MÉTODOS: Se incluyeron 220 pacientes con pérdida no intencionada de peso (con 0 sin astenia y anorexia) remitidos (en su gran mayoría desde el servicio de Urgencias) a una consulta de respuesta rápida de Medicina Interna de un hospital terciario, durante el período de un año (Marzo 2012 - Febrero 2013). Un total de 109 (49, 5\%) eran varones. La edad mediana era 78 años (rango, 19 - 94 años). Se analizaron los posibles factores demográficos, de estilo de vida, clínicos y biológicos asociados a la presencia de neoplasia maligna mediante revisión de los historiales clínicos.

RESULTADOS: Se diagnosticó neoplasia maligna en 60 casos (27\%). En 30 de los casos (50\%) presentaba diseminación metastásica. En el análisis univariante, la presencia de neoplasia se asoció con el sexo masculino, con una exploración física anormal y orientativa, con cifras bajas de hemoglobina y cifras altas de plaquetas, de VSG, de PCR y de LDH. No se observaron diferencias significativas entre los pacientes con y sin neoplasia respecto a la edad, el tabaquismo, el consumo de riesgo de alcohol, el tiempo de evolución o el grado de pérdida de peso. En un modelo multivariante mostraron asociación con neoplasia el sexo masculino (OR 2, 22; IC 95\% 1, 18-4, 17; p=0, 01), la elevación de VSG (OR 2, 01; IC 95\% 1, 07-3, 78; $p=0$, 03) y una exploración física anormal y orientativa ( $0 R 2$, 05; IC 95\% 0, 99-4, 25; $p=0.05$ ). Sólo 29 pacientes (13\%) tuvieron que ingresar en el hospital por algún motivo, si bien el ingreso fue más frecuente en los pacientes con neoplasia. CONCLUSIONES: La gran mayoría de los pacientes con pérdida no intencionada de peso pueden ser estudiados ambulatoriamente. Algunas variables básicas demográficas (como el sexo masculino), clínicas (como la exploración física) y biológicas (como la elevación de VSG) permiten identificar un grupo de pacientes con un alto riesgo de neoplasia entre los remitidos por pérdida no intencionada de peso a una consulta específica.

\section{FIEBRE Q CRÓNICA}

Matute G, Gozález-Rivero C, Guillén C, Martinez M. MEDICINA INTERNA E. C. H. UNIVERSITARIO A CORUÑA.

Se presenta el caso clínico de una paciente de 80 años que consulta por síndrome general de 6 meses de evolución. Como antecedentes personales presentaba bioprótesis aórtica, FA permanente, DM, HTA. A la exploración física, tenía un buen estado general estando afebril en todo momento. En las exploraciones complementarias realizadas destaca pancitopenia, colestasis disociada, frotis de sangre periférica con células maduras sin datos de clonalidad. El TAC toraco-abdomino-pélvico evidencia hepatoesplenomegalia sin masas ni adenopatías. La serología para VIH, VHB, VHC, Śfilils, CMV y EBV resultó negativa y el estudio de hepatopatia autoinmune y los marcadores tumorales fueron así mismo negativos. La gastroscopia y colonoscopia no mostraron datos patológicos. Prosiguiendo el estudio para enfermedades de tejido conectivo el FR fue muy elevado, siendo CPK, Aldolasa, Anticuerpos antiCCP y ECA negativos. La biopsia de grasa subcutánea no mostró alteraciones relevantes. Se realizaron hemocultivos (negativos) y ecocardiograma transtorácico y transesofágico sin datos concluyentes de endocarditis. Sin embargo, la serología para C. burnetti fue significativamente positiva para lgG fase I con diagnóstico final de Fiebre Q crónica con posible endocarditis asociada (1 criterio mayor y dos menores). La fiebre $Q$ es una zoonosis de distribución mundial que constituye un desafío diagnóstico en la fase crónica. Dada la inespecificidad de la clínica, los hallazgos ecocardiográficos no concluyentes y los hemocultivos negativos, pueden llevar frecuentemente a un retraso en el diagnóstico por lo que se necesita una alta sospecha clínica en su estudio.

\section{FUSOBACTERIUM NECROPHORUM: MÁS ALLÁ DEL SÍNDROME DE LEMIERRE}

Fernández Fernández FJ, Valle Feijoo ML, Enríquez Gómez H, Araújo Fernández S, Novoa Lamazares L, De la Fuente Aguado J.

MEDICINA INTERNA. POVISA

INTRODUCCIÓN: Fusobacterium necrophorum es un bacilo gramnegativo anaerobio, habitualmente presente en la cavidad oral. Es el patógeno que con más frecuencia causa el síndrome de Lemierre o tromboflebitis séptica de la vena yugular interna. De forma excepcional ha sido descrito como agente de otras manifestaciones clínicas, como empiema 0 absceso hepático. Caso 1: Un varón de 35 años ingresa por dolor en costado izquierdo, tos con expectoración y fiebre de 5 días de evolución. Como antecedentes había sido diagnosticado de reflujo gastroesofágico mediante pHmetría y era fumador de 10 cigarrillos diarios. En la exploración la Ta era de $38.3^{\circ} \mathrm{C}$, la boca era séptica y se apreciaba una disminución de ruidos respiratorios en hemitórax izquierdo. En los análisis destacaba leucocitosis (18230/mm3), trombocitosis (601000/mm3), anemia (Hb 12.5) y elevación de reactantes de fase aguda (NSG $95 \mathrm{~mm} / \mathrm{h}$ y proteína C reactiva $22.8 \mathrm{mg} / \mathrm{dL}$ ). La Rx de tórax mostró un derrame pleural izquierdo loculado. El líquido pleural demostró 3150 células (95\% PMN), con un pH de 6. 7 , y en el cultivo del líquido pleural creció Fusobacterium necrophorum sensible a penicilina. Se pautó tratamiento con ceftriaxona y clindamicina y se colocó un tubo de tórax. Ante la ausencia de respuesta al drenaje se practica decorticación pleural, confirmándose posteriormente la reexpansión pulmonar completa. Caso 2: Un varón de 77 años ingresa en el hospital por cuadro de 1 semana de evolución de fiebre y dolor abdominal en epigastrio e hipocondrio derecho. Como antecedentes había sido diagnosticado de HTA, DM tipo 2 a tratamiento con metformina, y adenocarcinoma de recto que fue tratado mediante resección abdominoperineal, quimioterapia y radioterapia 16 años antes. En la exploración la Ta era de $37.9^{\circ} \mathrm{C}$, y se apreciaba una hepatomegalia de $4 \mathrm{~cm}$. En análisis existía leucocitosis (14250/mm3), elevación de enzimas hepáticas (GPT 98 U/L, GGT 189 U/L y FA 440 U/L y de la VSG (49mm/h). La ecografía y posteriormente la TC abdominal mostraron múltiples lesiones hipodensas hepáticas sugestivas de abscesos. En hemocultivos creció Fusobacterium necrophorum sensible a penicilina. Se pautó tratamiento con Amoxicilina-clavulánico por vía intravenosa durante 2 semanas y posteriormente oral. La evolución fue favorable con resolución de las alteraciones previamente descritas.

CONCLUSIONES: Aunque en animales F necrophorum puede producir abscesos viscerales de modo relativamente común, en humanos es infrecuente su presentación clínica más allá del síndrome de Lemierre. Probablemente el origen de la infección sea orofaríngeo con diseminación hematógena, 
aunque no se ha podido demostrar. A diferencia del síndrome de Lemierre, que puede ser mortal, las manifestaciones atípicas descritas en la literatura suelen tener una evolución favorable con tratamiento antimicrobiano y drenaje de las colecciones en caso necesario.

\section{GIARDIASE INTESTINAL, HIPERPLASIA NODULAR LINFOIDE E NEUMONÍA: ALERTA SOBRE A POSIBILIDADE DUNHA INMUNODEFICIENCIA PRIMARIA}

Sánchez Trigo S, Caínzos Romero T, Sardina Ferreiro R, Gómez Buela I, Lijó Carballeda C, García Alén D, Bravo Blázquez I, Vilariño Maneiro L, Mariño Callejo A MEDICINA INTERNA. COMPLEXO HOSPITALARIO UNIIERSTTARIO DE FERROL.

INTRODUCCIÓN: A Inmunodeficiencia Común Variable (ICV) é unha inmunodeficiencia primaria (IP) caracterizada por un defecto na diferenciación das células B e unha alteración na producción de inmunoglobulinas. É a IP sintomática máis común en adultos. A presentación clínica é heteroxénea e caracterízase pola presenza de infeccións recurrentes, trastornos autoinmunes, patoloxía gastrointestinal e un risco aumentado de neoplasias.

CASO CLÍ́NICO: Presentamos o caso de un home, de 74 anos, que ingresou no servizo de Medicina Interna por síntomas gastrointestinais, consistentes en diarrea subaguda con coprocultivos negativos. Os estudos analíticos xerais (hemograma, función renal, función hepática e ions) non mostraron alteracións. Realizouse unha endoscopia dixestiva alta (EDA) con biopsia duodenal, que mostrou presenza de microorganismos concordantes con Giardia lamblia e Hiperplasia Nodular Linfoide. Completouse 0 estudo analítico que mostrou déficit de inmunoglobulinas (IgM 28, IgA 83 e lgG 242). Posteriormente á alta hospitalaria presentou unha Neumonía, tratada de forma ambulatoria con antibioterapia, con evolución favorable. Ante a sospeita de IP, remitiuse a consulta específica, onde se completou estudo. A seroloxía de VIH foi negativa. 0 estudo de poboacións linfocitarias, complemento (CH50) e autoinmunidade, non mostrou alteracións. Finalmente, estudouse a resposta a vacinas de Neumococo e Haemophilus influenzae tipo B, que foi negativa. Tras establecer o diagnóstico de $I C V$, iniciouse tratamento sustitutivo con inmunoglobulina intravenosa (IgIV) con evolución favorable, recuperación dos niveis de lgG ata o rango de normalidade e ausencia de novas infeccións tras 18 meses de seguemento.

DISCUSIÓN: A ICV defínese polo déficit de lgG e IgA e/ou lgM e a ausencia de resposta ás inmunizacións tras descartar causas secundarias de inmunodeficiencia. As manifestacións clínicas afectan a múltiples órganos e sistemas, e non son específicas, desde infeccións de repetición ata patoloxía pulmonar ou gastrointestinal crónica, síndrome de malabsorción, patoloxía autoinmune ou neoplasias. A variabilidade na presentación clínica fai que exista un retraso diagnóstico evidente, o que conleva un maior deterioro clínico dos pacientes. 0 tratamento con IgIV reduce de forma signiticativa o número de infeccións. Os pacientes con ICV requiren seguemento en consulta especializada, realizando búsqueda activa das posibles complicacións

\section{HEMATOMA CEREBRAL COMO FORMA DE PRESENTACIÓN DE PROBABLE ENFERMEDAD DE MOYA MOYA}

Verdeal Dacal R; Suárez Fuentetaja R; Clavero Fernández E; Marey López J.

MEDICINA INTERNA. COMPLEJO HOSPITALARIO UNIIERSITARIO A CORUÑA.

INTRODUCCIÓN Y OBJETIVOS: La infrecuente enfermedad de Moya Moya se caracteriza por la oclusión progresiva de la arteria carótida interna supraclinoidea y sus ramas en el polígono de Willis generándose una red vascular fina de arterias perforantes dilatadas. De mayor incidencia en e sudeste asiático y mujeres, tiene dos picos de incidencia, uno en niños y otro en adultos. La prueba gold estándar es la angiografía cerebral y el tratamiento varía desde un manejo conservador hasta cirugías de revascularización directa y/o indirecta.

MÉTODO: Descripción de un caso clínico y revisión de la literatura.

RESULTADOS: Mujer, 55 años, caucásica, con migraña como único antecedente. Acudió por cefalea holocraneal de dos días de evolución y parestesias en hemifacies y hemicuerpo izquierdos. A la exploración no presentaba alteraciones a nivel físico ni neurológico. El TAC craneal mostró un hematoma intraparenquimatoso agudo en el lóbulo temporal posterior derecho. La bioquímica, hemograma, VSG, proteína C reactiva, FR, ANAs, ANCA, función tiroidea, fólico y B12 fueron normales. La serología solo presentó una IgM positiva para VEB, realizando PCR del virus en sangre y LCR que fue negativo. Se realizó AngioTAC de arterias supraaórticas mostrando displasia del segmento M1 de la cerebral media derecha con una estenosis significativa, completando el estudio con una arteriografía cerebral que objetiva estenosis del segmento supraclinoideo de la carótida interna derecha que se asocia a proliferación de múltiples arterias tálamoperforantes y lenticuloestriadas y múltiples colaterales, diagnóstico de probable enfermedad de Moya Moya derecha. Estando la paciente asintomática y con buena evolución en TAC de control, valorada conjuntamente por Interna, Neurología, Neurocirugía y Neurorradiología se decidió tratamiento conservador y seguimiento con neuroimagen ambulatorio.

CONCLUSIÓN: La enfermedad de Moya Moya es una patología infrecuente cuyo manejo requiere un enfoque multidisciplinar

\section{HIPERSENSIBILIDAD A LA AZATIOPRINA TIPO SÍNDROME DE SWEET}

Araújo Fernández $S^{1}$, Fernández Fernández FJ ${ }^{1}$, Enríquez Gómez $H^{1}$, Álvárez Otero $J^{1}$ Fernández Villaverde A², De La Fuente Aguado J'.

MEDICINA INTERNA ${ }^{1}$, DIGESTIVO². HOSPITAL POVISA.

INTRODUCCIÓN: El síndrome de Sweet es una dermatosis reactiva, pustulosis y estéril que se puede asociar a infecciones, enfermedades inflamatorias, neoplasias o administración de fármacos. La asociación con el uso de azatioprina (AZA) ha sido descrita de forma excepcional en la literatura. CASO CLíNICO: Un varón de 54 años ingresa por un cuadro de 48 horas de evolución de fiebre y deposiciones líquidas, sin aumento del número diario, con un episodio aislado de hematuria. En la exploración física destaca la presencia de fiebre. Había sido diagnosticado de enfermedad de Crohn y realizaba tratamiento con budesonida y AZA desde 12 días antes. En el análisis de sangre presenta leucocitosis y en el sedimento de orina piuria y hematuria. A las 24 horas del ingreso aparecen lesiones eritemato-pustulosas y costrosas no pruriginosas, dolorosas, localizadas en miembros superiores, abdomen, cuello y cabeza. Se realizó una biopsia cutánea que demostró una dermatosis neutrofilica tipo Sweet. Se diagnosticó, por tanto, de síndrome de hipersensibilidad a la AZA tipo síndrome de Sweet y se suspendió la AZA. Presentó una rápida resolución de las lesiones cutáneas y de la fiebre. DISCUSIÓN: El síndrome de hipersensibilidad a la AZA se trata de una reacción dosis-independiente que ocurre en las primeras 4 semanas del tratamiento. Las manifestaciones clínicas más frecuentes son fiebre, artralgias, mialgias y lesiones cutáneas, entre las que se encuentra el síndrome de Sweet. El diagnóstico del síndrome de Sweet inducido por fármacos se realiza si se cumplen los 5 criterios de Walker y Cohen: aparición de lesiones cutáneas, infiltración dérmica de PMN, fiebre, relación temporal y rápida respuesta a la retirada del fármaco.

CONCLUSIÓN: El síndrome de Sweet asociado al uso de AZA es muy poco frecuente. Debemos tenerlo en cuenta ante la aparición de lesiones cutáneas y fiebre, ya que en muchas ocasiones se asocian a la enfermedad de base.

\section{ICTUS Y TROMBO VENTRICULAR IZQUIERDO TRAS INFARTO AGUDO DE MIOCARDIO}

Gondar Barcala T, Álvarez Otero J, García Poutón N, Fernández Fernández FJ, De la Fuente Aguado $J$.

MEDICINA INTERNA. POVISAS. A.

INTRODUCCIÓN: Los trombos intraventriculares ocurren en el $20 \%$ de los pacientes con infarto agudo de miocardio (IAM) no tratados con anticoagulantes. La incidencia se eleva hasta el $40 \%$ si el IAM es de cara anterior y al 60\% si afecta también al ápex.

CASO CLínICO: Mujer de 54 años, fumadora de 20 cigarrillos que ingresa por IAM, con ascenso del segmento ST en cara anterior, en ritmo sinusal. Se realiza angioplastia en arteria descendente anterior y se inicia doble antiagregación y anticoagulación que se suspende a las 72 horas del ingreso. En el ecocardiograma se detecta una extensa acinesia ventricular anteroseptal y apical con disfunción sistólica global. Continúa tratamiento con AAS, clopidogrel, bisoprolol, ramipril, rosuvastatina y furosemida. A los 14 días la paciente reingresa por hemiplejia, parálisis facial y disartria de instauración brusca. En la TC craneal se evidencia oclusión completa de la arteria carótida interna derecha, sifón carotídeo y amputación de la arteria cerebral media derecha con pérdida de la diferenciación de la sustancia gris-blanca. En el ecocardiograma se aprecia un probable trombo a nivel anteroapical y se pauta anticoagulación con heparina. La TC cardíaca de confirma la presencia de trombos intraventriculares a nivel del ápex y signos de miocardiopatía dilatada isquémica. Se inicia rehabilitación y se mantiene tratamiento anticoagulante con acenocumarol.

DISCUSIÓN: En los IAM anteroseptales con hipocinesia extensa y afección del ápex la incidencia de trombosis intraventricular supera el $50 \%$ siendo el riesgo mayor en los tres primeros meses post-IAM. La embolización cerebral sucede en el $10 \%$ de los casos en los que se detecta un trombo mural. La anticoagulación está indicada en presencia de trombo intracavitario. En pacientes con IAM anterior extenso no cardioembólico en los que no se detecte trombo la anticoagulación no está indicada, ya que el riesgo de embolización es muy bajo.

\section{IMPORTANCIA DA ESTRATIFICACIÓN NO TRATAMENTO DA POLIANXEITIS MICROSCÓPICA}

Rodríguez P, Seco E, Fernández I, Pérez V, López P, González A, Jiménez JL. MEDICINA INTERNA. COMPLEXO HOSPITALARIO UNIVERSITARIO DE OURENSE.

INTRODUCCIÓN: A polianxeítis microscópica (PAM) é a vasculitis ANCA positiva máis frecuente no noso medio e caracterízase por importante afectación reno-pulmonar e pANCA/MPO positivos. 0 tratamento débese realizar en función da extensión e gravidade da enfermidade, para conquerir a máxima supervivencia coa menor toxicidade.

CASO CLÍNICO: Paciente masculino de 78 anos, sen alerxias, hipertenso, fumador, EPOC tipo enfisematoso e colecistectomizado. Hospitalizado 4 meses antes por cadro compatible con neumonía grave. Refería ao ingreso tos e expectoración verdosa dunha semana de evolución, sen febre. Na exploración destacaban crepitantes en bases, e edemas en membros inferiores, sen lesións cutáneas. Ante a sospeita de reagudización infecciosa, tratouse con Cefepime, Azitromicina e Oseltamivir, sen milloría clínica. Realizouse tomografía torácica que amosou enfisema centrolobulillar, infiltrados alveolares e áreas de vidro deslustrado en lóbulos superiores, e bronquiectasias en lóbulos inferiores, con infiltrado periférico suxestivo de infección e zoas de "árbol en brote" en lóbulo inferior esquerdo. Un ecocardio descartou cardiopatía. Unha fibrobroncoscopia presentaba datos de hemorraxia pulmonar. Na analítica presentaba p-ANCA (1/320), con antimieloperoxidasa positivo (119), sendo negativos antiMBG, cANCA/PR3, anticardiolipina, anticoagulante lúpico e antiglicoproteína-beta I. Foi tratado con Oseltamivir, Piperacilina/Tazobactam e Metilprednisolona (3 doses de $250 \mathrm{mg} / \mathrm{día}$, seguidas de $2 \mathrm{mg} / \mathrm{kg} /$ día) con resolución da clínica respiratoria. Posteriormente presenta anasarca refractario a tratamento depletivo, con creatinina de $2 \mathrm{mg} / \mathrm{dl}$, hematuria de 11-20 hematíes/campo e proteinuria en 24 horas de 1, $8 \mathrm{~g}$. Na biopsia renal, confírmase glomerulonefritis focal activa proliferativa, con pouca cronicidad, e afectación intersticial leve. Un EMG amosa polineuropatía motora e sensitiva de longa evolución. Dada a sospeita de vasculitis sistémica xeralizada, iníciase tratamento con Ciclofosfamida iv $(0,5 \mathrm{~g} / \mathrm{m} 2: 1 \mathrm{~g})$ con bóa tolerancia inicial, aínda que en días posteriores, presenta episodio de hipotensión e anemización. Tras un mes de corticoterapia a 1mg/ $\mathrm{kg} / \mathrm{d}$, indícase pauta descendente e continúase con pulsos mensuais de Ciclofosfamida iv, até cumplir 6; tamén se engade un IECA como antihipertensivo e antiproteinúrico, con bóa resposta clínica.

DISCUSIÓN: Con este caso resaltamos a importancia de estratificar a enfermidade avaliando a afectación de órgaos vitais, antes de planificar o tratamento, xa que éste varía según se trate de enfermidade localizada (tracto respiratorio superior e/ou inferior) ou xeralizada (afectación renal máis/ menos outros órgaos vitais). 


\section{INFECCIONES RELACIONADAS CON CATÉTER INTRAVASCULAR: APORTACIÓN DEL CHUO AL ESTUDIO NUVE}

López Mato P, González Noya A, De Toro M, Díaz López D, Fernández Regal I, Pérez Carral V, Rodríguez Álvarez P.

MEDICINA INTERNA. COMPLEJO HOSPITALARIO UNIVERSITARIO DE OURENSE (CHUO).

INTRODUCCIÓN: El uso de vías endovasculares se ha incrementado considerablemente en estos años; por dicha razón se realizó el estudio NUVE (Estudio Nacional de Medicina Interna sobre el Uso de Vías Endovasculares) para registrar las características de estos dispositivos en España. El CHUO participó en su análisis.

OBJETIVOS: Describir las características de los catéteres intravasculares en Medicina Interna del CHUO, partiendo de los datos para estudio NUVE.

MATERIAL Y MÉTODO: Estudio descriptivo transversal de pacientes ingresados el día 27 Junio 2013 a cargo de Medicina Interna, en plantas de Área Médica.

RESULTADOS: Se registraron 158 pacientes, con edad media 79 años siendo 52\% hombres; 65, 2\% presentaban índice de Charlson de 4 a 7. El 84, 9\% portaba vía periférica, y 2 vías el 3, 8\%; ninguno tenía vía central. El lugar más frecuente de inserción fue antebrazo (36, 9\%), seguido de dorso de mano (25, 5\%). El 2, 3\% de las vías tenía signos de infección leve, y aquellos pacientes con signos de sepsis $(3,1 \%)$ tenían foco infeccioso alternativo. Todas las vías fueron colocadas por enfermería, y en $99,5 \%$ de los casos existía registro de fecha de inserción, así como vigilancia diaria. Todas presentaban apósito transparente, y un 37\% de ellas usaba tapones cerrados. En caso de no tener medicación i. v. pautada, la mayoría de las vías permanecían colocadas para posibles rescates; en $6,2 \%$ casos no había causa que justificase la vía. No había establecida una valoración reglada de la necesidad de catéter, y subjetivamente se podrían retirar el $35 \%$ de las vías.

CONCLUSIONES: Los resultados muestran una mayor frecuencia de catéteres respecto a la media nacional, con cifras de infección similares. En nuestro hospital no se estudia la necesidad de mantenimiento del catéter, un factor analizado en $40 \%$ de hospitales participantes. La implementación de esta medida es un objetivo a conseguir para mejorar el índice de infecciones y la calidad asistencial en nuestro medio.

\section{LESIONES DESMIELINIZANTES EN LA ENFERMEDAD DE BEHÇET}

Rodríguez Arias M, González Vázquez L, González Lorenzo JR, Santos Armentía E, Valle Feijoo L, Fernández Fernández FJ, De la Fuente Aguado J.

MEDICINA INTERNA. POVISA.

INTRODUCCIÓN: La afectación neurológica en la enfermedad de Behçet (EB) se produce en un $5-10 \%$ de los casos, con 2 patrones: parenquimatoso y no parenquimatoso. Las lesiones desmielinizantes son una forma rara de afectación parenquimatosa.

OBJETIVOS: describir las manifestaciones clínicas, alteraciones analíticas, la localización de las lesiones desmielinizantes, tratamiento y evolución.

MÉTODOS: estudio retrospectivo de pacientes diagnosticados de EB con afección neurológica entre enero de 1990 y diciembre de 2013 en nuestro hospital. El diagnóstico se realizó en base a los criteriosdel International Study Group of Behçet's Disease. Se evaluaron los hallazgos de resonancia magnética cerebral (RM) y LCR.

RESULTADOS: se diagnosticaron de EB 32 pacientes, 6 (18.7\%) con lesiones desmielinizantes en la RM con edad media al diagnóstico de 31 (15-62) años y 4 (66.6\%) eran mujeres. Síntomas: cefalea (100\%), alteración de pares craneales (66.6\%) - dos con neuritis óptica bilateral y 2 con parálisis facial periférica recurrente-, déficits sensitivos (50\%), ataxia en 1 y déficit motor transitorio en 1. Tres pacientes presentaron ANA positivos a título bajo. LCR: pleocitosis y proteinorraquia en 1 caso y en 3 bandas oligoclonales (50\%). La RM mostró alteraciones en la sustancia blanca en todos los casos, supra e infratentorialmente. Tratamiento: colchicina en 3, azatioprina en 3, corticoides orales en 3 y pulsos de MP en 5. Cuatro pacientes permanecen estables: dos de ellos con corticoides a bajas dosis, uno con adalimumab y otro sin tratamiento; un paciente presentó una recaída a pesar de recibir tratamiento con infliximab y otro con poca adhesión al tratamiento presentó progresión. CONCLUSIONES: Las lesiones desmielinizantes en la EB son poco frecuentes y pueden simular una esclerosis múltiple tanto clínica como radiológicamente. En todos los pacientes con lesiones desmielinizantes se debe valorar síntomas de enfermedad sistémica y realizar seguimiento a largo plazo.

\section{LINFOMA PRIMARIO DE CAVIDADES SEROSAS: CAMBI0 DE PARADIGMA}

Suárez $R$, Clavero E, Verdeal $R$, Yañez J, Busto $E$.

MEDICINA INTERNA. CHUAC.

INTRODUCCIÓN: El linfoma primario de cavidades serosas (LPCS) es una variante infrecuente de los linfomas no Hodgkin B difuso de células grandes que afecta a pacientes inmunodeprimidos severos. Se ha descrito al HHV- 8 como agente etiológico. Se caracteriza por afectación de cavidades serosas en ausencia de organomegalia y adenopatías.

OBJETIVOS Y MÉTODOS: Descripción de un caso clínico y revisión de la literatura al respecto. RESULTADOS: Se trata de una paciente de 69 años diagnosticada en 2008 de cirrosis mixta (enólica e infecciosa por VHB) con carga viral negativa. No realiza seguimientos ambulatorios ni toma tratamientos habituales. Ingresa en Julio 2013 en el Servicio de Digestivo por cuadro de descompensación icteroascítica. Realizamos paracentesis diagnóstica objetivándose la presencia de 12000 leucocitos con $90 \%$ de mononucleares y LDH de 3600, manteniendo los niveles de glucosa, amilasa y ADA dentro de rango. Los cultivos para Mycobacterium Tuberculosis y microorganismos aerobios y anaerobios resultaron negativos. La citología del líquido peritoneal presentaba positividad para células malignas con inmunofenotipo de LPCS (Imágenes adjuntas). Tanto la biopsia de médula ósea como la TAC ósea no revelaron alteraciones significativas. El genoma del virus VHH-8 y la serología de VIH eran negativas. Tras el diagnóstico de LPCS se inició tratamiento con R-CHOP, consiguiendo una supervivencia de 5 meses, patrón de supervivencia similar a los pacientes $\mathrm{VIH}$ con LPCS.

CONCLUSIONES: Presentamos un caso clínico de una paciente con cirrosis de etiología enólica e infecciosa por VHB que rompe el paradigma del LPCS en relación con la etiología y los factores de riesgo que predisponen su aparición. El VHB, virus linfotropo, podría ser el estímulo desencadenante para el desarrollo de LPCS, pero actualmente no disponemos de literatura suficiente al respecto.

\section{LUPUS INDUCIDO POR ANTITNF}

Lijó Carballeda C, Sardina Ferreiro R, Gómez Buela I, García Alén D, Bravo Blázquez I, Sánchez Trigo S, Caínzos Romero T, Vilariño Maneiro L, Echarri Piudo A. MEDICINA INTERNA. COMPLEHO HOSPITALARIO UNIVERSITARIO DE FERROL.

INTRODUCCIÓN: La introducción de los antiTNFa en 1998 marcó el inicio de una nueva era en el tratamiento de las enfermedades inflamatorias crónicas como la Artritis Reumatoide, las Espondiloartropatías y las Enfermedades Inflamatorias intestinales (Ell). Los fármacos antiTNF han demostrado una eficacia clínica superior a los tratamientos clásicos, con un adecuado perfil de seguridad, si bien ocasionalmente pueden presentar efectos secundarios importantes que pueden condicionar la suspensión del fármaco. En relación con el tratamiento antiTNF de la Ell, los efectos secundarios más frecuentes son los cutáneos, por lo general leves y suelen resolverse con corticoides tópicos, siendo pocas veces necesaria la suspensión del fármaco.

CASO CLíNICO: Se presenta el caso de una mujer de 35 años, fumadora, sin antecedentes médicos de interés excepto un aborto diferido. La paciente había sido diagnosticada 6 años atrás de Enfermedad de Crohn (EC) con afectación ileocólica y perianal (A2L3B1 de la Clasificación de Montreal) con artropatía asociada. Dada la refractariedad del cuadro clínico al tratamiento con Azatioprina, se inició Infliximab con una respuesta adecuada, presentando tras la inducción ( $3^{a}$ dosis), una reacción anafiláctica grave durante la infusión. Se cambió el tratamiento a Adalimumab, con buena respuesta. Tras 29 meses de tratamiento continuado, presentó lesiones eritematosas en región nasal, escote, interfalángicas, en dorso de articulaciones, fotosensibilidad y alopecia difusa por lo que se remitió a Consulta de Dermatología, donde se inició tratamiento con esteroides tópicos con mejoría del cuadro. Analíticamente presentaba anticuerpos antinucleares (ANA) positivos a un título 1: 320, patrón homogéneo, con disminución de C3 y C4. Los Anti-DNA y ENAs fueron negativos. Unos meses más tarde presentó nuevo brote grave articular y cutáneo consistente en artralgias generalizadas, lesiones pápulo-edematosas, rosadas, con centro purpúrico y eritema periungueal. Se realizó una biopia que confirmó Lupus Discoide. Se suspendió Adalimumab y se inicia Prednisona, asociando Metotrexate por la dificultad para el control del brote inflamatorio articular, con buena evolución clínica de las lesiones cutáneas.

DISCUSIÓN: La incidencia global del lupus inducido por anti-TNF es de un 1\%. Infliximab y Etarnecept son los fármacos que se asocian con más frecuencia, siendo menor la incidencia del mismo en relación con Adalimumab. El lupus inducido por anti-TNF se asocia con la positividad de los ANAs (95\%) y los anti-DNA son raramente positivos (<5\%). La positividad de los mismos, sin presentar manifestaciones clínicas asociadas, es frecuente y no justifica la suspensión de la terapia. No hay estudios concluyentes que apoyen de manera categórica la contraindicación de la utilización de antiTNF tras el desarrollo de un lupus inducido por estos fármacos, tampoco existe una evidencia cientifica clara que avale la seguridad del tratamiento con otro antiTNF.

\section{MANEJO EN UN CASO DE BACTERIEMIA POR S. PNEUMONIAE ASOCIADA A CATÉTER VENOSO CENTRAL PARA HEMODIÁLISIS}

Lorenzo Castro R; Martínez Vidal Al; Rodríguez Gómez AM; Sousa Domínguez A; Rodríguez Pérez MT, Argibay Filgueira AB; Nodar Germiñas A; Rivera Gallego A.

MEDICINA INTERNA UNIDAD DE INFECCIOSAS. HOSPITAL XERAL DE VIGO.

INTRODUCCIÓN: Streptococcus pneumoniae es la causa más habitual de neumonía y de meningitis adquirida en la comunidad, también ha sido descrito como causa de infecciones nosocomiales. Excepcionalmente puede colonizar catéteres venosos centrales durante la colocación del catéter 0 bien tras su manipulación por el personal sanitario (nasofaringe) 0 del propio paciente (pacientes con broncopatía). La tasa de bacteriemia asociada a catéter es en torno al $4 \%$, pero la mortalidad puede llegar hasta el 25\%.

OBJETIVO: Presentación de un caso de bacteriemia por S. pneumoniae asociada a catéter venoso central para hemodiálisis y evolución con tratamiento conservador.

MÉTODOS: Presentación de un caso y revisión de la literatura.

RESULTADOS: Varón de 65 años portador de catéter de larga duración (tipo Hickman) yugular interno derecho para hemodiálisis que ingresó por fiebre de 24 horas de evolución. Seguido por síndrome antifosfolípidico primario con trombosis arterial (cerebral y renal), GMSI y episodio de endocarditis nativa mitral por S. aureus meiticilina sensible 1 año antes. Al ingreso presentaba afectación del estado general e hipotensión. En la analítica destacaba leucocitosis (17480/mm3) con neutrofilia, plaquetopenia $(52000 / \mathrm{mm} 3)$ y PCT de 21.18. La radiografía de tórax fue normal. En los hemocultivos extraídos por el catéter se aisló S. pneumoniae, serotipo 10A, siendo negativos los de sangre periférica. Se inició ceftriaxona (7 días) y sellados del catéter con vancomicina (14 días), con resolución del cuadro clínico. Durante el seguimiento (4 meses) no ha presentado recurrencia de la infección. El ecocardiograma transtorácico no visualizó vegetaciones. № se ha encontrado ningún caso publicado de infección de catéter de larga duración por S. pneumoniae.

CONCLUSIONES: S. pneumoniae es causa excepcional de bacteriemia asociada a catéter de larga duración. En estos casos se podría realizar tratamiento conservador, mediante sellado del catéter con glucopéptidos. 


\section{MANEJO MULTIDISCIPLINAR DEL PACIENTE SOMETIDO A ARTROPLASTIA ELECTIVA DE CADERA Y RODILLA EN EL HOSPITAL QUIRON A CORUÑA}

Meijide H, Serrano J, Porteiro J, Moreno JA, Gonzalez V, Carrero J, Asensio P, Rico P. MEDICINA INTERNA. SERVICIO DE CIRUGIA ORTOPEDICA Y TRAUMATOLOGIA. HOSPITAL QUIRONA CORUÑA. INTRODUCCIÓN: La cirugía ortopédica protésica mejora sustancialmente la calidad de vida de los pacientes sometidos a intervención quirúrgica, aunque no está exenta de complicaciones. OBJETIVOS: Definir el perfil del paciente que se somete a una artroplastia de cadera o rodilla. Evaluar las complicaciones derivadas de dicho procedimiento. Comparar el consumo de recursos respecto a etapa previa a la implantación del programa.

MATERIAL Y MÉTODOS: Estudio observacional de cohortes prospectivo llevado a cabo en el periodo comprendido entre Noviembre 2011 - Noviembre 2013 en un hospital de segundo nivel (Hospital Quirón A Coruña). Se recogieron los pacientes sometidos a artroplastia electiva de cadera y rodilla. Se analizaron características epidemiológicas, clínicas, complicaciones médicas y quirúrgicas, tasa infección protésica y la mortalidad global a 30 días. Se compararon resultados globales de consumo de recursos (estancias, gasto farmaceutico) antes y despues de la implantacion del programa. RESULTADOS: Se reclutaron un total de 182 pacientes, $70 \%$ mujeres, con una edad media de 70, $6 \pm 8.1$ años. El 44\% tenían un Indice de Charlson $\geq 2$, el $82 \%$ un riesgo anestésico ASA $\geq 2$ y el $55 \%$ tenían algún grado de dependencia funcional (Escala Cruz Roja $\geq 2$ ). Hasta un $63 \%$ de los pacientes tomaban 40 más fármacos. Por tipo de cirugía se distribuyeron en 120 artoplastias rodilla, 52 artroplastias de cadera, 6 recambio prótesis rodilla y 4 recambio prótesis cadera. En todos los pacientes se cumplieron los protocolos de profilaxis antibiótica, profilaxis enfermedad tromboembólica y hemorragia digestiva. Respecto a las complicaciones, el 14\% desarrolló descompensación de patología previa, el 28, 9\% alguna complicación médica y el 3, 9\% alguna complicación quirúrgica. La tasa de infección protésica fue de 2, 2\% (4 pacientes, aislándose SAMS x2, SAMR, y Enterobacter cloacae). El internista tomó decisiones en un $42 \%$ de los casos. Se obtuvo respuesta clínica favorable en el 98, 4\% y fracaso en 3 pacientes (1,6\%), uno de ellos falleció (mortalidad global 0, 5\%). Comparando los periodos, se observó una menor estancia media (4.03 vs 3.63), un menor número de estancias en UCl-Reanimación (254 vs 72) y un menor gasto en medicación por paciente (71.17? vs 53.99?) tras la implantación del programa.

CONCLUSIONES: 1-El perfil del paciente que se somete a una artroplastia es una mujer de edad avanzada, con elevada comorbilidad y polifarmacia. 2-La descompensación de patologías previas y el desarrollo de complicaciones médicas durante la hospitalización hacen necesario plantear programas de atención multidisciplinar. 3-En todos los pacientes se logró el cumplimiento de los distintos protocolos vigentes y la conciliación farmacológica evitando errores relacionados con la medicación. 4-De manera indirecta se comprobó un menor consumo de recursos respecto a la etapa previa a la implantación del programa.

\section{MASA CEREBELOSA COMO FORMA DE PRESENTACIÓN DE NEUROSARCOIDOSIS}

Álvarez Otero J, Lamas Ferreiro JL, González González L, Sanjurjo Rivo A, Gondar Barcala T, Santos Armentia E, de la Fuente Aguado J.

MEDICINA INTERNA, RADIODIAGNÓSTICO. HOSPITAL POVISA.

INTRODUCCIÓN: La sarcoidosis es una enfermedad multisistémica granulomatosa de etiología desconocida que afecta fundamentalmente al pulmón. La afectación neurológica es infrecuente, entre el $5-15 \%$ de los pacientes con sarcoidosis.

OBJETIVOS: Aportar un caso de presentación atípica de neurosarcoidosis, recordando que dicha entidad se puede manifestar de múltiples formas tanto clínica como radiológicamente, por lo que debemos incluirla en el diagnóstico diferencial de diversas patologías neurológicas.

MATERIAL Y MÉTODOS: Presentamos el caso de un paciente con neurosarcoidosis que simuló inicialmente una masa cerebelosa.

RESULTADOS: Varón de 37 años que acudió a nuestro centro por cuadro de un año de evolución de cefalea y síndrome vertiginoso intermitente. Una semana antes del ingreso se asoció dolor punzante a nivel cervical. No tenía antecedentes personales de interés, excepto nódulos cutáneos en el año 2000 compatibles con eritema nodoso. En la exploración neurológica no presentaba ninguna focalidad. Se realizó una TC que mostró una lesión ocupante de espacio en vérmix cerebeloso con hidrocefalia supratentorial y discreta herniación de las amígdalas cerebelosas. Con la sospecha de neoplasia, se realizó estudio de extensión, demostrándose la existencia de adenopatías en múltiples territorios y un patrón intersticial pulmonar compatibles con sarcoidosis. Se objetivó ECA elevada e hipercalciuria, asi como una alteración leve de la difusión pulmonar. La biopsia transbronquial demostró la presencia de granulomas no necrotizantes. Se inició tratamiento con corticoides con buena respuesta clínica y radiológica, observándose resolución de la masa en vérmix cerebeloso y desaparición de la hidrocefalia. CONCLUSIONES: La neurosarcoidosis es una entidad infrecuente que puede presentarse con síntomas muy diversos. Es importante identificarla, ya que puede producir cuadros clínicos muy graves y su respuesta a tratamiento corticoideo suele ser muy favorable.

\section{MASAS MUSCULARES COMO FORMA DE PRESENTACIÓN DE UN LINFOMA}

Sardina Ferreiro R', Gómez Buela I', Lijó Carballeda C', Garcia Alén D', Bravo Blázquez I', Pardo Souto $M C^{2}$, Sánchez Trigo $S^{1}$, Caínzos Romero $T^{\prime}$, Vilariño Maneiro $L^{1}$, Sesma Sánchez $P^{\prime}$. SERVICIO DE MEDICINA INTERNA', SERVICIO DE RADIOLOGÍ². COMPLEJO HOSPITALARIO UNIVERSITARIO DE FERROL.

INTRODUCCIÓN: Aproximadamente un tercio de los LNH tienen una localización extranodal, con afectación más frecuente a nivel del tracto gastrointestinal, de la piel y del sistema nervioso central. La afectación muscular es excepcional.

CASO CLínICO: Presentamos el caso de un varón de 72 años, con antecedentes de hipertensión arterial y dislipemia, que consultó por aumento progresivo del perímetro del miembro inferior derecho
(MID) de 1 mes de evolución. En la exploración física presentaba un edema severo del miembro inferior derecho, desde la raíz del muslo, con signo de Homans positivo. El resto de la exploración física era normal. Se realizó una ecografía doppler que mostró una TVP fémoro-poplítea. Se observó, además, una distorsión de la arquitectura muscular en el cuádriceps adyacente, con edema subcutáneo. El estudio de laboratorio evidenció una elevación de LDH, con beta-2-microglobulina normal y proteinograma sin pico monoclonal. Se realizó una RMN del MID que confirmó la existencia de dos masas tumorales, de alrededor de $20 \mathrm{~cm}$ de eje mayor, a nivel de la musculatura posterior del muslo y de la región inguinal (esta última, se continuaba hacia el interior de la pelvis). Una TC toraco-abdómino pélvica reveló, además, un conglomerado adenopático retroperitoneal. Se efectuó una biopsia con aguja gruesa de la masa del muslo con resultado de linfoma no Hodgkin (LNH) difuso de célula grande B.

DISCUSIÓN: El linfoma muscular primario es una entidad poco frecuente. Su incidencia en las series publicadas oscila entre el $1,5 \%$ de los $L$ NH y el $0,5 \%$ de los LH, con un predominio de los casos LNH de células B. Generalmente tienen una presentación clínica insidiosa, con dolor y aumento del perímetro del miembro afecto, sin existir, en muchos casos síntomas B. La edad media de presentación es de 70 años, y la localización muscular más frecuente, son las extremidades inferiores, generalmente en el muslo. Se ha postulado, en algunos estudios, la posible existencia de una relación causal con una estimulación mecánica previa. La RMN es el estudio más útil para su caracterización. Se presentan como una masa focal o difusa hipointensa en T1 e hiperintensa en T2, con afectación segmentaria y multicompartimental, siendo muy específica la existencia de trabeculación y adelgazamiendo cutáneo, así como la existencia de vasos en su interior. El diagnóstico diferencial debe hacerse principalmente con el histiocitoma fibroso maligno, diversos tipos de sarcomas, así como metástasis de órganos sólidos, fundamentalmente de tumores pulmonares, gastrointestinales o renales.

\section{MENINGITIS BACTERIANA POSTQUIRÚRGICA POR LISTERIA MONOCYTOGENES}

García Alén D', Lijó Carballeda C', Sardina Ferreiro R', Gómez Buela I" Bravo Blázquez I', Sánchez Trigo $S^{\prime}$, Caínzos Romero T', Gómez Canosa $S^{2}$

${ }^{1}$ MEDICINA INTERNA COMPLEJO HOSPITALARIO UNIVERSITARIO DE FERROL. ' 2 UCI COMPLEJO HOSPITALARIO UNIVERSITARIO DE FERROL. ARQUITECTO MARCIDE.

INTRODUCCIÓN: Listeria monocytogenes es un bacilo gram positivo intracelular, ampliamente distribuido en la naturaleza, siendo la tercera causa más frecuente de meningitis bacteriana en nuestro medio. A continuación se presenta un caso clínico de meningitis bacteriana por Listeria monocytogenes en un paciente con intervención quirúrgica cerebral previa.

CASO CLíNICO: Varón de 78 años, intervenido quirúrgicamente de una lesión parietal izquierda (exéresis completa), altamente sugestiva de metástasis cerebral, una semana antes de su ingreso actual. Recibe tratamiento con dexametasona a dosis elevadas desde el momento de su diagnóstico (mes y medio). El paciente acudió al servicio de urgencias por presentar torpeza motora en extremidades inferiores, acompañada de alteración del lenguaje y fiebre. Estando en urgencias, presenta un episodio de crisis comicial tónico-clónica generalizada autolimitada. En la exploración física presentaba auscultación cardiopulmonar, exploración abdominal y de extremidades inferiores estrictamente normal. Neurológicamente, destaca un nivel de consciencia fluctuante, con un Glasgow entre 9 y 11 , con meningismo, movimientos oculares asimétricos y reflejo plantar bilateral flexor. Como pruebas complementarias se realizan una TAC craneal, que no mostraba cambios agudos, y una punción lumbar, obteniéndose en el líquido cefalorraquídeo (LCR) 290 células (90\% polimorfonucleares), proteínas 112 $\mathrm{mg} / \mathrm{dL}$ y glucosa de $103 \mathrm{mg} / \mathrm{dL}$ (glucemia de $170 \mathrm{mg} / \mathrm{dL}$ ). Se realizaron también petición de cultivo en LCR, antígenos de Haemophilus influenza, Streptococo pneumoniae y Neiseria meningitidis A, B y $\mathrm{C}$, y hemocultivos. Con la sospecha diagnóstica de una meningitis bacteriana postquirúrgica precoz, el paciente es ingresado en la Unidad de Cuidados Intensivos y se inicia tratamiento antibiótico de amplio espectro con cefepime y linezolid, asociándose fármacos anticomiciales y corticoterapia. Tanto el cultivo del LCR como los hemocultivos resultaron positivos para Listeria monocytogenes, modificándose el tratamiento antibiótico dirigido con ampicilina y gentamicina. El paciente evolucionó de forma desfavorable, siendo exitus a los cinco días de su ingreso.

DISCUSIÓN: La meningitis bacteriana por Listeria monocytogenes afecta fundamentalmente a pacientes inmunodeprimidos o con comorbilidades asociadas, como es el caso de nuestro paciente, que recibía altas dosis de corticoides, aunque también puede ocurrir en pacientes sin ningún factor de riesgo. Se estima que la incidencia de meningitis bacteriana aguda por Listeria está entre un 5-10\% en Norte América y Europa. En conclusión, hay que tener un alto grado de sospecha de etiología por dicho bacilo en infecciones graves del sistema nervioso central, sobre todo en pacientes ancianos e inmunosuprimidos.

\section{MIOCARDIOPATÍA NO COMPACTADA Y TROMBOSIS VENOSA PERIFÉRICA}

Verdeal Dacal R; Clavero Fernández E; Suárez Fuentataja R; Otero González I. MEDICINA INTERNA. COMPLEJO HOSPITALARIO UNIVERSITARIO A CORUÑA.

INTRODUCCIÓN Y OBJETIVOS: La miocardiopatía no compactada (MCNC) es una cardiopatía genética primaria caracterizada por una pared miocárdica alterada con trabéculas prominentes y recesos intertrabeculares que resultan de la no compactación del ventrículo izquierdo (VI) en la etapa fetal y la formación de dos capas de miocardio, compactado y no compactado. Su clínica principal es fallo cardíaco, arritmias y tromboembolismos. Su diagnóstico se hace por criterios ecocardiográficos con apoyo del TAC, RMN cardíaca y test genéticos. Su manejo abarca desde el tratamiento de sus complicaciones hasta el trasplante

MÉTODO: Descripción de un caso clínico y revisión de la literatura.

RESULTADOS: Varón, 54 años, padre con cardiomegalia no filiada, pólipos de colon sin displasia, anemia crónica desde hace un año, ingresa por neumonía bilateral y anemia severa. Al ingreso se administra hierro parenteral por vía periférica en miembro superior izquierdo, presentando horas después edema y dolor en este miembro. Ante empeoramiento respiratorio se realiza angioTAC que muestra gran cardiomegalia y trombosis de las venas subclavia, axilar y yugular interna izquierdas, sin TEP. Se completó estudio con endoscopias alta y baja, sin hallazgos salvo pólipo rectal con displasia 
de bajo grado. Fólico, B12, TSH, autoinmunidad, ferrocinética, haptoglobina y Coombs evidenciaron anemia ferropénica y TAC cervical, abdominopélvico y marcadores tumorales no vieron datos de malignidad. El ETT mostró FEVI del 17\% y morfología de trabeculación grosera sugestiva de no compactación miocárdica apical del VI. Se realizó estudio de coagulación que no mostró datos de hipercoagulabilidad y RMN cardíaca que confirmó una MCNC

CONCLUSIONES: La MCNC se asocia a eventos trombóticos de diversos tipos. En este caso su trombosis parece más en relación con episodio de tromboflebitis pero se necesitan más estudios que aclaren qué favorece la procoagulabilidad de esta cardiopatía y que pudiera influir en este paciente

\section{MODELO DE ASISTENCIA COMPARTIDA EN HOSPITAL QUIRON A CORUÑA. ADSCRIPCION DE UN INTERNISTA A UN SERVICIO DE CIRUGIA ORTOPEDICAY TRAUMATOLOGIA. ENCUESTA DE OPINION}

Meijide H, Porteiro J, Serrano J, Moreno JA, Gonzalez V, Carrero J, Asensio P, Rico P. SERVICIO DE MEDICINA INTERNA. SERVICIO DE CIRUGIA ORTOPEDICAY TRAUMATOLOGIA. HOSPITAL QUIRONA CORUÑA.

INTRODUCCIÓN: Estudios previos han demostrado que la atención a los pacientes ingresados en los Servicios de Cirugía Ortopédica y Traumatología (COT) puede beneficiarse de la colaboración de médicos clínicos.

OBJETIVOS: Analizar en una encuesta de opinión el nivel de satisfacción tanto del personal facultativo de COT como del personal de Enfermería tras la implantación del programa de Internista de Proceso Quirúrgico con la adscripción de un internista al equipo. Conocer el grado de satisfacción de los pacientes.

MATERIAL Y MÉTODOS: Se recogieron los pacientes sometidos a artroplastia electiva de cadera y rodilla en el seno del programa internista de proceso quirurgico entre Noviembre 2011- Noviembre 2013. En Enero 2014 se realizó una encuesta de 10 preguntas (adaptada de Huddleston et a) confidencial y anónima al personal de COT y Enfermería para conocer el nivel de satisfacción con el actual modelo de trabajo de asistencia compartida. Todos habían trabajado con ambos modelos. Las preguntas eran de tipo cerrado, con 5 posibles respuestas. Se escogió una muestra al azar de pacientes intervenidos durante un periodo de 2 meses consecutivos y mediante sistema de llamada telefónica se preguntó por el grado de satisfacción sobre el equipo multidisciplinar que lo había atendido.

RESULTADOS: Se incluyeron en el periodo de estudio 182 pacientes, 70\% mujeres, con una edad media de 70, $6 \pm 8.1$ años. El 44\% tenían un Indice de Charlson $\geq 2$, el $82 \%$ un riesgo anestésico ASA $\geq 2$ y el $55 \%$ tenían algún grado de dependencia (Escala Cruz Roja $\geq 2$ ). Hasta un $63 \%$ de los pacientes tomaban 4 o más fármacos. Completaron la encuesta 7 facultativos COT y 16 DUE. Tanto el personal de enfermería como el personal facultativo de COT prefieren claramente el sistema de trabajo multidisplinar. Destaca el mayor grado de satisfacción en el colectivo COT. El personal DUE puntúa más bajo la comunicación $(3,6 \pm 1,2)$ y la coordinación entre el personal facultativo $(3,7 \pm 1)$. La calidad de la atención médica $(4,7 \pm 0,5)$ y la celeridad de atención ante un problema post-operatorio $(4,5 \pm 0$, 7) fueron muy bien valorados. Contestaron a la encuesta telefónica los 26 pacientes correspondientes a las intervenciones de los meses Septiembre - Octubre 2013. Sólo un paciente se mostró poco satisfecho. El 96\% se mostró satisfecho con el modelo de asistencia compartida.

CONCLUSIONES: 1-El perfil del paciente que se somete a una artroplastia es una mujer de edad avanzada, con elevada comorbilidad y polifarmacia, lo que evidencia una clara necesidad de un modelo multidisciplinar.2-En general ambos colectivos prefieren el modelo de asistencia compartida, aunque destaca el mayor grado de satisfacción en el colectivo COT.3-El personal DUE puntúa más bajo la comunicación y coordinación entre personal facultativo; sin embargo, la calidad de la atención médica y la celeridad de atención ante un problema post-operatorio fueron muy bien valorados.4- La satisfacción global de los pacientes ascendió a 96\%.

\section{MUJER CON HEMOPTISIS Y FIEBRE: HEMOSIDEROSIS PULMONAR IDIOPÁTICA}

Clavero E, Rodriguez-Segade S, Marcos P.

MEDICINA INTERNA Y NEUMOLOGÍA. HOSPITAL CLIINICO UNIVERSITARIO DEA CORUÑA.

INTRODUCCIÓN Y OBJETIVO: La hemosiderosis pulmonar idiopática (HPI) es un entidad rara, de difíci reconocimiento y que implica un amplio diagnóstico diferencial. El diagnóstico final se obtiene por biopsia pulmonar tras excluir otras causas de hemorragia alveolar.

RESULTADOS: Mujer de 38 años fumadora, asmática leve que consultó por tos, hemoptisis, fiebre y disnea progresiva las últimas 2 semanas. Se interpretó como infección bronquial y se trató con antibióticos sin mejoría. Estaba pálida, taquipneica y en la auscultación predominaba la hipofonesis sin broncoespasmo. Se objetivó insuficiencia respiratoria, anemia microcítica y ligera leucocitosis, con coagulación y función renal normales. La radiografía de tórax mostró infiltrados micronodulares bilaterales difusos y las auraminas en esputo fueron negativas. Sin exposiciones tóxicomedicamentosas ni clínica sistémica. Los estudios microbiológicos, serológicos, autoinmunidad y ETT fueron normales. La TC mostró afectación difusa con patrón en vidrio deslustrado y micronódulos. La broncoscopia con LBA confirmó la sospecha de hemorragia pulmonar. Ante la ausencia otras causas que justificasen el proceso, se realizó biopsia pulmonar mediante videotoracoscopia que confirmó el diagnóstico de HPI. Como complicación se produjo rotura traqueal precisando reintervención con buena evolución. Dadas las potenciales complicaciones de los corticoides orales, se optó por los inhalados con mejoría clínica y radiológica.

CONCLUSIONES: No existen ensayos controlados de tratamiento por lo que la terapia se basa en las experiencia de casos individuales y pequeñas series en los que los corticoides sistémicos reducen la morbimortalidad y la progresión a fibrosis pulmonar. En caso de refractariedad se pueden añadir inmunosupresores. El trasplante no se recomienda por riesgo de recurrencia en el injerto. Existen casos descritos de respuesta a corticoides inhalados cuando no se tolera el tratamiento sistémico como en este caso.

\section{NEOFORMACIÓN TESTICULAR COMO FORMA DE PRESENTACIÓN DE VASCULITIS}

Pérez A, Montes J, Estéz M, López J, Machado B, Fernández J. MEDICINA INTERNA. COMPLEXO HOSPITALARIO UNIVERSTTARIO DE VIGO

INTRODUCCIÓN: Las vasculitis son un conjunto de enfermedades caracterizadas por la infiltración de leucocitos en las paredes de los vasos sanguíneos, que causa una desestructuración de los mismos, con el consiguiente riesgo de ruptura, sangrado, oclusión 0 isquemia. En general, las vasculitis se distinguen en función del tamaño, localización o tipo de vasos que afectan. Estas entidades pueden presentarse de forma aislada o asociadas a otras enfermedades. La infiltración en los diversos órganos genera anomalías en los mismos: hemorragias, isquemia o seudomasas.

MATERIAL: Reportamos dos casos de vasculitis que cursaron con la aparición sendas masas testiculares.

MÉTODO: En el primero de los casos, un varón de 45 años de edad, ingresó por dificultad respiratoria e infiltrados pulmonares múltiples, alteración de la función renal y una masa testicular, que inicialmente se sospechó como neoplásica. Tras constatar el diagnóstico de vasculitis necrotizante sistémica, se instauró tratamiento inmunosupresor, alcanzándose remisión sintomática, desapareciendo dicha masa. En el segundo caso, un varón de 51 años, se detectó una masa testicular, que fue extirpada por sospecha de neoplasia. En el estudio anatomopatológico, se apreciaron hallazgos sugerentes de poliarteritis nodosa. El estudio de extensión y de inmunidad fue negativo.

CONCLUSIONES: La aparición de una masa testicular en el seno de una enfermedad vasculítica es un hallazgo excepcional, pero que podemos encontrar en cierto número de pacientes. El principal diagnóstico diferencial es el tumor primario de testículo, neoplasia sólida más común en varones de esta edad. La ecografía testicular sigue siendo el método diagnóstico de elección. En nuestro caso, no hubo elevación de marcadores tumorales típicos de tumor testicular, especialmente en formas metastásicas.

\section{NEUMONÍA COMUNITARIA Y NEUMONÍA ASOCIADA A CUIDADOS SANITARIOS ¿ENTIDADES DISTINTAS?}

A. Sousa Domínguez, M.T. Pérez-Rodríguez, N. Val Domínguez, A. Martínez Vidal, A. Rodríguez Gómez, R. Lorenzo Castro, A. Baroja Basanta, J.M. Gómez Sousa, A. Argibay, A. Nodar MEDICINA INTERNA-UNIDAD DE PATOLOGÍA INFECCIOSA. COMPLEJO HOSPITALARIO UNIVERSTTARIO DE VIGOHOSPITAL XERAL

OBJETIVOS: La neumonía asociada a cuidados sanitarios (NACS) se ha asociado con un peor pronóstico y un mayor riesgo de microorganismos nosocomiales que la de adquisición comunitaria. Los objetivos del trabajo fueron comparar las características clínicas, epidemiológicas y terapéuticas, así como los factores de riesgo asociados con mortalidad de estos dos grupos.

MATERIAL Y MÉTODO: De forma retrospectiva se los casos de neumonía comunitaria (NAC) y NACS, entre enero y diciembre de 2013. Se definieron ambos grupos según las guías ATS (2005) y se analizaron las características clínicas, epidemiológicas, tratamiento y evolución clínica de los pacientes. RESULTADOS: Se identificaron 164 pacientes con neumonía, 66 (40.2\%) de ellos cumplían criterios NACS, aunque sólo 4 pacientes (6\%) fueron identificados como tal. El 55.5\% del total eran mujeres, con una edad media global de $73 \pm 16.7$ años. El principal criterio de inclusión en el grupo de NACS fue el ingreso previo reciente (54.5\%), seguido de la institucionalización (34.8\%). Al comparar ambos grupos se observó una edad superior en los pacientes con NACS (78 \pm 13.0 años vs $70 \pm 18.2$ años; $\mathrm{p}=0.003$ ), así como un mayor grado de comorbilidad (índice de Charlson $5 \pm 2.7$ vs $3 \pm 2.6, p=0.013$ ) y de gravedad de la neumonía (PSI 4 [2-5] vs 4 [1-5], $p=0.003$ y CURB-65 2 [0-4] vs 1 [0-4], $p=0.005$ ). Se realizó al menos un estudio microbiológico el $84.8 \%$ de los pacientes $(63.4 \%$ antigenurias, $62.8 \%$ hemocultivos y $36.6 \%$ cultivo de esputo), identificándose el agente etiológico en el $22 \%$ de los casos. Streptococcus pneumoniae fue el más frecuente en ambos grupos (14 casos, 25\% del total de aislamientos) y los microorganismos resistentes (S. aureus meticilin resistente, Pseudomonas aeruginosa y Enterococcus faecium) se identificaron con mayor frecuencia en pacientes con NACS $(10.6 \%$ vs $2 \%, p=0,053)$

La adherencia a las guías de tratamiento fue del $36 \%(50 \%$ NAC vs $15 \%$ NACS, $p<0.001)$. El motivo de la inadecuación del tratamiento fue sobretratamiento en la NAC ( $37 \%$ NAC vs $0 \%$ NACS, $p<0.001$ ) e infratratamiento en la HCAP (15.3\% NAC vs $81.8 \%$ NACS, $p<0.001)$. La duración del ingreso fue superior en los paciente con HCAP (14 [2-60] días vs 10 [2-77] días, $p=0$, 022), así como en el tratamiento antibiótico endovenoso (8 [0-26 días] vs 5 [0-25] días, $p<0,001)$.

La mortalidad fue $18 \%$, siendo significativamente superior en NACS ( $9 \%$ VS $31 \%$; $p<0.001$ ). En el análisis multivariado los factores que se asociaron con una mayor mortalidad fueron el score de Pitt (OR 1, 8 IC al 95\% 1, 2-5, 3), la edad superior a 70 años (OR 9, 2, IC al 95\% 6, 2-15,3) y el diagnóstico de NACS (OR 4, 0 IC al 95\% 1, 3-7, 9).

CONCLUSIONES: La neumonía asociada a cuidados sanitarios es una categoría muy poco reconocida como tal pese a presentar un peor pronóstico. El diagnóstico etiológico se logró en un porcentaje bajo de los casos. La mortalidad se asoció significativamente con la edad, con el diagnóstico de NACS y con la gravedad de la infección pero no con el tratamiento empírico o adherencia a las guías terapeúticas.

\section{NEURITIS ÓPTICA POR ANTI-TNF EN PACIENTE CON ENFERMEDAD DE BEHÇET}

Soto Peleteiro A, Gómez Sousa JM, Rodríguez Gómez A, Alonso Parada M, Lorenzo Castro R, Baroja Basanta A, Freire Dapena M, Rivera Gallego $A$.

UNIDAD DE TROMBOSIS Y VASCULITIS, SERVIIIO DE MEDICINA INTERNA. HOSPITAL XERAL-CÍES DEVIGO. COMPLEJO HOSPITALARIO UNIVERSITARIO DE VIGO (CHUVI).

INTRODUCCIÓN: Los agentes inhibidores del factor de necrosis tumoral (TNF) son cada vez más empleados. Su uso se ha relacionado recientemente con la aparición de enfermedad desmielinizante. OBJETIVOS: Describir un caso clínico de neuritis óptica (NO) por anti-TNF y revisar la literatura. MATERIAL Y MÉTODOS: Revisión retrospectiva de la historia clínica de nuestro paciente y búsqueda relacionada en MEDLINE. 
RESULTADOS: Varón de 18 años con enfermedad de Behçet definida diagnosticada en 2012 en base a aftas orales de repetición, pseudofoliculitis, paniculitis, vitritis y vasculitis retiniana. Inicialmente tratado con prednisona y azatioprina con mala respuesta. En 2013 se inició adalimumab con control completo. Consulta por pérdida de agudeza visual en ojo derecho de 48 horas de evolución, observándose en la exploración un escotoma casi total y una papila pálida. Analíticamente sin alteraciones significativas y citobioquímica de LCR normal. Los potenciales evocados visuales (PEV) muestran signos de NO leve. La RM no evidencia alteraciones de señal. Se decide suspender adalimumab por su probable implicación en base a casos descritos previos y se prescriben pulsos de metilprednisolona, recuperando el paciente la agudeza visual de forma completa con evidencia de mejoría en los PEV. Aunque la NO puede ser una manifestación de neuro-Behcet, su aparición y la de otros trastornos desmielinizantes se ha relacionado con el empleo de anti-TNF. Una revisión reciente identificó 21 casos de NO en pacientes tratados con adalimumab (4), infliximab (12) y etanercept (5). Su mecanismo no ha sido aclarado. La experiencia en el manejo de esta entidad es escasa; en general se recomienda su interrupción y bolos de corticoides.

CONCLUSIONES: En entidades como la enfermedad de Behçet en las que la NO puede ser un síntoma, es necesario tener en cuenta la enfermedad desmielinizante por anti-TNF si están siendo empleados, ya que se recomienda su suspensión.

\section{NO TODA MASA ES UNA NEOPLASIA}

Gómez Buela I, Sánchez Trigo S, Sardina Ferreiro R, Lijó Carballeda C, García Alén D, Bravo Blázquez I, Caínzos Romero T, Vilariño Maneiro L, Barbagelata López C, Fernández Bouza E, Mella Pérez $C$.

MEDICINA INTERNA. COMPLEXO HOSPITALARIO UNIVERSITARIO DE FERROL.

INTRODUCCIÓN: Ante la presencia en un estudio radiológico de una masa pulmonar con características compatibles, la sospecha predominante suele ser de neoplasia. Sin embargo existe patología principalmente vascular e infecciosa que ha de ser descartada.

CASO CLÍNICO: Presentamos el caso de una paciente de 62 años sin antecedentes de interés, que consulta por cuadro de tos con expectoración hemoptoica, síndrome general y fiebre; en la radiografía de tórax se observaron múltiples lesiones pulmonares. Se realizó TC tóracoabdominal objetivándose una masa hiliar derecha con compresión bronquial, múltiples nódulos en ambos parénquimas pulmonares y adenopatías mediastínicas. Se instauró tratamiento antibiótico y corticoideo por datos de sobreinfección respiratoria con mejoría del cuadro. Ante la sospecha de neoplasia de pulmón se realizó fibrobroncoscopia con biopsia a nivel de la estenosis bronquial que parecía infiltrada; histológicamente no presentaba datos de malignidad. Los diversos cultivos microbiológicos fueron negativos. Se decidió realizar punción de la masa guiada por TC que resultó también negativa para malignidad, con infiltrado inflamatorio constituido por linfocitos, polimorfonucleares, histiocitos y macrófagos hemosiderófagos. Analíticamente presentaba elevación de reactantes de fase aguda (RFA), leucocitosis con neutrofilia sin eosinofilia, trombocitosis y, progresivamente, anemia e insuficiencia renal, con proteinuria en rango no nefrótico y hematuria. Teniendo en cuenta estas alteraciones, la negatividad de la Anatomía Patológica y la mejoría radiológica tras corticoterapia, se decidió realizar biopsia renal que fue sugestiva de glomerulonefritis necrotizante pauciinmune; los ANCA-PR3 fueron positivos (39) y los ANCA-MP0, antinucleares y anti-membrana basal glomerular negativos. Con el diagnóstico de Granulomatosis con poliangeítis (GPA) se inició tratamiento con pulsos de Ciclofosfamida (CF) y Metilprednisolona seguida de Prednisona, con mejoría clínica, analítica y radiológica del cuadro, y descenso de los ANCA-PR3.

DISCUSIÓN: La GPA (Wegener) es una vasculitis de pequeño vaso, incluída dentro de las vasculitis asociadas a Anticuerpos Anti-Citoplasma de Neutrófilo (ANCA). Característicamente, produce afectación pulmonar en forma de infiltrados inflamatorios aunque, ocasionalmente, las características radiológicas son indistinguibles de una neoplasia. La afectación en otros órganos y sistemas, sobre todo renal y otorrinolaringológico puede ayudar a orientar el diagnóstico. La positividad de ANCAPR3 es muy específica, y aparece hasta en un 40-90\% de los casos. El tratamiento, cuando hay afectación importante de órganos diana, debe incluir un tratamiento de inducción con pulsos de Metilprednisolona (seguidos de corticoides en dosis de $1 \mathrm{mg} / \mathrm{kg} / \mathrm{día}$ ) y pulsos de CF, y con tratamiento de mantenimiento con dosis bajas de corticoides y Azatioprina.

\section{OSTEOMIELITIS CLAVICULAR POR E. COLI}

Lorenzo Castro R, Sousa Dominguez A, Soto Peleteiro A, Gomez Sousa JM, Vazquez Triñanes MC Martinez Vidal Al, Rodríguez Gomez AM, Perez Rodríguez MT, Argibay Filgueira AB, Nodar Germiñas A, Rivera Gallego A.

MEDICINA INTERNA UNIDAD DE INFECCIOSAS. HOSPITAL XERAL DE VIGO.

INTRODUCCIÓN: La osteomileitis clavicular es una entidad infrecuente que puede producirse bien por contigüidad (tras cirugía de cuello, radioterapia, cateterismo subclavia), bien por diseminación hematógena. El agente más frecuente aislado es S. aureus (80\%), también se han descrito casos por Streptococcus, Klebsiella, Bacteroides y E. coli.

OBJETIVOS: Presentación de un caso de osteomielitis clavicular por E. coli.

MÉTODO: Presentación de un caso y revisión de la literatura.

RESULTADOS: Mujer de 56 años con tumoración supraclavicular izquierda dolorosa desde hacía 2 meses. No traumatismo, cuadro constitucional o fiebre. Histerectomizada con doble anexectomía hacía 6 meses por adenocarcinoma de endometrio; despúes recibió braquiterapia sin recidiva actual. En la juventud había presentado bocio multinodular por lo que se le realizó tiroidectomía izquierda y derecha parcial. En la analítica destacaba VSG $111 \mathrm{~mm} / \mathrm{h}$ y PCR 45 mg/l. Ante sospecha de patología tumoral se realizó TC clavicular y tóraco abdominal detectándose masa lítica en esternón, clavícula y arco costal derecho con afectación del parénquima pulmonar adyacente (sin recidiva tumoral ginecológica). Se realizó PAAF, con obtención de 6 muestras que no fue diagnóstica por lo que se solicitó biopsia ósea abierta. En todas las muestras todas se aisló E. coli. Se inició trimetropimsulfametoxazol y ciprofloxacino (según antibiograma) con mejoría. Tras revisión de la historia sólo se encontró como posible fuente del E. coli la manipulación repetida de la vía urinaria (sondajes recurrentes) en los ciclos de braquiterapia. En la literatura la infección por E. coli extraurinario a nivel óseo es excepcional, los casos encontrados fueron como el expuesto y otro en una falange.
CONCLUSIÓN: La osteomielitis clavicular por E. coli es una entidad rara y que aunque a priori no exista sospecha de infección, se deben enviar muestras óseas para cultivo, ya que es la única forma de llegar al diagnóstico.

\section{PACIENTE CON FALSA HEMOPTISIS, HEMARTROS Y LESIONES CUTÁNEAS}

Suárez $R$, Aparicio $M$, Verdeal $R$, Clavero E, García J, Busto E.

NEUMOLOGIÁA-MEDICINA INTERNA. CHUAC

INTRODUCCIÓN: La hemoptisis es una causa frecuente de ingreso hospitalario. Entre la etiología más frecuente destaca la bronquitis, neoplasias, bronquiectasias, neumonía o absceso pulmonar y TB. En ocasiones es difícil localizar la causa del sangrado precisando descartar el origen del mismo a nivel digestivo y ORL.

OBJETIVOS Y MÉTODOS: Descripción de un caso clínico con falsa hemoptisis y revisión de la literatura al respecto.

RESULTADOS: Paciente de 47 años indigente, con alimentación exclusiva a base de arroz, que ingresa en Octubre del 2013 por un cuadro de tos ocasional con episodios aislados de expectoración hemoptoica de 2 meses de evolución, junto con dolor y aumento del volumen de rodilla izquierda. Presenta boca séptica con piezas dentales móviles y encías engrosadas con tendencia al sangrado. No presenta adenopatías palpables, sin alteraciones cardiopulmonares. A nivel cutáneo destaca la presencia de lesiones cutáneas simétricas en ambos miembros inferiores tipo púrpura folicular (figura 1). Los datos analíticos reflejaban anemia normocítica normocrómica, sin alteraciones a nivel de bioquímica y coagulación. En la placa de tórax no presenta alteraciones agudas y en la radiografía de rodilla izquierda se objetiva derrame a nivel articular. Como otros estudios complementarios se llevó a cabo la punción de la rodilla izquierda en la que se objetivó importante hemartros (43.000 hematíes por litro). Se descartaron otras causas de hemoptisis tales como TB, infecciones respiratorias, alteraciones de la coagulación, etc. El diagnóstico se obtuvo mediante biopsia de las lesiones cutáneas (figura2), altamente sugestivas de escorbuto; y la determinación en sangre de los niveles de ácido ascórbico, siendo estos 22 ng/ml (valores normales: 30 - 100) confirmándose el diagnóstico de escorbuto.

CONCLUSIONES: El escorbuto es un trastorno nutricional tratable que puede llevar a la muerte del paciente si no se diagnostica a tiempo.

\section{PANCREATITIS AGUDA Y SÍNDROME HEMOLÍTICO URÉMICO}

Bravo Blázquez I, Lijó Carballeda C, Sardina Ferreiro, Gómez Buela I, R García Alén D, Sánchez Trigo S, Caínzos Romero T, Vilariño Maneiro L, López Vázquez M, Arrojo Alonso F. MEDICINA INTERNA. COMPLEXO HOSPTTALARIO UNIVERSITARIO DE FERROL.

INTRODUCCIÓN: Descripción de un caso de SHU que se presentó en el contexto de pancreatitis aguda de probable etiología enólica.

CASO CLÍNICO: Varón de 38 años, fumador y bebedor activo, que consultó por cuadro clínico de horas de evolución, consistente en dolor abdominal intenso y continuo, predominante en hemiabdomen superior, asociado a náuseas, vómitos biliosos y coluria. No refería fiebre 0 alteración del hábito intestinal. En la exploración física destacaba un abdomen doloroso a la palpación de predominio en hipocondrio derecho, con ruidos hidroaéreos disminuidos. A su llegada a urgencias se realizaron hemograma, bioquímica y coagulación, donde destacaban: creatinina 2.15, amilasa 1127 y 68000 plaquetas. Se realizó también ecografía abdominal, compatible con pancreatitis aguda. Durante su estancia en Urgencias, el paciente desarrolló oligoanuria a pesar de sueroterapia intensiva, así como deterioro de la función renal y trombopenia progresivas, por lo que fue trasladado a la Unidad de Cuidados Intensivos. Alli se intensificó soporte fluidoterápico y se pautó tratamiento diurético, a pesar de lo cual persistía la anuria, por lo que se inició hemodiálisis. Simultáneamente, se objetivó en analisis de control anemización progresiva con aumento de LDH y descenso de haptoglobina, ante lo que se solicitaron: frotis de sangre periférica, en el que se evidenció la presencia de esquistocitos: test de Coombs directo, que resultó negativo; y actividad de la proteasa ADAMTS 13, que fue normal. El paciente fue diagnosticado de SHU y trasladado a hospital de referencia para la realización de aféresis terapéutica con reposición de plasma. Tras la primera sesión, sufrió insuficiencia respiratoria aguda en relación con TRALI (daño pulmonar agudo relacionado con transfusiones), por lo que posteriormente se continuó aféresis terapéutica con reposición de albúmina, recibiendo un total de ocho sesiones, tras las cuales se normalizaron los valores de LDH y plaquetas y desaparecieron los esquistocitos. La diuresis y la función renal también se recuperaron tras haber recibido un total de 15 sesiones de hemodiálisis. En controles posteriores se solicitó estudio genético de SHU, que aún se encuentra pendiente.

DISCUSIÓN: El SHU es un trastorno de la microvasculatura definido por anemia microangiopática, trombopenia y fracaso renal. Su forma más frecuente (90\%) se denomina SHU clásico y se asocia con diarrea causada por E. Coli. El 10\% restante de los casos, SHU atípico, no se relaciona con mutaciones de genes que codifican elementos de la vía alternativa del complemento. La pancreatitis aguda como posible desencadenante de SHU atípico ha sido descrita previamente en la literatura y aunque la patogenia del mismo está aún sin esclarecer, parece establecido el beneficio de iniciar tratamiento precoz con aféresis terapéuticas o bien con pauta de eculizumab, un anticuerpo monoclonal humanizado de reciente aparición que actúa bloqueando la vía alternativa del complemento.

\section{PATOLOGÍA DE AORTA TORÁCICA (PAT). ANÁLISIS DE 89 PACIENTES}

Brea Aparício R, Diéguez Paz J, Fernández González A, Velo García A, Rios Prego M, Alves Pereira DE, García García JC, Anibarro García I, Núñez Fernández MJ SERVICIO DE MEDICINA INTERNA. COMPLEJO HOSPITALARIO DE PONTEVEDRA. OBJETIVO: Conocer las características de los pacientes diagnosticados de patología que afecta a la aorta torácica en nuestro centro. 
MATERIAL Y MÉTODOS: Se analizan retrospectivamente los pacientes diagnosticados de aneurisma, disección de aorta, úlcera penetrante y dilataciones saculares, localizados en la aorta torácica, en un período de 9 años (2005-2013).

RESULTADOS: Son incluidos un total de 89 pacientes (62 varones), la edad media es de 71 años (3593 años). Se estudian 73 aneurismas, 13 disecciones (6 con aneurisma), 2 dilataciones saculares, 1 ulcera penetrante. Se estableció el diagnóstico de sospecha clínica o por radiografía simple de tórax, en 18 (6 con disección), en el resto fue un hallazgo incidental en una prueba de imagen (75\% después de una TAC, 22\% tras una ecocardiografía). Entre los factores vasculares no clásicos había: arteritis de células gigantes (3), artritis reumatoide (2), accidente de tráfico (2), śfilis (1), enf Takayasu (1), enf relacionada con lgG4 (1). Entre los factores vasculares clásicos (FVC) destacaba: HTA (74\%), tabaquismo (56\%), dislipemia (55\%); se detectaron 2 o más FVC en el $72 \%$ de la serie. Un 38\% de pacientes tenían asociado aneurisma aorta abdominal, seguido de enfermedad vascular periférica (32\%), cardiopatía isquémica (31\%), e insuficiencia renal crónica (24\%); tres cuartas partes de los pacientes evidenciaban enfermedad cardiovascular establecida. Los aneurismas se localizaban en aorta ascendente (42) con un tamaño medio de 5'5 cm (4'2-9 cm); aorta torácica descendente (19) con tamaño medio de $4{ }^{\prime} 7 \mathrm{~cm}\left(3^{\prime} 1-11^{\prime} 5 \mathrm{~cm}\right)$; todo el arco (13). Fueron intervenidos quirúrgicamente 35 (51\% con cirugía abierta; $49 \%$ con cirugía cerrada). En el momento del diagnóstico, el 30\% de los aneurismas sin disección cumplían criterios de tratamiento quirúrgico. Fallecen el $48 \%$ del global. En el grupo de aneurismas sin disección: la mortalidad afecta al 50\% de los no intervenidos, $33 \%$ en el grupo de cirugía abierta, y $33 \%$ en el grupo de cirugía cerrada. En el grupo de disección: fallecen el $88 \%$ de los no intervenidos, $75 \%$ en el grupo de cirugía abierta, y $33 \%$ en el grupo de cirugía cerrada. Los no intervenidos presentan mayor mortalidad global (54\%) respecto los intervenidos quirúrgicamente $(40 \%)$

CONCLUSIONES: En la patología de la aorta torácica predominan los aneurismas, que afectan preferentemente a varones, siendo su diagnóstico mayoritariamente incidental, tras la realización de una prueba de imagen. Hemos detectado en nuestro centro de forma minoritaria procesos que pueden producir PAT. En la mayoría de la serie se evidencia FVC, destacando la HTA. Como consecuencia existe enfermedad cardiovascular establecida siendo la más frecuente el aneurisma de aorta abdominal (en más de un tercio de la serie). La patología que afecta a la aorta torácica necesita una valoración multidisciplinar por parte de cirujanos cardiovasculares, cardiólogos, radiólogos e internistas.

\section{PATOLOGÍA INFECCIOSA IMPORTADA: HISTOPLASMOSIS AGUDA DISEMINADA DE PRESENTACIÓN ATÍPICA}

Gónzalez Fernández C*, López Mato P, Gónzalez Noya A, Fernández Regal I, Bustillo Casado M, Naval Calviño G, Fernández Rodríguez $R$.

SERVICIO DE NEUMOLOGÍA *, MEDICINA INTERNA -UNIDAD DE ENFERMEDADES INFECCIOSAS. COMPLEXO HOSPITALARIO UNIVERSITARIO DE OURENSE.

La histoplasmosis es una infección fúngica que con frecuencia es definitoria de SIDA en zonas endémicas. La var. capsulatum es endémica en zonas de América, Africa y Asia. La var. duboisil sólo existe en Africa. En Europa es inexistente: casi todos los casos son importados. La infección aguda puede dar una afectación respiratoria de intensidad variable, a menudo benigna en inmunocompetentes. En inmunodeprimidos cursa con frecuencia de forma diseminada, a veces letal. Mujer de 48 años, panameña, que emigró a Galicia hace dos meses. Acude por astenia y rectorragias en las ultimas tres semanas. Exploración: caquexia, palidez cutánea y sangre roja con las heces en el tacto rectal. Analítica : Hb 11, $1 \mathrm{~g} / \mathrm{dL}$. La rx tórax era normal. Colonoscopia : úlcera rectal de $3 \times 4 \mathrm{cms}$ de diámetro, con hemorragias puntiformes en su base (fig 1). Una semana después de la colonoscopia aqueja fiebre, tos y disnea por lo que vuelve a Urgencias. La rx : infiltrado reticulonodulillar difuso bilateral (fig 2). Ingresó en la U. Infecciosas y se diagnosticó infección VHH con una carga viral : 448.000 copias/ml (5, 65 log) y CD4 : 6 /ml. Analítica: Hb 7, 2 g/dl, LDH: 1890 U/L En este momento se informa la biopsia de la úlcera rectal (fig 3): macrófagos cargados de estructuras levuriformes intra y extracitoplásmicas características de Histoplasma capsulatum (Gomori- Grocott, hematoxilina-eosina). Se inicio tratamiento con Amfotericina liposomal y Atripla@ (efavirenz $600 \mathrm{mg}$ -tenofovir 300 mg -emtricitabina 200 mg /d)j. La PCR confirma en el LBA, BAS y MO : Histoplasma capsulatum var. capsulatum. En el cultivo se aisla a las $4 \mathrm{~S}$ Histoplasma capsulatum en la biopsia transbronquial, LBA y MO. A las 6 S : CD $4: 28 / \mathrm{ml}$, carga viral VIH indetectable, radiografía de tórax normal. En un mundo global podemos atender patologías exóticas cuya evolución puede ser fatal en caso de retraso diagnóstico. Ante una enfermedad respiratoria hay que pensar en histoplasmosis si el paciente viene de área endémica, aunque sea viajero ocasional, aunque sea inmunocompetente. En inmunodeprimidos hay formas atípicas y diseminadas más dificiles de reconocer como síndrome febril, lesiones cutáneas, óseas, o del aparato digestivo. En el caso que presentamos la manifestación inicial fue una hemorragia digestiva por úlcera rectal.

\section{PATRON TEMPORAL DE LA ENFERMEDAD TROMBOEMBÓLICA VENOSA}

Puerta Louro RB, Lamas Ferreiro JL, Fernández Fernández FJ, González Vázquez L, Valle Feijoo ML, Álvarez Otero J, Rodríguez Arias M, De La Fuente Aguado J.

MEDICINA INTERNA. POVISA. VIGO.

INTRODUCCIÓN: La enfermedad tromboembólica (ETV), incluyendo trombosis venosa profunda (TVP) y tromboembolismo pulmonar (TEP), es un diagnóstico común en los pacientes ingresados en nuestros hospitales. La incidencia a lo largo del año parece ser diferente según el mes en el que nos encontremos.

OBJETIVO: El objetivo de este estudio fue analizar la incidencia de la ETV en los diferentes meses de año, mostrando cual es su patrón de distribución temporal.

DISEÑO Y MÉTODOS: Realizamos un análisis retrospectivo de todos los ingresos hospitalarios entre cuyos diagnósticos se incluya TVP y TEP desde el 1 de Enero de 2007 al 31 de Diciembre de 2009. Recogimos sexo, edad, y mes en el que se produjo el ingreso del paciente.

RESULTADOS: Identificamos 528 casos, edad media 69 años, 54\% mujeres, media de 14 casos a mes (rango 7-26). El mes con menor número de casos de los años 2007, 2008 y 2009 es el mes de abril con 7, 8 y 11 casos respectivamente, siendo el mes de enero el de mayor número de casos con 14, 16, y 26. La estación con mayor número de casos es el invierno, mientras la de menor número la primavera.

CONCLUSIONES: Hay una mayor incidencia de ETV en los meses de invierno, siendo menor en primavera. Identificar los posibles factores que puedan condicionar esta variación estacional y tratar de corregirlos, si es posible, podría ayudar a disminuir la incidencia de ETV.

\section{PERFIL ACTUAL DE PACIENTES COINFECTADOS VIH VHC EN EL AREA SANITARIA DE A CORUÑA. IMPACTO ESPERADO DEL TRATAMIENTO CON NUEVOS ANTIVIRALES}

Rodriguez-Osorio I, Meijide H, Mena A, Castro-Iglesias A, López S, Vázquez P, Pernas B, Pedreira JD y Poveda E.

GRUPO DE VIROLOGÍA CLÍNICA, INIBIC-COMPLEJO HOSPITALARIO UNIVERSTTARIO DEA CORUÑA. CHUAC.

INTRODUCCIÓN: La hepatopatía crónica progresa más rápidamente en los pacientes coinfectados VIH-VHC que en los monoinfectados. Los nuevos antivirales han demostrado significativa mejora en las tasas de respuesta virológica sostenida en esta población. Sin embargo, su actividad antiviral se ve influenciada por las características del virus y del huésped. Se evaluó el perfil clínico de los pacientes coinfectados VIH-VHC atendidos en una clínica de referencia para predecir el impacto de las nuevas terapias.

MÉTODOS: Se identificaron todos los pacientes coinfectados VIH-VHC con RNA_VHC detectable seguidos en nuestra institución en el último trimestre del año 2013. Se registraron los siguientes parámetros: RNA_HCV, genotipo VHC, experiencia previa con interferón, fibrosis hepática (por elastometría) y alelos IL28B. Del mismo modo, los datos demográficos y los datos sobre el estado de la infección VIH (RNA VIH, recuento CD4 y terapia antiretroviral) también fueron recogidos. RESULTADOS: Se identificaron un total de 455 pacientes coinfectados (74 \% varones, edad media 43 años). La mayoría (80, 8\%) habían sido consumidores de drogas intravenosas en el pasado. El 70, $2 \%$ estaban en terapia antirretroviral. La media del recuento de células CD4-T fue de 500 células / ul y $58,4 \%$ de los sujetos tenía RNA_VIH indetectable. En general, la mayoría de los pacientes ( 80 , 4\%) fueron naïve a la terapia anti-VHC. La media RNA VHC fue de 6,1 \pm 0, $9 \mathrm{log} \mathrm{UI} / \mathrm{ml}$. Respecto a la distribución de genotipos del VHC: $56,6 \%$ G1; 25, 1\% G3; $16,7 \%$ G4 y 1, 6\% G2. El 33, 1\% de los pacientes tenía fibrosis avanzada (F3-F4). Por último, el $57,7 \%$ de los pacientes presentaba alelos IL28B CT / T.

CONCLUSIONES: El perfil actual de los pacientes coinfectados VIH_VHC en nuestra Unidad está dominado por grupos difíciles de tratar, como G1/G4 (73,3\%), fibrosis hepática avanzada (33, 1\%) y alelos IL28B desfavorables (57,7\%). Por lo tanto, las terapias basadas en antivirales de acción directa podrían ser especialmente recomendadas en esta población.

\section{PERFIL LIPÍDICO EN PACIENTES CON ICTUS ISQUÉMICO}

\section{Álvarez Otero J, Puerta Louro R, Rodríguez Arias M, Lamas Ferreiro JL, Gondar Barcala T, De la} Fuente Aguado J.

MEDICINA INTERNA. POVISA. VIGO.

INTRODUCCIÓN: El control de los factores de riesgo cardiovascular es importante en los pacientes con evidencia de enfermedad cardiovascular. La hiperlipidemia siendo un factor de riesgo importante para la enfermedad coronaria, parece ser un factor de riesgo más débil para el ictus isquémico. OBJETIVOS: Determinar el perfil lipídico en pacientes ingresados en nuestro centro hospitalario con el diagnóstico de ictus isquémico.

MATERIAL Y MÉTODOS: Estudio descriptivo y retrospectivo en el que se incluyeron pacientes ingresados con diagnóstico de ictus isquémico entre los meses de enero y diciembre de 2011. Se analizaron las características epidemiológicas y clínicas de los pacientes así como el colesterol total, C-LDL, C-HDL, triglicéridos, además del índice de masa corporal y el hábito tabáquico.

RESULTADOS: Se incluyeron 198 pacientes con edad media de 76 años, 56\% mujeres. Las comorbilidades más comunes asociadas fueron hipertensión arterial $70 \%$, diabetes mellitus $26 \%$, fibrilación auricular $25,8 \%$, insuficiencia renal crónica 17, 2\%, arteriopatía periférica $13,6 \%$, cardiopatía isquémica $8,6 \%$ e insuficiencia cardíaca $8 \%$. La mortalidad fue del $12,6 \%$. El valores medios del perfil lípídico fue colesterol total 174 (87-341) mg/dl, C-LDL 104 (38-251), C-HDL 45 (19156) y triglicéridos 126 (32-907). El índice de masa corporal medio fue de 26, 89 (18-39) Respecto al hábito tabáquico de los pacientes eran 20\% fumadores y 17\% ex-fumadores, mientras un $63 \%$ no fumadores.

CONCLUSIONES: Las diferentes causas de isquemia cerebral en las que la aterosclerosis tiene un papel diferente (importante en la trombosis, mientras no lo es en la embolización y infarto lacunar), puede explicar que un $49 \%$ de los nuestros pacientes con ictus isquémico presenten valores de C-LDL menores de $100 \mathrm{mg} / \mathrm{dL}$.

\section{PORFIRIA CUTANEA TARDA E INFECCIÓN POR EL VIH}

González Noya A, González Fernández C*, Lopez Mato A, Pérez Carral V, Díaz López MD, Fernández Rodriguez $R$.

UNIDAD DE INFECCIOSAS - MEDICINA INTERNA Y NEUMOLOGÍA* COMPIEXO HOSPITALARIO UNIVERSITARIO DE OURENSE

Porfiria cutánea tarda (PCT) es la forma más común de las porfirias. A diferencia de otras porfirias que se deben a errores congénitos del metabolismo, PCT es con frecuencia adquirida (75-80\% de los casos). La clínica se manifiesta cuando el descenso de la actividad de la enzima uroporfirinógenodecarboxilasa es $>75 \%$. La etiología de la PCT se relaciona con enfermedades hepáticas causadas por factores exógenos con una etiopatogenia común: depósito de Fe y stress oxidativo en los hepatocitos. Varón de 79 años diagnosticado de infección VIH hace 25 años, en tto con lopinavir-r, tenofovir y emtricitabina desde hace 15 años. No tiene coinfección por VHC ni VHB. Tiene lipodistrofia. No consume alcohol. Gota tofácea desde los 40 años. Desde hace años mantiene CV negativa y 
CD4> 750/ml. Hace un año se diagnóstica anemia e IRC ; recibió tratamiento con fe y EPO y fueron retirados tenofovir y emtricitabina. Consulta por ampollas cutáneas que evolucionan a costras en manos y cuero cabelludo desde hace 2 meses (Fig 1-3). Copro+uroporfirinas fraccionadas en orina: coproporfirinas $122 \mu \mathrm{g} / 24 \mathrm{~h}$, uroporfirinas $6039 \mu \mathrm{g} / 24 \mathrm{~h}$, pentacarboxil $525 \mu \mathrm{g} / 24 \mathrm{~h}$, hexacarboxil $2132 \mu \mathrm{g} / 24 \mathrm{~h}$, heptacarboxil $9225 \mu \mathrm{g} / 24 \mathrm{~h}$. Ya había sido retirado el Fe hacía 6 meses. Se indicó fotoprotección y tratamiento con hidroxicloroquina $125 \mathrm{mg} / \mathrm{semana}$; hay una respuesta favorable a los dos meses del tratamiento. La relación entre la infección VIH y la PCT es infrecuente y poco conocida. En los pacientes VIH se encuentra en discusión si el HIV está directamente relacionado con la aparición de PCT o si la concomitancia de otros factores como el VHC, VHB, las drogas hepatotóxicas y el alcoholismo, son las causas desencadenantes. EI TARV estaría implicado alterando el metabolismo del Hem al actuar sobre el CYAP450. Nuestro enfermo tenía TARV desde larga data y recibió aporte de hierro ; no existían otros factores predisponentes. La PCT mejora con la redución de los depósitos de Fe a través de sangrías periódicas que reducen también la progresión de la hepatitis crónica por VHC y el riesgo de desarrolar hepatoCa. Bajas dosis de antipalúdicos puede ser un tratamiento alternativo eficaz en la PCT. Debemos pensar en factores de riesgo para la infección VIH en los pacientes con PCT. Asimismo puede ser necesario realizar un estudio de porfirinas en algunos pacientes $\mathrm{VIH}$ positivos.

\section{PSEUDOANEURISMA DE ARTERIA PANCREÁTICO- DUODENAL SECUNDARIO A PANCREATITIS CRÓNICA}

Romay E*, Ventura P, Piñeiro J, López-Reboiro M, Iñiguez I, Rubal D, Matesanz M, Pombo B. MEDICINA INTERNA. HOSPITAL UNIVERSITARIO LUCUS AUGUSTI.

INTRODUCCIÓN: El pseudoaneurisma de arteria pancreático-duodenal es una complicación rara de la pancreatitis crónica que se produce por agresión enzimática de la pared vascular. La forma de presentación más frecuente tras el dolor abdominal es el sangrado secundario a ruptura del mismo. MATERIAL Y MÉTODOS: Descripción de un caso y revisión de la literatura a través de la base de datos de Pubmed usando como palabras clave "pseudoaneurysms" y "chronic pancreatitis".

CASO CLínICO: Presentamos el caso de un varón de 50 años, exbebedor y diabético, con dolor epigástrico continuo de dos años de evolución, síndrome general y deposiciones melénicas en los últimos 15 días. En las pruebas de laboratorio presenta anemia normocítica normocrómica, ferropenia y colestasis disociada con resto de parámetros normales. Los estudios endoscópicos no demostraron lesiones sangrantes a nivel del tubo digestivo. En el TAC abdominal y la colangiorresonacia se describieron datos de pancreatitis crónica con pseudoaneurisma de arteria pancreático-duodenal de $4 \mathrm{~cm}$. Se realizó arteriografía que confirmó el hallazgo y permitió la obliteración parcial de mismo mediante embolización. Dos semanas más tarde precisó nueva arteriografía por episodio de rectorragia consiguiendo en esta ocasión embolización completa.

CONCLUSIÓN: Ante una hemorragia digestiva inexplicada en pacientes con pancreatitis crónica hay que tener en cuenta la posibilidad de complicación por sangrado de pesudoaneurismas. El diagnóstico de confirmación se obtiene mediante arteriografía, que permite la embolización arterial en el mismo acto con una tasa de éxito del 80\%, siendo este el tratamiento de elección. A pesar de esto, se han descrito resangrados tras dicha técnica, siendo más frecuente en los primeros 30 días. La tendencia actual ante un nuevo evento hemorrágico es repetir la embolización, reservando la cirugía para situaciones de inestabilidad hemodinámica con una tasa de mortalidad que oscila entre el 12 y el $50 \%$.

\section{QUISTE MESENTÉRICO: UN DIAGNÓSTICO POCO FRECUENTE DE MASA ABDOMINAL}

Sardina Ferreiro R, Trigas Ferrín M, Gómez Buela I, Lijó Carballeda C, Garcia Alén D, Bravo Blázquez I, Ferreira González L, Sánchez Trigo S, Cainzos Romero T, Pastor Rubín E.

MEDICINA INTERNA. COMPLEJO HOSPITALARIO UNIVERSTTARIO DE FERROL (CHUF).

INTRODUCCIÓN: El mesenterio esta formado por dos hojas peritoneales que fijan las asas del intestino a la pared posterior del abdomen. Se denomina quiste mesentérico a toda tumoración de contenido líquido que se situa entre las dos hojas del mesenterio.

CASO CLíNICO: Se trata de un paciente de 74 años con múltiples factores de riesgo cardiovascular y portador de una prótesis aórtica normofuncionante, que ingresó en nuestro servicio para estudio de cuadro presincopal en relación con una fibrilación auricular lenta. Incidentalmente en la exploración física se objetivaba un efecto masa a nivel de fosa ilíaca derecha, móvil, no pulsátil ni dolorosa. E paciente no refería clínica digestiva ni síndrome general. Los estudios de laboratorio con hemograma, bioquímica y hormonas tiroideas se encontraban dentro de los valores de referencia. Se realizó una TAC abdominal que objetivó una masa retroperitoneal derecha, bien delimitada, de gran tamaño $(14 \times 13,6 \times 8,1 \mathrm{~cm})$ de naturaleza quística, sin nódulos, septos ni calcificaciones en su interior, sugestiva de quiste mesentérico. Al alta se remitió el paciente al servicio de cirugía general para extirpación quirúrgica de la misma; encontrándose en la actualidad pendiente de la intervención. DISCUSIÓN: Los quistes mesentéricos son tumoraciones benignas poco frecuentes, con mayor incidencia en la edad pediátrica. En adultos representa tan sólo el 1/100000 ingresos hospitalarios. Su etiopatogenia es desconocida. La teoría más aceptada señala que son proliferaciones benignas de tejido linfático ectópico. Lo más frecuente es su aparición en el mesenterio del intestino delgado. De todas las lesiones, las más frecuentes son las de origen linfático y mesotelial. La mayoría presenta un comportamiento benigno aunque algunos de ellos, como el linfangioma quístico y el mesotelioma quístico pueden mostrar un comportamiento agresivo e invasivo. El riesgo de malignización en las series publicadas está en torno al 3\%, y se ha puesto en relación con la edad avanzada. Hasta en un $50 \%$ de los casos son un hallazgo casual, siendo la exploración física clave para el diagnóstico. La ecografía abdominal y la TAC son las técnicas de imagen para su caracterización. El tratamiento de elección es la exéresis quirúrgica incluso en los casos asintomáticos, por el riesgo de complicaciones (clínica compresiva, hemorragia o infección) y la necesidad de establecer el diagnóstico definitivo. CONCLUSIONES: El quiste mesentérico es una entidad poco frecuente que debe tenerse en cuenta en el diagnóstico diferencial al detectarse una masa abdominal, y que obliga a realizar más estudios complementarios para su caracterización.

\section{RADIOLÓGÍA Y MORTALIDAD EN PACIENTES CON ASPERGILOSIS PULMONAR INVASIVA}

Molinos-Castro $S^{1}$, Rodríguez-Fernández $S^{\prime}$, Pesqueira-Fontán PM', Gayol-Fernández MC', BaloAraujo $S^{\prime}$, Rial-Rama MP, García-Suárez $F^{3}$, Varela-García PM', Naveiro-Soneira J', RodríguezFramil M', Padín Paz EM', Díaz-Peromingo JA33, Pérez del Molino ML', Iglesias Gallego M',

${ }^{1}$ SERVICIO DE MEDICINA INTERNA, HOSPITAL BARBANZA (A CORUÑA). ${ }^{2}$ SERVIICIO DE RADIOLOGÍA, HOSPITAL BARBANZA (A CORUÑA). ${ }^{3}$ SERVICIO DE MEDICINA INTERNA, C. H. U. DE SANTIAGO DE COMPOSTELA (A CORUÑA). ${ }^{4}$ SERVICIO DE MICROBIOLOGÍA, C. H. U. DE SANTIAGO DE COMPOSTELA (A CORUÑA). ${ }^{4 H O S P I T A L}$ BARBANZA, CHUS

INTRODUCCIÓN: El conocimiento de las manifestaciones radiológicas en la Aspergilosis pulmonar invasiva (API) es necesario para realizar un diagnóstico precoz e iniciar un tratamiento antifúngico adecuado con el objeto de mejorar la supervivencia.

OBJETIVOS: Ver las alteraciones radiológicas presentes en pacientes con aspergilosis pulmonar invasiva (API) y determinar cuáles se asocian a mayor mortalidad .

MATERIAL Y MÉTODOS: Estudio retrospectivo de pacientes con API en nuestro centro, durante un periodo de 7 años (entre el 1 de Enero de 2007 y el 31 de Diciembre de 2012). Se recogieron variables relacionadas con las alteraciones radiológicas observadas y evaluó la mortalidad relacionada con el Aspergillus al final del episodio. Para la comparación entre grupos se realizó un análisis univariante utilizando test estadísticos paramétricos y no paramétricos según correspondiera, mediante el programa estadístico SPSS v.18.

RESULTADOS: Un total de 66 pacientes fueron incluídos en el estudio (cumplían criterios de API probable según Bulpa y col. ). Se realizó TC en 36 pacientes (70.6\%) y Rx tórax en 15 (29.4\%\%). Los hallazgos radiológicos observados fueron: consolidaciones ó infiltrados de nueva aparición ( $n=45$, 88.2\%), nódulos u opacidades pseudonodulares ( $n=14,27.5 \%)$, cavitaciones $(n=2,3.9 \%)$, signo de árbol en brote $(n=20,55.6 \%)$, ground-glass $(n=19,52.8 \%)$, nódulos centrolobulillares $(n=4,11.1 \%)$, engrosamientos pleurales ( $n=16,31.4 \%$ ) y signo del halo (sólo en 3 pacientes, $8.3 \%$ ). № hemos encontrado asociación entre alteración radiológica y mortalidad.

CONCLUSIONES: Las alteraciones radiológicas observadas en pacientes con API son variadas y poco específicas, siendo las más frecuentes las consolidaciones ó infiltrados de nueva aparición, imagen de árbol en brote, engrosamientos pleurales y nódulos. No hemos encontrado asociación entre alteración radiológica y mortalidad.

\section{REINGRESO ANTES DE 30 DÍAS. ESTUDIO DESCRIPTIV0 DE LOS PACIENTES EN EL ÁREA MÉDICA DE LUGO ENTRE} EL 2000 Y EL 2012

Rubal D, Matesanz M, Iñiguez I, Fernández JC, López M, Casariego E.

MEDICINA INTERNA. LUCUS AUGUSTI.

INTRODUCCIÓN: Con el paso de los años asistimos al paulatino incremento de los reingresos en los distintos Servicios del Área Médica de adultos de nuestros hospitales. De ellos, los que suceden menos 30 días después del alta previa se producen por un elevado número de razones, entre las que se incluyen las deficiencias de la atención que reducen la calidad de vida del paciente y generan ingresos potencialmente evitables. OBJETIVO: Determinar la magnitud de este problema y describir relevancia en el manejo clínico de estos pacientes.

PACIENTES Y MÉTODOS: Estudio descriptivo sobre totalidad de ingresos registrados en todos los Servicios del área Médica del Hospital Universitario Lucus Augusti de Lugo entre 2000 y 2012. Para ello, el registro CMBD del Centro, de base episodio de ingreso, se trasformó a una base matricial, donde "cada línea" incluía a un único paciente con la totalidad de sus reingresos. Sobre las misma se realizaron cálculos secundarios (como por ejemplo el tiempo entre ingresos), identificaciones (como el día de la semana) y nuevas clasificaciones (como los motivos del ingreso, estratificando los rutinarios, como tratamientos programados). En el análisis se utilizaron técnicas habituales de estadística descriptiva. En las comparaciones entre estratos sucesivos de variables categóricas se utilizó el test ji al cuadrado de tendencia. La distribución de tiempos se evaluó con gráficos Q-Q. El nivel de significación estadístico fue $p<0.05$.

RESULTADOS: En el periodo señalado se registraron 139249 ingresos en 62515 pacientes. Tras su primer ingreso, reingresaron dentro de los primeros 30 días tras el alta, el $18,2 \%$ del total de pacientes que reingresaron por segunda vez. Esta cifra se elevó al 24\% en el tercer ingreso, al 27, $9 \%$ en el cuarto, $31,4 \%$ en el quinto y $36,2 \%$ en el sexto $(p<0.001)$. Tras retirar a los pacientes ingresados para tratamientos, procedimientos diagnósticos 0 considerados de fin de semana, los resultados fueros totalmente superponibles $(18,1 \%, 23,8 \%, 28,3 \%, 30,9 \%$ y $36,8 \%$, respectivamente). De hecho los reingresos en menos de 7 días oscilaron entre los ingresos $18 \%$ entre el $1^{\circ}$ y $2^{\circ}, 16$, $8 \%$ entre $2^{\circ}$ y $3^{\circ}, 12,8 \%$ entre $3^{\circ}$ y $4^{\circ}, 14,3 \%$ entre $4^{\circ}$ y $5^{\circ}$ y $16,3 \%$ entre $5^{\circ}$ y $6^{\circ}(p=N S)$. Por el contrario, el porcentaje de reingresos entre 7 y 30 días se incremento de manera paulatina entre Ios sucesivos reingresos: $33,5 \%, 41,5 \%, 53,4 \%, 60,3 \%$ y $65,5 \%$, respectivamente $(p<0.001)$. Las infecciones respiratorias, insuficiencia cardiaca, descompensación de pacientes con EPOC y la cirrosis hepática son los procesos predominantes en todos los sucesivos reingresos estudiados. CONCLUSIONES: El porcentaje de pacientes que reingresa antes de 30 días es muy elevado y se incrementa con los sucesivos reingresos. Puesto que el reingreso a tan corto plazo tiene un impacto muy negativo sobre la calidad de vida de los pacientes, es preciso usar alternativas a la hospitalización convencional, sobre todo en aquellos con reingresos múltiples.

\section{SEPSIS POSTESPLENECTOMÍA: NO TODOS SON GÉRMENES CAPSULADOS}

Vilariño Maneiro L, Lijó Carballeda C, Orona Naya M, Sánchez Trigo S, Caínzos Romero T, Sardina Ferreiro R, Gómez Buela I, García Alén D, Mariño Callejo Al, García Jiménez A. MEDICINA INTERNA. XERENCIA DE XESTIÓN INTEGRADA DE FERROL.

OBJETIVO: Describir un caso atípico de sepsis postesplenectomía (SP) en una paciente vacunada contra gérmenes capsulados. Caso clínico Se trata de una mujer de 51 años que consulta por fiebre 
elevada, tiritona y mialgias. Entre sus antecedentes personales destacan una reacción adversa a penicilina en la infancia, LES de 30 años de evolución (tratado con $2.5 \mathrm{mg}$ de prednisona al día), sin actividad, y asma bronquial. Se le practicó una esplenectomía 18 meses antes, con diagnóstico anatomopatológico de LNH-B linfocítico de célula pequeña, en remisión. En los dos meses siguientes a la cirugía es vacunada contra patógenos capsulados y meningococo. Dos días antes de acudir al hospital, sufre una mordedura de su perro en la mano izquierda, constatando, a la exploración física, escara necrótica de $2.5 \mathrm{~cm}$. Presenta afectación intensa del estado general, vómitos y desarrolla progresivamente hipotensión y oligoanuria. Ante la sospecha de sepsis de origen cutáneo, se extraen hemocultivos y se inicia soporte inotrópico, así como antibioterapia empírica (levofloxacino y clindamicina). Se decide modificar tratamiento, iniciando posteriormente meropenem en pauta de desensibilización, que tolera adecuadamente. Ocho días después, se recibe resultado de hemocultivos (positivos para Capnocytophaga canimorsus, sensible a amoxicilina-clavulánico, ampicilina y cefotaxima). La paciente evoluciona favorablemente con meropenem (que se secuencia a ertapenem por comodidad de administración), siendo posible el alta tras 14 días de tratamiento antibiótico, sin complicaciones. Discusión La SP es una patología letal en el 50-70\% de los casos. Debe sospecharse en todo paciente con asplenia o hiposplenia, síndrome febril y síntomas digestivos o de otra focalidad. Los microorganismos más frecuentemente implicados en su etiología son los gérmenes capsulados (S. pneumoniae y H. influenzae tipo B) y N. meningitidis. Capnocytophaga canimorsus ha sido descrito en la literatura como uno de los patógenos responsables de SP en pacientes con antecedente de mordedura de perro o inoculación inadvertida en tejidos excoriados por íntimo contacto con mascotas. En el $80 \%$ de los casos, aparece en un paciente con inmunodepresión (alcoholismo, tratamiento esteroideo. ). Se trata de un bacilo gramnegativo de crecimiento lento que da lugar a un amplio espectro clínico: meningitis, bacteriemia, endocarditis, artritis, celulitis, etc. Una correcta vacunación contra gérmenes capsulados y la existencia de un factor predisponente (mordedura de perro) hicieron sospechar de inicio una etiología atípica de SP en nuestra paciente, que los estudios microbiológicos confirmaron posteriormente. La amoxicilina-clavulánico constituye el tratamiento de primera línea, aunque se ha encontrado en algunas series que hasta un $30 \%$ de las cepas son productoras de BLEE.

\section{SESIONES "CHOOSING WISELY": ESTIMULANTEY EFECTIVO INSTRUMENTO PARA MEJORAR LA PRÁCTICA CLÍNICA}

Gómez-Tato C, Pérez A, Rodil V, Estévez M, Pérez R, Montes J. MEDICINA INTERNA. COMPLEJO HOSPITALARIO UNIVERSITARIO. VIGO.

INTRODUCCIÓN: La National Physicians Alliance (EEUU) promovió el proyecto "Choosing Wisely": Sociedades científicas desarrollarían 5 recomendaciones para uso eficaz de recursos, en relación con pruebas diagnóstico-terapéuticas. Desde 2011, 50 Sociedades publicaron las suyas. El NICE (RU) incluye en sus Guías recomendaciones "Do not do" sobre intervenciones de dudoso beneficio/riesgo o evidencia pobre. El Ministerio de Sanidad español publicó -12/2013- 50 recomendaciones (de 12 Sociedades, con 39 ya adheridas) del "Compromiso por la Calidad de las Sociedades Científicas". Desde el inicio SEMFyC y SEMI participaron y el Dr. Garcia-Alegría (SEMI) fue nombrado Presidente de la Comisión de desarrollo.

OBJETIVOS: En nuestro Centro a partir de 04/2014 se programaron Sesiones dedicadas a difundir dichas recomendaciones. Esta comunicación muestra sus experiencias preliminares. Métodos. Sobre recomendaciones españolas, un MIR -con tutoría de un staff- eligió 3, evaluó y realizó búsquedas bibliográficas y presentó conclusiones. Se institucionalizaron cada 15 días "Sesiones Choosing", alternando con tradicionales. Se animó a que MIR rotantes las extendieran por sus Servicios. Se estudia con Docencia su extensión a todo el Centro. Resultados. Se han desarrollado 3 sesiones (MIR Familia: 1; MIR M. interna: 2). Se sugirió para la elección aprovechar experiencia en rotaciones recientes. Se abordó desde imagen en lumbalgia, antibióticos en otitis media o bacteriuria asintomática, uso de omeprazol/AINES o antiagregación en cardiopatía isquémica. El debate suscitó cuestiones trasladables a la práctica habitual (p. ej. : alternativas a AINES y reducción de dosis habituales de paracetamol para prevenir toxicidad). Los participantes expresaron satisfacción por el formato.

CONCLUSIONES: Las sesiones "Choosing wisely" son un instrumento de docencia de MIR/staff altamente estimulante. Sus conclusiones son inmediatamente aplicables y a menudo modifican la práctica clínica rutinaria.

\section{SÍNDROME ANTIFOSFOLÍPIDO Y AFECTACIÓN CARDIACA}

Martínez-Vidal A, Vázquez-Triñanes C, Villaverde-Álvarez I, Rodriquez Gómez A, Lorenzo-Castro $R$, Soto Peleteiro A, Sousa Dominguez A, Gómez Sousa J, Baroja-Basanta A, Val Dominguez N, Pérez-Rodriguez MT, Argibay Filgueira A, Freire-Dapena M, Rivera Gallego A.

UNIDAD DE TROMBOSIS Y VASCULITIS (TYY). SERVICIO DE MEDICINA INTERNA HOSPITAL XERAL DE VIGO. VIGO (PONTEVEDRA). HOSPITAL XERAL-CIES. COMPLEJO HOSPITALARIO UNIVERSITARIO DEVIGO.

INTRODUCCIÓN: El síndrome antifosfolípido (SAF) es una entidad en la que se producen tanto complicaciones obstétricas como trombosis en cualquier territorio vascular, afectando a todos los órganos y sistemas del organismo. En torno al 10-20\% de los pacientes con SAF pueden presentar afectación cardiaca, alcanzando hasta el 50\% en algunas series. Sin embargo, son pocas las series publicadas y la mayoría tienen un corto tiempo de seguimiento.

OBJETIVOS: El objetivo de nuestro estudio es conocer la prevalencia de afectación cardiaca en Ios pacientes con SAF, así como saber el tipo de afectación más frecuente, los factores de riesgo asociados y la evolución y tratamiento en estos pacientes.

MATERIAL Y MÉTODO: Estudio descriptivo retrospectivo de los casos de SAF definido diagnosticados y seguidos durante un largo periodo en una unidad específica de Trombosis y Vasculitis y revisión de la literatura.

RESULTADOS: Entraron en el estudio 20 pacientes, 65\% mujeres, con una edad media de 67, 6 \pm 15 , 60años [rango 34-84] y un seguimiento medio de 10, 7 años (mediana 11 años). El $75 \%$ tenían un SAF primario. Los SAF secundarios (25\%) se presentaron en 2 pacientes con LES, 2 con síndrome de Sjögren y 1 enfermedad desmielinizante. El 10\% eran SAF obstétricos puros, el 25\% tuvieron un evento arterial, el $25 \%$ tuvieron un evento venoso y el $40 \%$ presentaron eventos mixtos (arteriales, venosos y obstétricos). El 80\% de los pacientes presentaban algún factor de riesgo cardiovascular (HTA, dislipemia, DM tipo 2). De los 20 pacientes el 50\% presentaban afectación cardiaca. De estos, el $80 \%$ tenían afectación valvular (88\% en la válvula mitral), y el 20\% presentaron un evento isquémico coronario. Los pacientes con afectación cardiaca eran más mayores $(74 \pm 12,4$ años vs 61 , $2 \pm 16,39(p=0.06)$ y el $90 \%$ vs $70 \%(p=0.07)$ tenían factores de riesgo cardiovascular asociados. Por otro lado, el 90\% de los pacientes con afectación cardiaca tenían un SAF primario, y ninguno de Ios pacientes con SAF puramente obstétrico presentaron afectación a nivel cardiaco. El 70\% de los pacientes con afectación cardiaca presentaban positividad de ACLAS y anti-b2micromicroglobulina frente al 30\% en el grupo de los que no tenían afectación cardiaca ( $p$ 0.027), con valores de lgG ACLAS de $22,2 \pm 15,65$ vs $8,8 \pm 4,03(p=0.3)$, IgM ACLAS de $22,9 \pm 7$ vs $11,7 \pm 8,12$ (p 0.3 ) y anticuerpos antib2glicoproteina de $20,0 \pm 6,18$ vs $8,3 \pm 7,27$ ( $p=0.2$ ).

CONCLUSIONES: La mitad de los pacientes con SAF tenían afectación cardiaca y ésta fue más frecuente en pacientes de mayor edad y con factores de riesgo cardiovascular asociados. La forma de presentación más frecuente fue la valvulopatía y menos frecuentes los eventos coronarios. Los pacientes con afectación cardiaca tenían positividad paraACLAS y antib2glicoproteinal, y a títulos más elevados. No encontramos afectación cardiaca en las pacientes afectas de SAF puramente obstétrico.

\section{SÍNDROME DE EAGLE: UNA CAUSA INFRECUENTE DE SÍNDROME DE HORNER}

Enríquez Gómez H, Sánchez Conde P, Araujo Fernández S, Álvarez Otero J, Fernández Fernández FJ, De la Fuente Aguado J.

MEDICINA INTERNA. POVISA.

INTRODUCCIÓN: El Síndrome de Eagle (SE) o Síndrome estilohioideo es el conjunto de síntomas causado por la elongación de la estiloides y/o la mineralización del ligamento estilohioideo por irritación de estructuras anatómicas, vasculares y nerviosas que se encuentran en su vecindad. OBJETIVOS: Describir el Síndrome de Eagle como causa infrecuente de Síndrome de Horner (SH) mediante la descripción de un caso clínico.

CASO CLíNICO: Mujer de 71 años que acude a Urgencias por cuadro de cefalea holocraneal de predominio hemicraneal derecho, sensación de inestabilidad sin giro de objetos, náuseas ni vómitos y visión borrosa. Quince días antes presentó episodio similar tras giro cefálico hacia la derecha. En la exploración física destacaba anisocoria (miosis derecha), ptosis palpebral y enoftalmos derechos. Se realizaron análisis y radiografía de tórax sin alteraciones, y TC craneal sin patología intracraneal aguda. Se ingresó con el diagnóstico de SH a estudio. Se realizó una RM cerebral que no evidenciaba patología aguda y una TC cervical, informada como apófisis estiloides muy aumentadas de tamaño, sobre todo en el lado derecho, que alcanzan la superficie de la mucosa faríngea, compatible con SE. Se completó el estudio con una angio-TC de troncos supraórticos que ponía de manifiesto la íntima relación de la apófisis estiloides derecha con la arteria carótida interna derecha. Se estableció, por tanto, causalidad entre el SE y el SH en probable relación con irritación de la vaina nerviosa simpática carotídea. Se consultó con el Servicio de Otorrinolaringología, que procedió a la realización de una cervicotomía bilateral con extirpación de los ligamentos estilohioideos osificados. A los 5 meses postcirugía la paciente presentó resolución completa del SH sin nuevos episodios de inestabilidad. CONCLUSIONES: El Síndrome de Eagle puede ser causa de Síndrome de Horner, por lo que habría que tenerlo en cuenta en su diagnóstico diferencial.

\section{SINDROME DE KOUNIS: A PROPÓSITO DE UN CASO}

${ }^{1}$ Sánchez Trigo S, 'Mella Pérez C, ${ }^{1}$ Fernández Bouza E, ${ }^{2}$ Rodríguez Vilela A, ${ }^{1}$ Cainzos Romero T, 'Sardina Ferreiro R, ' 'Gómez Buela I, 'Lijó Carballeda C, 'Garcia Alén D, '`Sesma Sánchez P. 'MEDICINA INTERNA. COMPLEXO HOSPITALARIO UNIVERSITARIO DE FERROL. 'SECCIÓN DE CARDIOLOGIA. COMPLEXO HOSPITALARIO UNIVERSITARIO DE FERROL. COMPLEXO HOSPITALARIO UNIVERSITARIO DE FERROL.

INTRODUCCIÓN: El síndrome de Kounis (SK) es una angina o infarto de miocardio en el contexto de una reacción alérgica. Se describió en 1991 y se conocen tres subtipos: el tipo I 0 angina alérgica vasoespástica, el tipo II o infarto de miocardio alérgico y el tipo III 0 trombosis intrastent con trombo oclusivo infiltrado por mastocitos y eosinófilos. Su fisiopatología no está bien definida y no existe consenso acerca de su tratamiento.

CASO CLínICO: Mujer de 49 años, con alergia a ibuprofeno y cacahuetes, fumadora, obesa dislipémica, que ingresó por IAM no Q, Killip 1. Se realizó coronariografia con enfermedad coronaria de 1 vaso, con colocación de un stent fármacoactivo liberador Zotarolimus en DAm, con resultado subóptimo, con implante posterior de stent liberador de Zotarolimus sobre DAp solapado con el anterior. Comentado con Alergia se inició aspirina (AAS) y clopidogrel con buena tolerancia. A las 24 horas del alta, tras la ingesta de AAS y clopidogrel, presentó disnea súbita, exantema pruriginoso, diarrea y alteración en fonación. Acude a urgencias objetivando hipotensión y dolor torácico persistente atípico, con elevación de enzimas de daño miocárdico, por lo que ingresó en la unidad de cuidados intensivos. En electrocardiogramas seriados, se apreció elevación de ST de 1 mm en V1-V2 que posteriormente normaliza. En el ecocardiograma transtorácico (ETT) se apreciaba acinesia medial y distal del tabique interventricular, no presente previamente. Se trató con clopidogrel, anticoagulación con heparina de bajo peso molecular y calcioantagonistas, con buena evolución y se trasladó a planta de cardiología, con la sospecha de SCA con elevación transitoria de ST, reacción alérgica en probable relación con AAS (SK tipo III). Se repitió coronariografia, mostrando trombosis subaguda de los stents. Tras comentar en sesión clínica, se optó por continuar con tratamiento médico, completar pruebas de alergia y valorar posibilidad de cirugía de revascularización coronaria.

DISCUSIÓN: EI SK es una enfermedad de prevalencia desconocida. Su pronóstico es bueno más allá de la fase aguda. Se han involucrado múltiples agentes (picaduras de himenópteros, fármacos, alimentos, cuerpos extraños) y los fármacos más frecuentemente implicados son los betalactámicos, AlNES, anestésicos generales y medios de contraste yodado. Ante una sospecha clínica debe determinarse el nivel de triptasa sérica y monitorizar sus valores tras el inicio de tratamiento, dado que es un marcador útil para el diagnóstico de anafilaxia. No existen guías de específicas de práctica clínica acerca del tratamiento del SK. El tratamiento es el específico del SCA y de la anafilaxia; los fármacos vasodilatadores, incluidos nitratos y antagonistas del calcio son de primera elección. En los pacientes con SK tipo II y alérgicos a AAS pueden realizarse desensibilización a este fármaco. 


\section{SÍNDROME DE TROUSSEAU Y PENFIGOIDE AMPOLLOSO PARANEOPLÁSICOS}

Gómez Buela I, Sardina Ferreiro R, Lijó Carballeda C, García Alén D, Bravo Blázquez I, Fernández Pérez C, Sánchez Trigo S, Caínzos Romero T, Vilariño Maneiro L, Barbagelata López C, Fernández Bouza E, Mella Pérez C, Monteagudo Sánchez B.

MEDICINA INTERNA. COMPLEXO HOSPITALARIO UNIVERSITARIO DE FERROL.

INTRODUCCIÓN: Los síndromes paraneoplásicos (SPN) son un grupo heterogéneo de alteraciones causadas por múltiples mecanismos inherentes a una neoplasia subyacente y que se producen a distancia del tumor o sus metástasis, pudiendo preceder al mismo incluso en años.

CASO CLínICO: Presentamos el caso de un varón de 54 años, fumador y ex-alcohólico. Consulta por inflamación y dolor en ambos miembros inferiores, objetivándose en la ecografía doppler tromboflebitis superficial (TVS) en ambas venas safenas internas próxima al cayado; la radiografía de tórax mostraba un nódulo pulmonar en lóbulo inferior izquierdo; la TC tóracoabdominal confirmó la existencia de un nódulo de $2 \mathrm{~cm}$ y adenopatías mediastínicas. La fibrobroncoscopia fue normal y la biopsia transbronquial de una adenopatía subcarinal fue negativa para malignidad. Se inició tratamiento anticoagulante con heparinas de bajo peso molecular (HBPM) y se solicitó ecobroncoscopia (EBUS). En este período el paciente presentó nuevo episodio de TVS, dolor en fosa renal izquierda demostrándose un infarto renal, bultoma cervical derecho en relación con trombosis yugular y datos de isquemia arterial en miembro superior izquierdo, confirmándose trombosis radial crónica mediante angiografía, por lo que se inició tratamiento con heparina no fraccionada intravenosa, no siendo subsidiario de tratamiento quirúrgico/endovascular. Se realizó biopsia mediante EBUS de adenopatía mediastínica con resultado de adenocarcinoma de pulmón; al alta se trató con Tinzaparina aumentando la dosis un 25\% en espera de evaluación para tratamiento oncológico. Días después consulta por hemiparesia derecha diagnosticándose de ictus isquémico y aumento de perímetro de miembro inferior derecho en contexto de trombosis venosa profunda, pautándose tratamiento con Tinzaparina con controles con factor anti-Xa y ácido acetilsalicílico. Presentaba además lesiones ampollosas diseminadas realizándose biopsia con diagnóstico de penfigoide ampolloso, iniciándose terapia con corticoides. Dada la recurrencia de fenómenos trombóticos a pesar de tratamiento y la aparición de un nuevo SPN, tras comentar el caso con Oncología se decidió iniciar quimioterapia de forma inmediata, resolviéndose las lesiones cutáneas y no presentando el paciente nuevos eventos isquémicos. DISCUSIÓN: En 1865 Armand Trousseau describió la asociación de la tromboflebitis migratoria superficial con la presencia de una neoplasia oculta; actualmente el término síndrome de Trousseau se emplea de forma habitual para designar a todos los fenómenos de hipercoagulabilidad, tanto venosos como arteriales, asociados al cáncer; esta asociación está ampliamente demostrada y tiene una fisiopatología compleja y multifactorial. El tratamiento inicial de elección son las HBPM, adaptando la anticoagulación en caso de recurrencia. En numerosas ocasiones el SPN es el que marca el pronóstico de la enfermedad de base y con frecuencia su tratamiento más eficaz es el de la neoplasia subyacente.

\section{SINDROME DRESS SECUNDARIO A FENITOÍNA}

Álvarez Otero J, Lamas Ferreiro JL, Crillo Calderón I, González González L, Fernández Fernández F, Paz Ferrín J, de la Fuente Aguado J.

MEDICINA INTERNA. HOSPITAL POVISA.

INTRODUCCIÓN: El síndrome DRESS (Drug Rash with Eosinophilia and Systemic Symptoms) es una reacción de hipersensibilidad tardía mediada por linfocitos T que cursa con erupción cutánea, fiebre, alteraciones hematológicas y síntomas sistémicos. Los fármacos más comúnmente asociados son Ios antiepilépticos.

OBJETIVOS: Incidir en la importancia de considerar el síndrome DRESS dentro del diagnóstico diferencial del rash cutáneo con clínica sistémica asociada, ya que la precocidad del diagnóstico presenta importantes implicaciones pronósticas.

MATERIAL Y MÉTODOS: Presentamos un caso de Síndrome DRESS asociado a tratamiento con fenitoína.

RESULTADOS: Varón de 64 años que acudió a nuestro centro por un cuadro de 24 horas de evolución de fiebre sin foco y malestar general. Posteriormente se inició un exantema generalizado con lesiones aftosas en orofaringe y edema facial de predominio peribucal. Se trataba de un paciente dado de alta de neurocirugía dos semanas antes con diagnóstico de glioma de alto grado, a tratamiento con fenitoína y dexametasona desde entonces. En la exploración destacaba fiebre de $38,7^{\circ} \mathrm{C}$ y un rash cutáneo maculopapuloso con afectación facial, de tronco y extremidades, asociado a eritema conjuntival. Analíticamente presentaba eosinófilos de 8, 8\%, linfocitos activados, GOT 68 U/L, GPT 100 U/L y GGT 357 U/L. Los hemocultivos y las serologías de herpes virus fueron negativas. La radiografía de tórax no mostró alteraciones y la ecografía abdominal únicamente presentó hallazgos incidentales sin relevancia. Con la sospecha de síndrome DRESS se suspendió la fenitoína y se inició tratamiento con prednisona y antihistamínicos con resolución completa en un mes.

CONCLUSIONES: El síndrome DRESS es una entidad infrecuente con una mortalidad de hasta e 10\%. Su presentación tardía tras la introducción del fármaco desencadenante puede dificultar el diagnóstico, por lo que es imprescindible sospecharlo en pacientes con lesiones cutáneas y síntomas sistémicos.

\section{TELEMEDICINA: UNA NUEVA FORMA DE CONSULTA ENTRE PROFESIONALES}

Pérez Carral V, Pérez Carral O, Rodriguez Alvarez AP, Fernandez Regal I, López Mato P, González Noya A, Jimenez Martinez JL, De Toro Santos JM. COMPLEXO HOSPITALARIO UNIVERSTTARIO DE OURENSE (CHUO).

INTRODUCCIÓN: En 2012 se crea por parte del Servicio de Medicina interna del CHUO un programa de Interconsultas vía Telemedicina (TC) para 32 Centros de Atención Primaria (CAP) de la Provincia de Ourense. El programa consta de 7 secciones integradas cada una de ellas por 4 facultativos especialistas y 5-6 CAP asignados por localización geográfica.
OBJETIVOS: Realizar un estudio retrospectivo entre los períodos: Octubre 2013 a Marzo 2014, acerca del funcionamiento y eficiencia del nuevo modelo de TC entre CAP y la especialidad de Medicina Interna

MATERIAL Y MÉTODOS: Se han analizado: Número total de TC en un período de 6 meses CAP teleconsultores, número de TC contestadas, período de respuesta, defectos en el sistema, patologías más teleconsultadas, y número de TC resueltas a través de ese medio y las que, a pesar de la TC, precisaron derivarse a Consultas de MI para estudio.

RESULTADOS: ver gráficos adjuntos.

CONCLUSIONES: La TC es una herramienta útil para resolver problemas clínicos sin desplazamiento de los pacientes. El grado de satisfacción de profesionales y pacientes es alto. La implicación del Servicio de M. I. del CHUO ha sido alta en la implementación de este nuevo dispositivo asistencial. Su uso por los médicos de AP es alto, por lo que la TC debería promocionarse desde los Servicios y las Gerencias. A pesar de ser una herramienta novedosa, nuestra experiencia muestra $(72.2 \%$ de los casos resueltos) que su uso es adecuado y útil, aunque debe mejorarse el formato electrónico para evitar disfunciones. La gran variabilidad en las patologías teleconsultadas, pone en valor la capacidad de integración y resolución de la M. I. como especialidad, también en el ámbito de las modalidades asistenciales no presenciales.

\section{TUBERCULOSIS: LA TRÁGICA ASESINA DE LA "XERACIÓN DOENTE"}

Montes-Santiago J.

MEDICINA INTERNA. COMPLEJO HOSPITALAIRO UNIVERSITARIO. VIGO.

Rosalía de Castro siempre temió que ella o su familia contrajeran tuberculosis (Tb). Falleció de un cáncer de útero pero sus temores se confirmarían pues su hijo Ovidio, que la retrató en su lecho de muerte, fallecería de ella. A pesar de radicales avances, autoridades recientes alertan del posible rebrote de Tb en países avanzados. D. Young, Director de la Iniciativa para la Vacuna de la Tuberculosis afirma (mayo-2014): "Vamos a ver famosos muriendo de tuberculosis resistente en los países ricos". Aquí se recuerda la tragedia que supuso en los albores del siglo XX el fallecimiento simultáneo de varios prometedores artistas gallegos.

MÉTODO: Estudio patobiográfico de 4 jóvenes pintores gallegos fallecidos de Tb. RESULTADOS: F. Bello Piñeiro y MF Barreiro calificaron de "Xeración Doente" (1922) a 4 pintores fallecidos de tuberculosis cerca de 1900, rondando 30 años. Ovidio Murguía Castro (1871-1900), hijo de Rosalía y Manue Murguía tras estudiar en Santiago, se trasladó a Madrid, donde siguió un aprendizaje autodidacta, copiando a los Maestros del Museo del Prado. También pinta la sierra de Guadarrama y retratos de políticos como Montero Ríos. Realiza algunas exposiciones pero la Tb provoca su muerte (A Coruña, 28). Xenaro Carrero Fernández (1874-1902), nacido en Noia, tras recibir clases en Compostela, se hace discípulo en Madrid de Sorolla. Influenciado por los impresionistas Monet y Pissarro realiza también excelentes retratos de personajes como la Condesa de Pardo Bazán o Montero Ríos. Muere de Tb (Santiago, 28). Ramón Parada Justel (1871-1902). Ingresa en la Academia de San Fernando de Madrid y consigue una beca para Roma. Aborda temas históricos y religiosos, pero al regresar a su Esgos natal (Ourense) se decanta por paisajes y costumbres. La Tb trunca su vida (Ourense, 31). Joaquín Vaamonde Cornide (1872-1900). Discípulo en Santiago de Brocos, fue protegido en Madrid de Emilia Pardo Bazán. Allí estudia los Maestros del Prado y realiza retratos de la burguesía. Son conocidos varios de la Condesa. Esta lo erige protagonista de su novela La Quimera. Y en su propiedad del Pazo de Meirás fallece de Tb (28).

CONCLUSIONES: La Tb truncó precozmente a principios del siglo XX las vidas de 4 artistas gallegos. Ante su posible rebrote y dificultad de tratamiento siguen de plena vigencia estrategias de vigilancia y erradicación.

\section{TUMOR MIOFIBROBLÁSTICO INFLAMATORIO DE PULMÓN: PRESENTACIÓN COMO NÓDULOS BILATERALES. RESOLUCIÓN ESPONTÁNEA}

Dubois A, Vázquez $R$, Seoane B, Ramos V, Nicolás $R$, Penado V, De la Iglesia $F$. UNIDAD DE CORTA ESTANCIA MÉDICA. SERVICIO DE MEDICINA INTERNA. COMPLEJO HOSPITALARIO UNIVERSITARIO A CORUNNA.

INTRODUCCIÓN Y OBJETIVOS: El tumor miofibroblástico inflamatorio (TMI) de pulmón es una entidad poco frecuente. Su etiología es desconocida, considerándose desde un proceso inflamatorio reactivo a una neoplasia mesenquimal de bajo grado. El tratamiento de elección es la resección quirúrgica, y cuando esta no es posible la actitud terapeútica no está bien definida.

MÉTODOS: Descripción de un caso clínico de presentación y curso atípicos y revisión de la literatura. RESULTADOS: Varón de 65 años, exfumador, con clínica de dos meses de evolución de síndrome general con astenia y pérdida ponderal moderada y 3 semanas de disnea, tos y expectoración, sin fiebre, hemoptisis ni otra clínica. En la exploración física no presentaba alteraciones relevantes excepto crepitantes pulmonares bilaterales. Analiticamente sólo destacaba anemia leve (hemoglobina 11, normocítica). Se realizó radiografía de tórax objetivándose lesiones pulmonares nodulares bilaterales cavitadas, hallazgo que confirmó el TAC. Se completó estudio analítico con parámetros inflamatorios (VSG 120, PCR 10), VIH (negativo) y autoinmunidad y complemento, ambos normales. Los cultivos de esputo para bacterias y micobacterias fueron negativos. El estudio tomográfico corporal no mostró afectación a otro nivel. Dado que los estudios no resultaron concluyentes se optó por realizar biopsia de lesión nodular guiada por videotoracoscopia. El diagnóstico histológico fue de tumor benigno mesenquimal sugestivo de TMl. Clínicamente mejoró durante su ingreso sin tratamiento específico por lo que se optó por actitud expectante. La radiografía realizada a los dos meses del diagnóstico mostró mejoría parcial de las lesiones, confirmandose en TAC a los cuatro meses la resolución completa. Durante el seguimiento al año permaneció asintomático y con normalización de parámetros inflamatorios.

CONCLUSIONES: EI TMI de pulmón representa menos del 1\% de las lesiones pulmonares resecadas quirúrgicamente. Su historia natural es variable y, aunque su curso suele ser benigno, existen formas invasivas. Habitualmente se presenta como un tumor solitario y la presencia de enfermedad bilateral 
es menos frecuente. En estos casos, donde la resección completa quirúgica no es posible, se ha descrito tratamiento con corticoides, quimioterapia y radioterápia con gran variabilidad en el resultado. En este caso existió remisión espontánea, que aunque descrita, es rara, sobre todo en los pacientes con lesiones bilaterales múltiples.

\section{UTILIDAD DE LOS SELLADOS EN EL TRATAMIENTO DE LA INFECCIÓN DE CATÉTER CENTRAL DE LARGA DURACIÓN POR ENTEROCOCCUS}

${ }^{1}$ Rodríguez Gómez $A,{ }^{1}$ Pérez Rodríguez MT, ${ }^{2}$ Martínez-Lamas $L,{ }^{1}$ Cidre $R,{ }^{1}$ Baroja A, ${ }^{\prime}$ Alonso M, Martínez A, 'Sousa A, ${ }^{1}$ Lorenzo $R,{ }^{1}$ Soto A, ${ }^{1}$ Gómez Sousa J, ${ }^{1}$ Val $N,{ }^{\top}$ Argibay A, ${ }^{1}$ NodarA, ${ }^{1}$ Rivera $A,{ }^{2}$ Álvarez-Fernández $M$.

'UNIDAD DE INFECCIOSAS. MEDICINA INTERNA. ${ }^{2}$ SERVICIO DE MICROBIOLOGIA. HOSPITAL XERAL. CHUVI. VIGO

INTRODUCCIÓN / OBJETIVOS: El tratamiento conservador con sellados y antibioterapia sistémica de las bacteriemias asociadas a catéter central de larga duración(BCLD)es una opción segura, cuando los microorganismos causales son Staphylococcus coagulasa negativos o bacilos gramnegativos. Actualmente existen pocos datos sobre el papel de los sellados en el tratamiento de estas infecciones producidas por Enterococcus. El objetivo del estudio fue analizar la eficacia y seguridad del tratamiento con sellados en las BCLD por Enterococcus sp.

MATERIAL Y MÉTODOS: De forma retrospectiva se revisaron todas las bacteriemias por Enterococcus sp entre nov-2009 y oct-2013. Se incluyeron las que cumplían criterios de BCLD(según IDSA 2009)y que habían recibido tratamiento antibiótico sistémico y con sellados. Se analizaron: características de los pacientes, antibiótico elegido y evolución.

RESULTADOS: Se documentaron un total de 157 bacteriemias por Enterococcus spp., 15/9.5 \%)cumplían criterios de BCLD(11 E. faecalis y 4 E. faecium, no se identificó ningún caso de Enterococcus resistente a vancomicina). La edad media de los pacientes fue de $49 \pm 12.4$ años y 7 eran varones(47\%). El tipo de catéter fue reservorio 13(87\%)y Hickman 2(13\%). En su mayoría eran pacientes hematológicos(93\%)y el 83\% recibían quimioterapia en el momento de la bacteriemia. El tratamiento sistémico empírico se realizó con teicoplanina(10 pacientes), vancomicina(4)y daptomicina(1), durante $14 \pm 4.1$ días. Los sellados se realizaron con teicoplanina(10 pacientes, $67 \%) y$ vancomicina(5, 33\%), durante una mediana de 13(2-21)días. Únicamente hubo fracaso microbiológico en un caso y ninguna recurrencia. Se retiraron dos catéteres, uno por trombosis y otro por fracaso microbiológico. La mediana de tiempo desde la infección hasta retirada del catéter o fin de seguimiento)fue de $9(0.06-18)$ meses.

CONCLUSIONES: El tratamiento conservador mediante sellados y antibioterapia sistémica es una estrategia segura en el manejo de la BCLD por Enteroccus sp.

\section{VIRUS HEPATITIS C: TRIPLE TERAPIA EN LA PRÁCTICA CLÍNICA HABITUAL}

Álvarez Otero J, Fernández Fernández F, Camba Estévez M, Araújo Fernández S, Enríquez Gómez $H$, de la Fuente Aguado J.

MEDICINA INTERNA. HOSPITAL POVISA.

INTRODUCCIÓN: El tratamiento del virus de la hepatitis $\mathrm{C}$ ha avanzado en los últimos años debido al mejor conocimiento de los mecanismos fisiopatológicos y al desarrollo de nuevos fármacos. OBJETIVOS: Analizar las características de los pacientes con infección por VHC a tratamiento con triple terapia (interferón, ribavirina y un inhibidor de proteasa, telaprevir o boceprevir), respuesta al tratamiento y efectos adversos.

MATERIAL Y MÉTODOS: Estudio descriptivo y retrospectivo en el que seleccionaron a Ipacientes con VHC a tratamiento con triple terapia. Se analizaron las características epidemiológicas, genotipo, IL 28, carga viral y elastografía. Se observó la carga viral a las 4 semanas, a las 12, al final de tratamiento y se constató la respuesta viral sostenida.

RESULTADOS: Se incluyeron 25 pacientes, 19 a tratamiento con doble terapia más telaprevir y 6 con doble terapia más boceprevir. La edad media fue 52 años y $76 \%$ de varones. Diez $(41,7 \%)$ pacientes presentaban genotipo $1 \mathrm{~A}, 13(54,2 \%)$ genotipo $1 \mathrm{~B}, 1(4,2 \%)$ genotipo $1 \mathrm{C}$ y otro $(4,2 \%)$ genotipo 1E. Cinco (20\%) pacientes tenían IL28 CC, 11 (44\%) CT y 9 (36\%) TT. Dieciseis (64\%) pacientes habían recibido previamente tratamiento antiviral con interferón y ribavirina (6 no respondedores, 5 recaedores, 3 mala tolerancia y 2 se desconoce). Se realizó fibroscan a 24 pacientes: 1 paciente F2, 14 pacientes F3 y 9 pacientes F4. En 11 pacientes se suspendió el tratamiento antes de la finalización: 8 por efectos adversos (1 paciente pancitopenia, otro neutropenia severa, 3 toxicodermia, 1 mala tolerancia, 1 gingivorragias y otro depresión grave) y 3 por no disminución de la carga viral a las 4 semanas (1 con telaprevir, y 2 asignados a boceprevir lead-in). Doce pacientes completaron el tratamiento y 2 aún no lo han finalizado. En la semana 4: 11 (50\%) pacientes presentaron carga viral negativa; en la semana 12: 15 (83, 3\%) pacientes tenían carga viral negativa; al final de tratamiento: $10(100 \%)$ pacientes tenían carga viral negativa. Los cinco pacientes que disponemos el RNA 6 meses tras finalizar tratamiento presentaron respuesta viral sostenida: 4 del grupo de tratamiento con telaprevir y 1 con boceprevir.

CONCLUSIÓN: El tratamiento con triple terapia parece ser eficaz aunque presenta un número elevado de eventos adversos, por lo que es fundamental que estos pacientes sean evaluados por clínicos experimentados.

\section{Normas de publicación Galicia Clínica}

Galicia Clínica es la revista oficial de la Sociedad Gallega de Medicina Interna (SOGAMI). Se publican 4 números al año, simultáneamente en papel y en www.galiciaclinica.info, incluyéndose en el segundo de ellos las comunicaciones enviadas a la correspondiente Reunión Ordinaria de la SOGAMI.

GALCIA CLÍNICA evaluará para su publicación trabajos médicos relacionados preferentemente con la Medicina Interna y sus subespecialidades, y/o con problemas médicos prevalentes en la Comunidad Autónoma de Galicia. Se admitirán para evaluación trabajos en castellano, gallego, inglés y portugués.

Para el envío de originales se ha habilitado un formulario en la pagina web www.galiciaclinica.info. El sistema confirmará la entrega y permitirá consultar el estado del manuscrito. No se aceptarán originales enviados por otros métodos.

El comité editorial, eventualmente con la ayuda de revisores externos, evaluará los trabajos enviados decidiendo si procede su publicación, si es necesario realizar correcciones o si se desestima la publicación. Una vez aceptado, se enviarán al autor las pruebas de imprenta para la corrección de posibles erratas.

Los trabajos reunirán los requisitos de uniformidad habituales en revistas biomédicas. Dichos requisitos se pueden consultar en "Uniform Requirements for Manuscripts Submitted to Biomedical Journals: Writing and Editing for Biomedical Publication Updated April 2010", disponible en http//mmwicmie org. Se recomienda encarecidamente

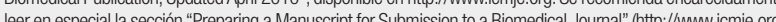
leer en especial la seccion "Preparing a Manuscript for Submission to a Biomedical Journal" (http://Tww. cmil Se recomienda el empleo de los programas más habituales de edición de texto (Ej., Word) tanto para el texto como para las tablas.

Dado que la mayoría de las páginas se imprimen en blanco y negro, se aconseja evitar en tablas y figuras en la medida de lo posible el uso de colores o tramas que no tengan el adecuado contraste para su identificación. Las figuras 0 imágenes se enviarán en archivo aparte, como archivo de imagen (jpeg o similar) 0 como PDF con una resolución de 300 ppp. a tamaño de impresión definitivo.

\section{La revista presenta las siguientes secciones:}

Editoriales

Habitualmente encargados por la dirección de la revista. Su extensión máxima será de 8 páginas de 30 líneas y se admitirá una figura o una tabla y quince citas bibliográficas.

El número máximo de firmantes será de dos.

Originales

Trabajos de investigación sobre cualquier aspecto médico. La estructura general de los trabajos será la tradiciona: Título: en el idioma original y en inglés, Resumen y Abstract en inglés, Palabras clave y Key words (que deben corresponder a los medical subjets headings -MESH- del Index Medicus), Introducción, Material y métodos, Resultados, Discusión, Bibliografía

La extensión máxima recomendada del texto es de 20 páginas de 30 lineas, a las que se podrán añadir 5 figuras y 5 tablas, y un máximo de 30 citas bibliográficas.

El número máximo de firmantes será de ocho.

Originales breves

Trabajos de investigación que por sus características no precisan un mayor espacio. Estructura similar a la de los originales. Su extensión máxima será de 10 páginas de 30 líneas, 3 figuras, 3 tablas y 20 citas bibliográficas.

El número máximo de firmantes será de seis.

\section{Revisiones}

Habitualmente encargadas por la dirección de la revista. La extensión máxima recomendada del texto es de 30 páginas de 30 lineas, a las que se podrán añadir 6 figuras y 6 tablas, y un máximo de 50 citas bibliográficas.

El número máximo de firmantes será de tres.

Preguntas clínicas

En esta sección se tratará de responder de forma concreta y sucinta a preguntas clínicas concretas que, bien han motivado una controversia o cuestionan actitudes arraigadas en la práctica diaria. La extensión máxima será de 6 páginas de 30 lineas, dos figuras y dos tablas y 15 citas bibliográficas.

El número máximo de firmantes será de dos.

Notas clínicas

Descripción de casos clínicos de excepcional interés. Constarán de una breve introducción caso clínico y discusión correspondiente. Su extensión máxima será de 6 páginas, 2 figuras y dos tablas y 15 citas bibliográficas. El número máximo de firmantes será de cuatro.

Cartas al director

Comentarios, opiniones u observaciones sobre los diversos trabajos publicados con anterioridad en la revista. La extensión máxima será de 4 páginas de 30 lineas y se admitirá una figura 0 una tabla y diez citas bibliográficas. El número máximo de firmantes será de dos.

Imágenes médicas

Imágenes curiosas, insólitas o demostrativas. Se acompañarán con un texto breve, como máximo 1 página de 30 líneas, en el que se explique el caso clínico, con una breve discusión acerca de la importancia de la imagen. El número máximo de firmantes será de dos.

Resúmenes de Tesis doctorales

Elaborados por el autor, describirán el trabajo realizado; su extensión máxima será de 2 páginas de 30 líneas. Debe incluirse un apéndice con los datos correspondientes a Universidad, departamento, director de la tesis y fecha de presentación.

Otros

La dirección de la revista considerará para su publicación cualquier artículo relacionado con la medicina en cualquier aspecto, aunque no se incluya exactamente dentro de los supuestos anteriores. En este caso se recomienda antes de su envio contactar con la dirección para acordar las características del mismo.

En el caso de que los trabajos enviados incluyan imágenes, figuras, tablas o textos sometidos a copyright, serà responsabilidad de los autores la obtención de los permisos necesarios para su publicación.

Todas las opiniones o afirmaciones expresadas en los artículos corresponden a los autores de los mismos. Tanto e comité editorial como la SOGAMI declinan cualquier responsabilidad a este respecto.

Los trabajos publicados serán propiedad de GALICIA CLIIIICA, cediendo los autores todos los derechos a la misma. 